\title{
Non-FDG PET/CT in Diagnostic Oncology: a pictorial review
}

Francesco Giammarile ${ }^{1 *}$ (D), Paolo Castellucci ${ }^{2}$, Rudi Dierckx ${ }^{3}$, Enrique Estrada Lobato ${ }^{1}$, Mohsen Farsad ${ }^{4}$, Roland Hustinx ${ }^{5}$, Amirreza Jalilian ${ }^{1}$, Olivier Pellet ${ }^{1}$, Susana Rossi ${ }^{6}$ and Diana Paez ${ }^{1}$

* Correspondence: francesco.
giammarile@gmail.com
${ }^{1}$ Department of Nuclear Sciences
and Applications, International
Atomic Energy Agency, Vienna,
Austria
Full list of author information is
available at the end of the article

* Correspondence: francesco. giammarile@gmail.com and Applications, International Atomic Energy Agency, Vienna, Full list of author information is

\begin{abstract}
Positron emission tomography/computed tomography (PET/CT) is currently one of the main imaging modalities for cancer patients worldwide. Fluorodeoxyglucose (FDG) PET/CT has earned its global recognition in the modern management of cancer patients and is rapidly becoming an important imaging modality for patients with cardiac, neurological, and infectious/inflammatory conditions.

Despite its proven benefits, FDG has limitations in the assessment of several relevant tumours such as prostate cancer. Therefore, there has been a pressing need for the development and clinical application of different PET radiopharmaceuticals that could image these tumours more precisely. Accordingly, several non-FDG PET radiopharmaceuticals have been introduced into the clinical arena for management of cancer. This trend will undoubtedly continue to spread internationally. The use of PET/CT with different PET radiopharmaceuticals specific to tumour type and biological process being assessed is part of the personalised precision medicine approach.

The objective of this publication is to provide a case-based method of understanding normal biodistribution, variants, and pitfalls, including several examples of different imaging appearances for the main oncological indications for each of the new nonFDG PET radiopharmaceuticals. This should facilitate the interpretation and recognition of common variants and pitfalls to ensure that, in clinical practice, the official report is accurate and helpful.

Some of these radiopharmaceuticals are already commercially available in many countries (e.g. ${ }^{68} \mathrm{Ga}$-DOTATATE and DOTATOC), others are in the process of becoming available (e.g. ${ }^{68} \mathrm{Ga}-\mathrm{PSMA}$ ), and some are still being researched. However, this list is subject to change as some radiopharmaceuticals are increasingly utilised, while others gradually decrease in use.
\end{abstract}

Keywords: PET/CT, Non-FDG, Pictorial

\section{Radioisotopes}

Carbon-11 is a PET radioisotope with a T1/2 of $20.4 \mathrm{~min}$. Due to the abundance of carbon in the chemistry of biomolecules, all C-11 radiopharmaceuticals demonstrate identical behaviour to natural compounds, allowing real tracing of the biological processes.

Fluorine-18 is a PET radioisotope with a T1/2 of $109.7 \mathrm{~min}$. Due to high chemical stability of the C-F bond in organic compounds, and the high water solubility of Fcompounds, F-18 tracers usually exhibit suitable stability and biodistribution in 
humans. The vast clinical application of F-compounds has led to the development of efficient automated production methods of F-18 tracers for clinical use.

Gallium-68 has a T1/2 of $67.7 \mathrm{~min}$, and is usually obtained from a germanium-68 generator. Due to the T1/2 of 271 days of the parent isotope, $68 \mathrm{Ge}$, the generator can be used for in-hospital production of Ga-68.

\section{Radiopharmaceuticals}

Acetate

Names: $\mathrm{CH}_{3}\left[{ }^{11} \mathrm{C}\right] \mathrm{O}_{2},{ }^{11} \mathrm{C}$-acetate

Biodistribution and metabolism (Fig. 1)

After injection ${ }^{11} \mathrm{C}$-acetate is dispersed in many human tissues including the pancreas, bowels, liver, kidneys, and spleen. The tracer is not excreted in urine under normal circumstances. ${ }^{11} \mathrm{C}$-acetate is typically incorporated into the cellular membrane in proportion to the cellular proliferation rate or alternatively oxidised to carbon dioxide and water. ${ }^{11} \mathrm{C}$-acetate may also be converted into amino acids (Seltzer et al. 2004; Karanikas and Beheshti 2014).

Scan acquisition

Fig. 1 Physiological bio-distribution of ${ }^{11} \mathrm{C}$-acetate 
- Fast of $4 \mathrm{~h}$ is suggested

- 4 or $5 \mathrm{MBq} \backslash \mathrm{Kg}$ of ${ }^{11} \mathrm{C}$-acetate iv

- Uptake time 10-20 min

- Acquisition starts from the pelvis

Clinical indications in oncology (Figs. 2 and 3)

The main clinical application of ${ }^{11} \mathrm{C}$-acetate is the detection of non ${ }^{18} \mathrm{~F}$-FDG-avid neoplasm, such as differentiated hepatocellular carcinoma and renal cell carcinomas (Hain and Maisey 2003; Ho et al. 2003; Park et al. 2008). Some other applications of ${ }^{11} \mathrm{C}$-acetate PET are brain tumours (Liu et al. 2006) and lung carcinomas, while in the past the tracer has been used in prostate cancer (Sandblom et al. 2006).

FES

Names: $16 \alpha-\left[{ }^{18} \mathrm{~F}\right]$ Fluoro-17 $\beta$-estradiol; 16 -Fluoroestradiol, ${ }^{18}$ F-fluoroestradiol Biodistribution and metabolism (Fig. 4)

After injection, the tracer is cleared from the blood and metabolised in $20 \mathrm{~min} .{ }^{18} \mathrm{~F}$ fluoroestradiol binds to the oestrogen receptors on the tumour cell surface as well as intratumoural receptors in oestrogen receptor-positive tumours (Liao et al. 2016).

Scan acquisition

- Treatment with oestrogen receptor antagonists (e.g. tamoxifen, fulvestrant, faslodex, oestrogens) should be suspended for at least 5 weeks prior to performing the scan. Aromatase inhibitors and luteinizing hormone releasing hormone agonists may be continued

- No fasting is required

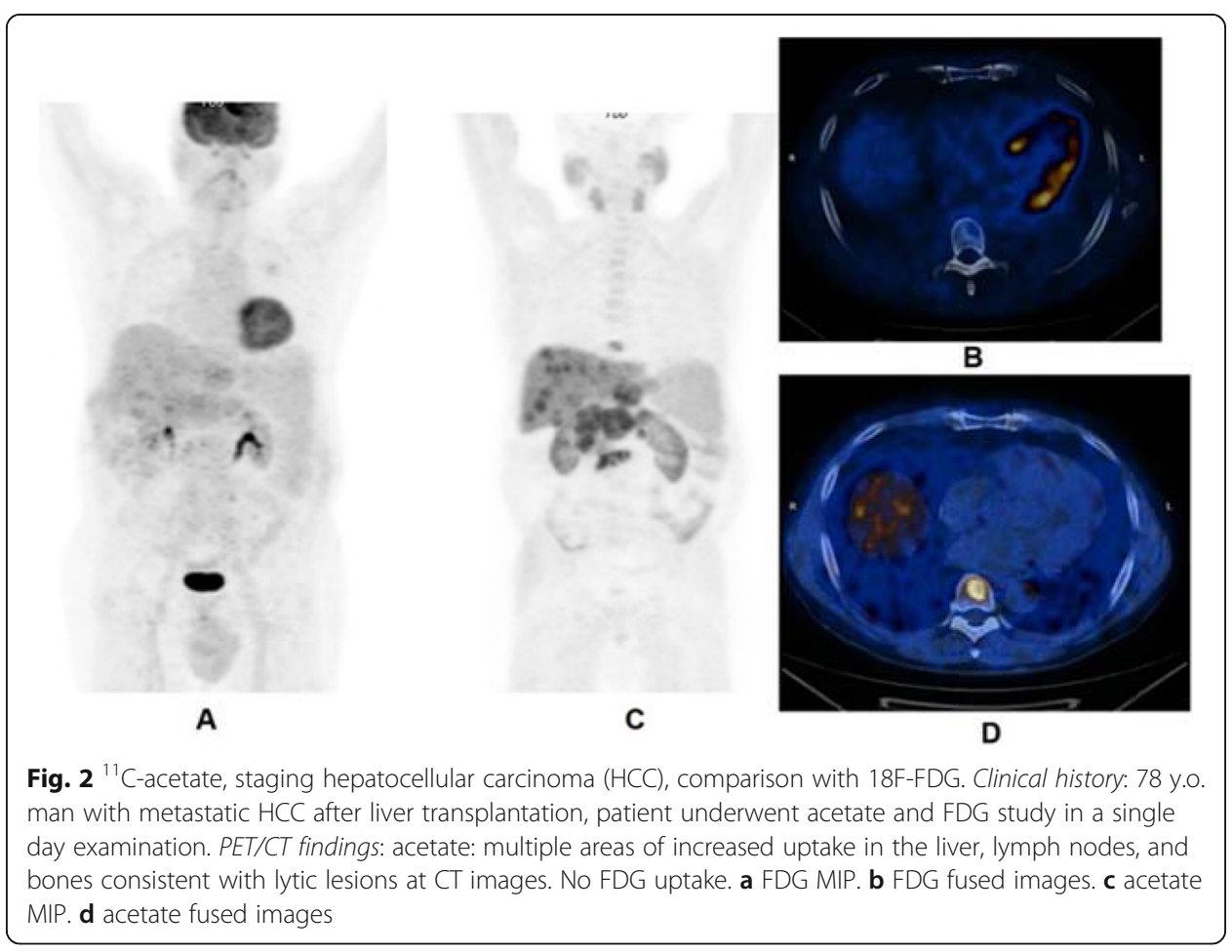



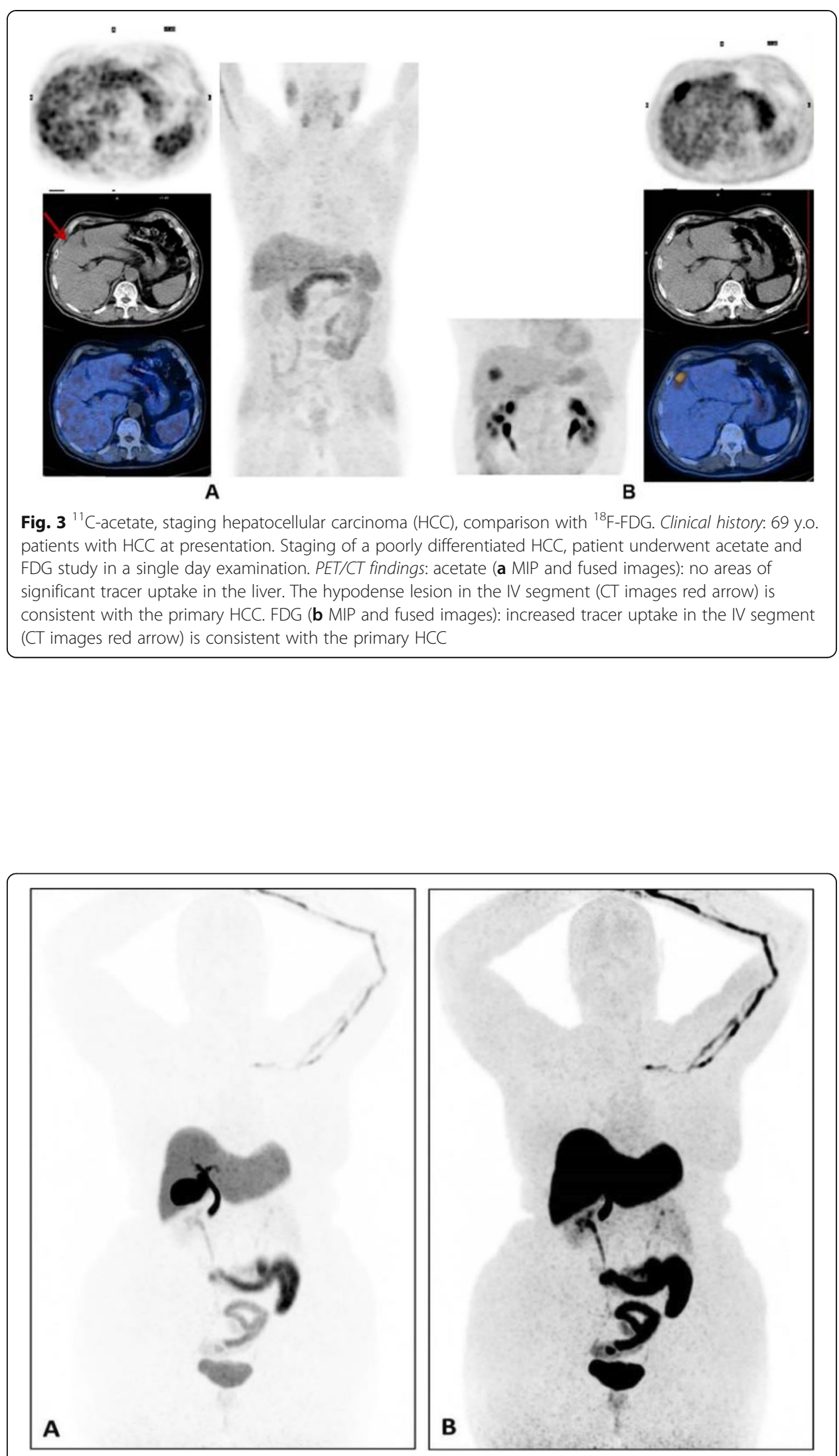

Fig. 4 Physiological bio-distribution of ${ }^{18} \mathrm{~F}$-fluoroestradiol. Low (a) and high (b) intensity MIP images 
- $200 \mathrm{MBq}$ of ${ }^{18} \mathrm{~F}$-fluoroestradiol iv

- Level of binding of ${ }^{18} \mathrm{~F}$-FES to the oestrogen receptors remains stable between 20 and 120 min postinjection. For logistical reasons, scanning procedure should start 60 min after injection

Clinical indications in oncology (Figs. 5 and 6)

${ }^{18} \mathrm{~F}$-fluoroestradiol is a valuable tracer for the studies of the oestrogen receptor status of primary and metastatic breast or ovarian cancers (Venema et al. 2016; van Kruchten et al. 2013a; van Kruchten et al. 2012; van Kruchten et al. 2013b; Peterson et al. 2011; Linden et al. 2011).

FET

Names: O- $\left(2-\left[{ }^{18} \mathrm{~F}\right]\right.$ Fluoroethyl)-L-tyrosine; ${ }^{18} \mathrm{~F}$-fluoroethyltyrosine

Biodistribution and metabolism (Fig. 7)

${ }^{18} \mathrm{~F}$-FET is an amino-acid PET tracer. After injection, the tracer is trapped into cancerous cells, though it is not incorporated into proteins (Abe et al. 2006).

Scan acquisition

- Fasting for at least $4 \mathrm{~h}$ is required

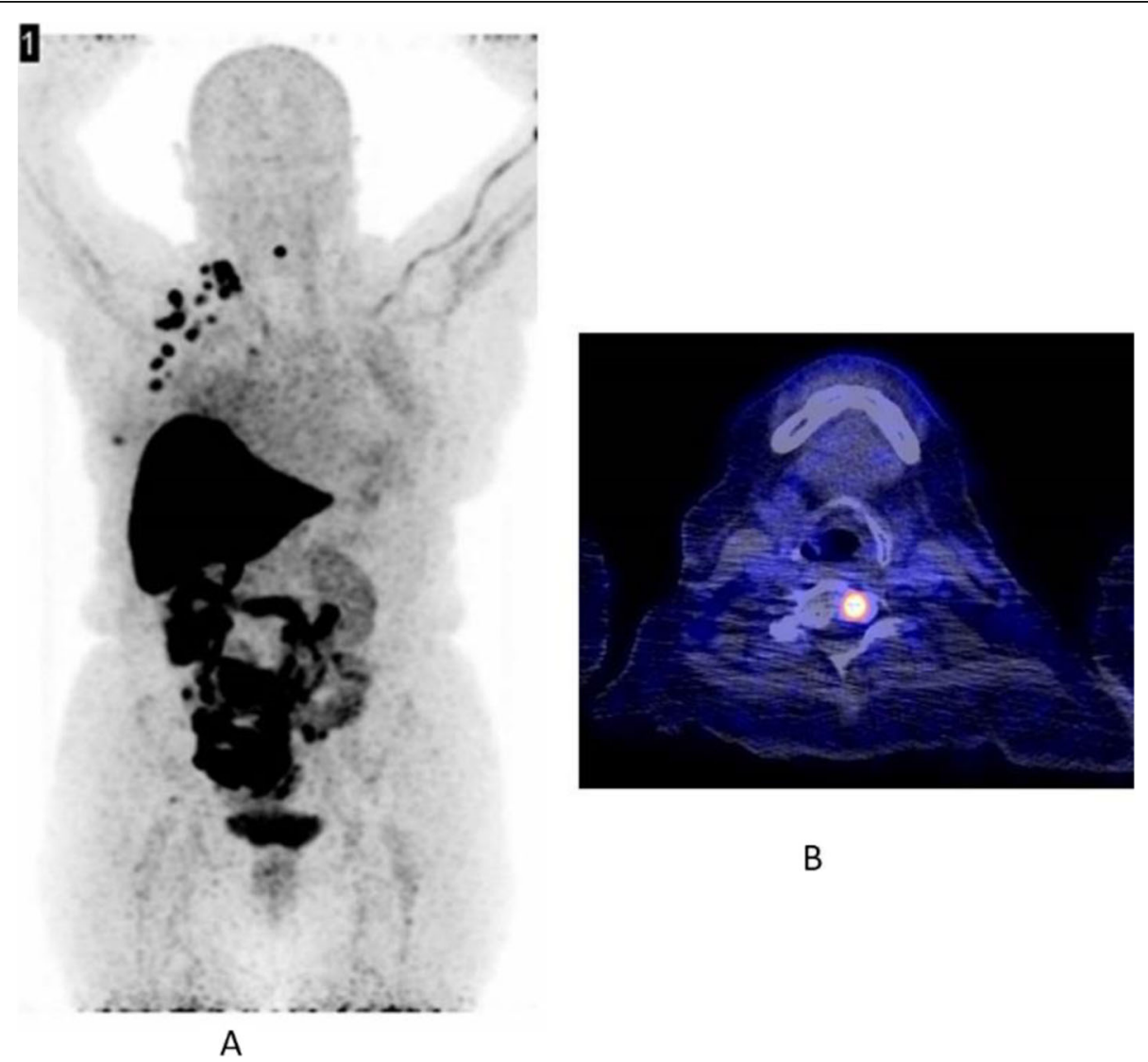

Fig. $5^{18} \mathrm{~F}$-fluoroestradiol, restaging breast cancer. Clinical history: 46 y.o. woman with proven breast cancer on the right side (ER+). Palpable lymph nodes in the right axilla. PET/CT findings: ER expression visible in the primary breast tumour and in several lymph nodes in the right axilla and in the right clavicular region in MIP (a); one focal lesion with increased ER expression in a cervical vertebra in fused images (b) 


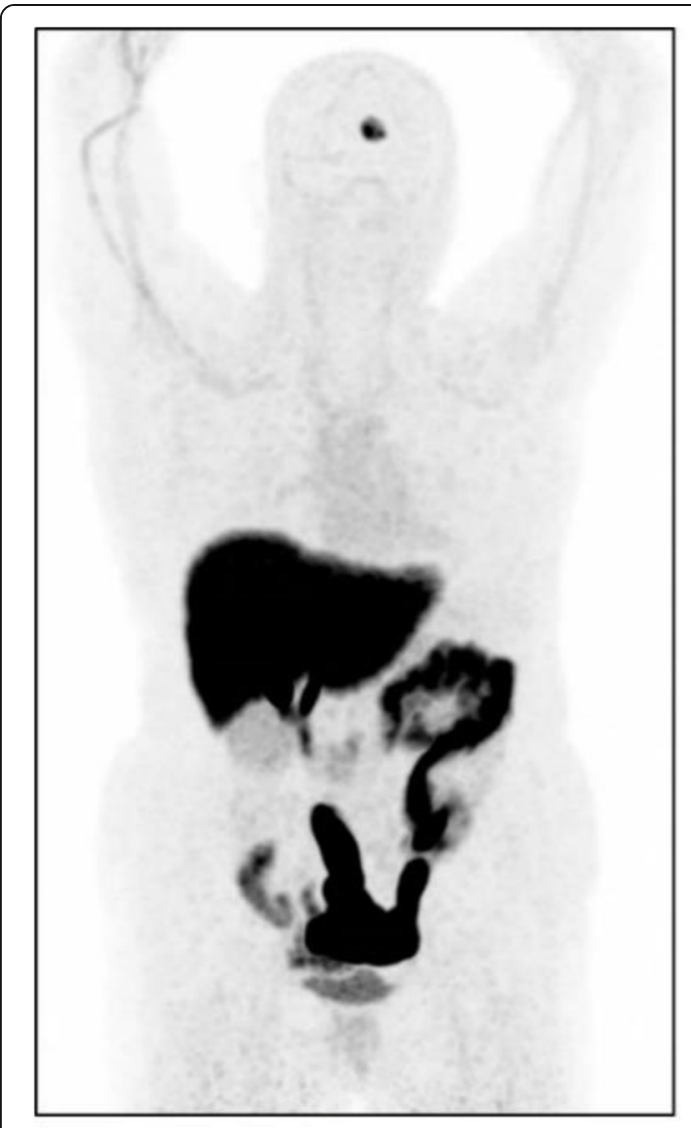

B
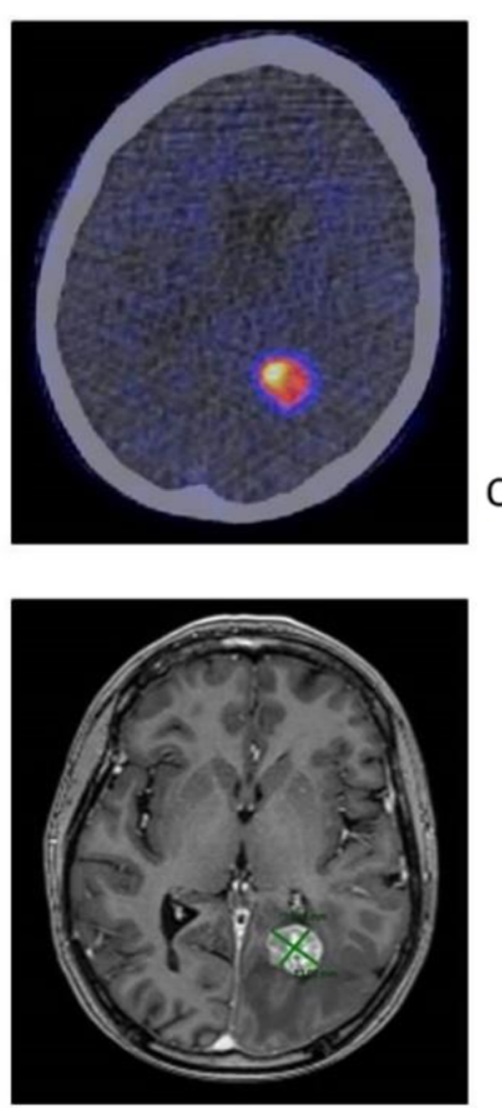

A

Fig. $6{ }^{18}$ F-fluoroestradiol, breast cancer, characterisation of brain metastasis. Clinical history: 53 y.o. woman with history of colon cancer (2004) and breast cancer (2011), ER+, presenting with an 18-mm brain lesion on MRI (a). Biopsy was not possible due to location. PET/CT findings: solitary lesion with increased ER expression in the brain in MIP (b), located in the left occipital lobe on fused images (c), suggesting brain metastasis from breast cancer

\section{- 4-5 MBq $\backslash \mathrm{Kg}$ of ${ }^{18} \mathrm{~F}$-FET iv}

- Dynamic one bed brain acquisition for $40 \mathrm{~min}$ or static one bed brain acquisitions at 10 and $40-50 \mathrm{~min}$. after injection, for $10 \mathrm{~min}$.

Clinical indications in oncology (Figs. 8, 9, and 10)

Diagnosis of central nervous system tumours (very low background in healthy brain) (Galldiks et al. 2015; Albert et al. 2016; Unterrainer et al. 2016; Kunz et al. 2011; Poulsen et al. 2017).

FLT

Names: $3^{\prime}$-deoxy-3' $-\left[{ }^{18} \mathrm{~F}\right]$-fluorothymidine; ${ }^{18} \mathrm{~F}$-fluorothymidine

Biodistribution and metabolism (Fig. 11)

${ }^{18} \mathrm{~F}-\mathrm{FLT}$ is an analogue of the nucleoside thymidine; however, substitution of the 3 '-F atom prevents from further entering the regular biochemical pathway. FLT is transported from the blood into cells by active transport and phosphorylated by thymidine kinase I without incorporation into the DNA. The conjugated FLT is cleared via the kidneys and excreted in the urine. The accumulated activity in the cells is proportional to thymidine kinase 1 activity as well as cellular proliferation (Grierson and Shields 2000; Oh et al. 2004; Shankar 2012; Turcotte et al. 2007; Vesselle et al. 2003). 


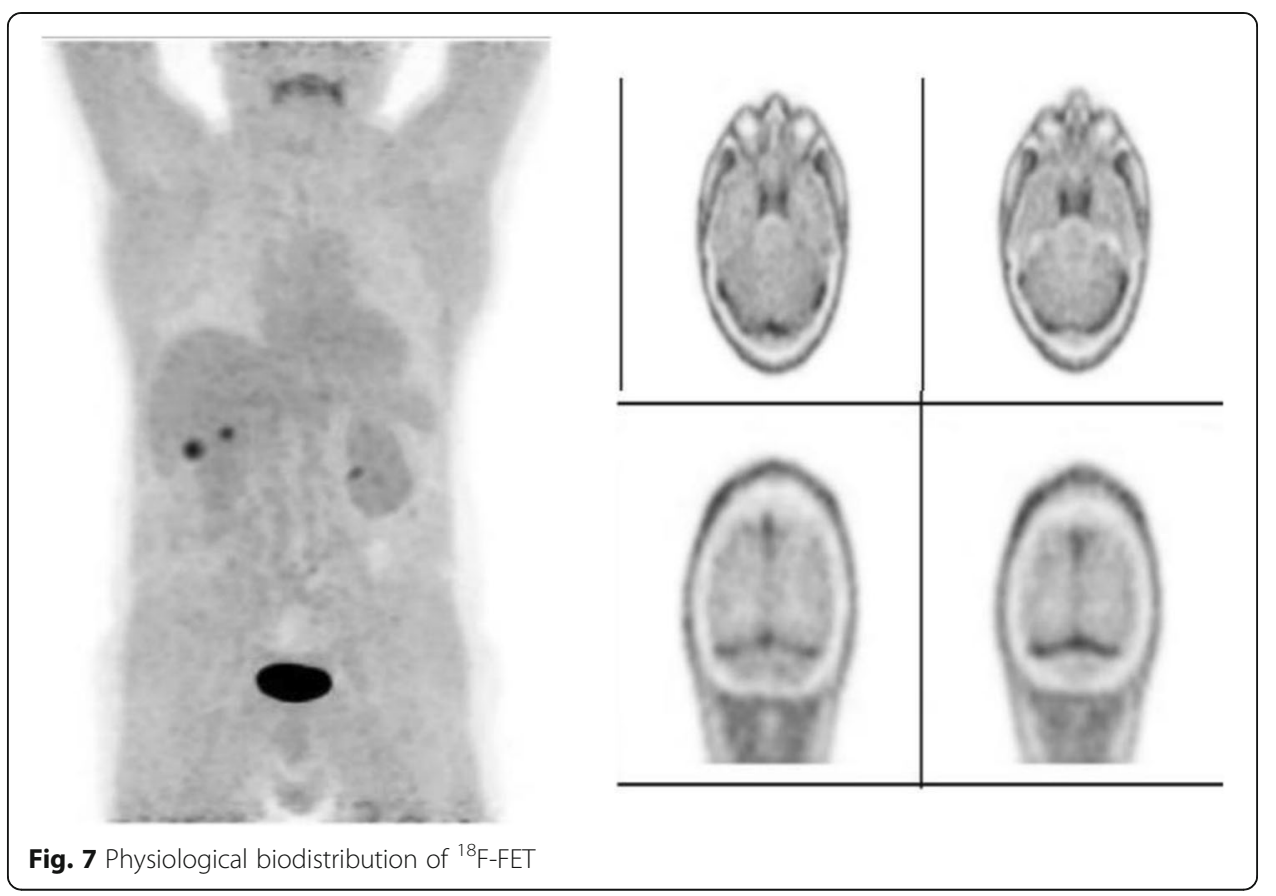

Scan acquisition

- No fasting is required

- 2-3 MBq $\backslash \mathrm{Kg}$ of ${ }^{18} \mathrm{~F}-\mathrm{FLT}$ iv

- Uptake time 50-60 min

Clinical indications in oncology (Figs. 12, 13, and 14)

${ }^{18} \mathrm{~F}-\mathrm{FLT}$ is a marker for tumour cell proliferation that has been introduced to improve the accuracy of early FDG PET assessment (Kenny et al. 2007).

\section{Methionine}

Names: L-[methyl- ${ }^{11} \mathrm{C}$ ] Methionine; ${ }^{11} \mathrm{C}$-Methionine

Biodistribution and metabolism (Fig. 15)

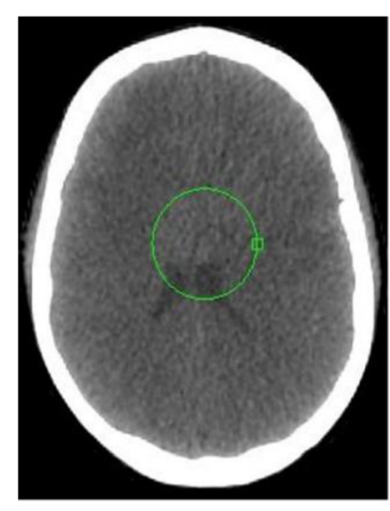

A

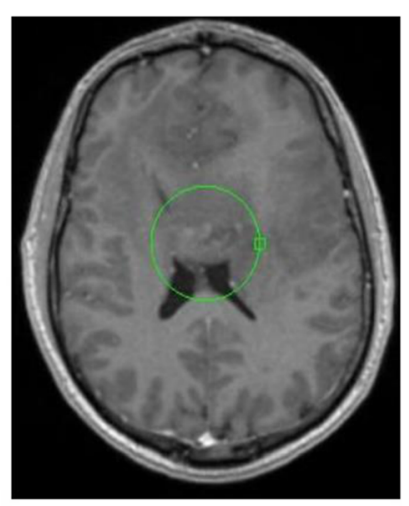

B

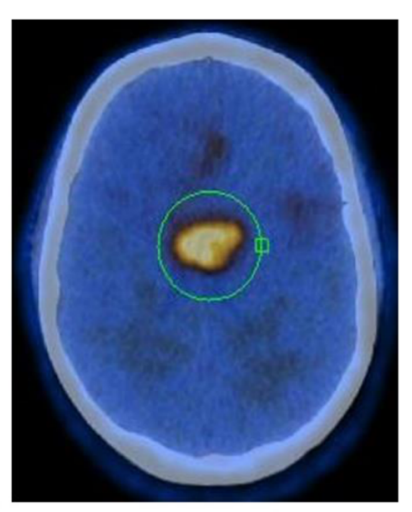

C

Fig. $8{ }^{18} \mathrm{~F}-\mathrm{FET}$, evaluation of a brain lesion. Clinical history: 46 y.o. man with nausea and headache. CT was non-informative (a). MRI shows an infiltrating lesion with low Gd enhancement (b). PET/CT findings: high FET uptake (c). Surgery confirmed a high-grade glioma 


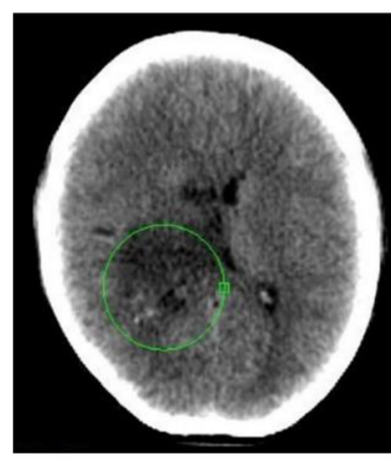

A

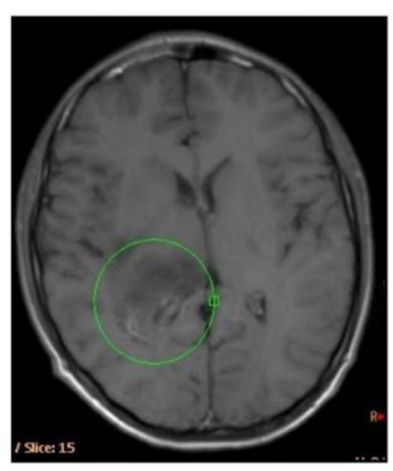

B

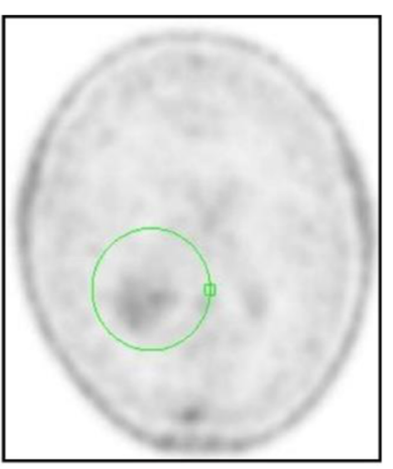

C

Fig. $9{ }^{18} \mathrm{~F}$-FET, evaluation of a brain lesion. Clinical history: 46 y.o. man with seizure. CT (a) and MRI (b) shows an infiltrating lesion in the right parietal region (a). PET/CT findings: faint FET uptake in PET (c). Surgery confirmed a low-grade glioma

${ }^{11} \mathrm{C}$-Methionine, an essential amino acid, enters the cells by various aminoacid transporters and is involved in the synthesis of proteins and lipids, as well as in the regulation and synthesis of DNA and RNA (Davis et al. 1982; Deloar et al. 1998; Harris et al. 2013).

Scan acquisition

- Fasting for at least $2 \mathrm{~h}$

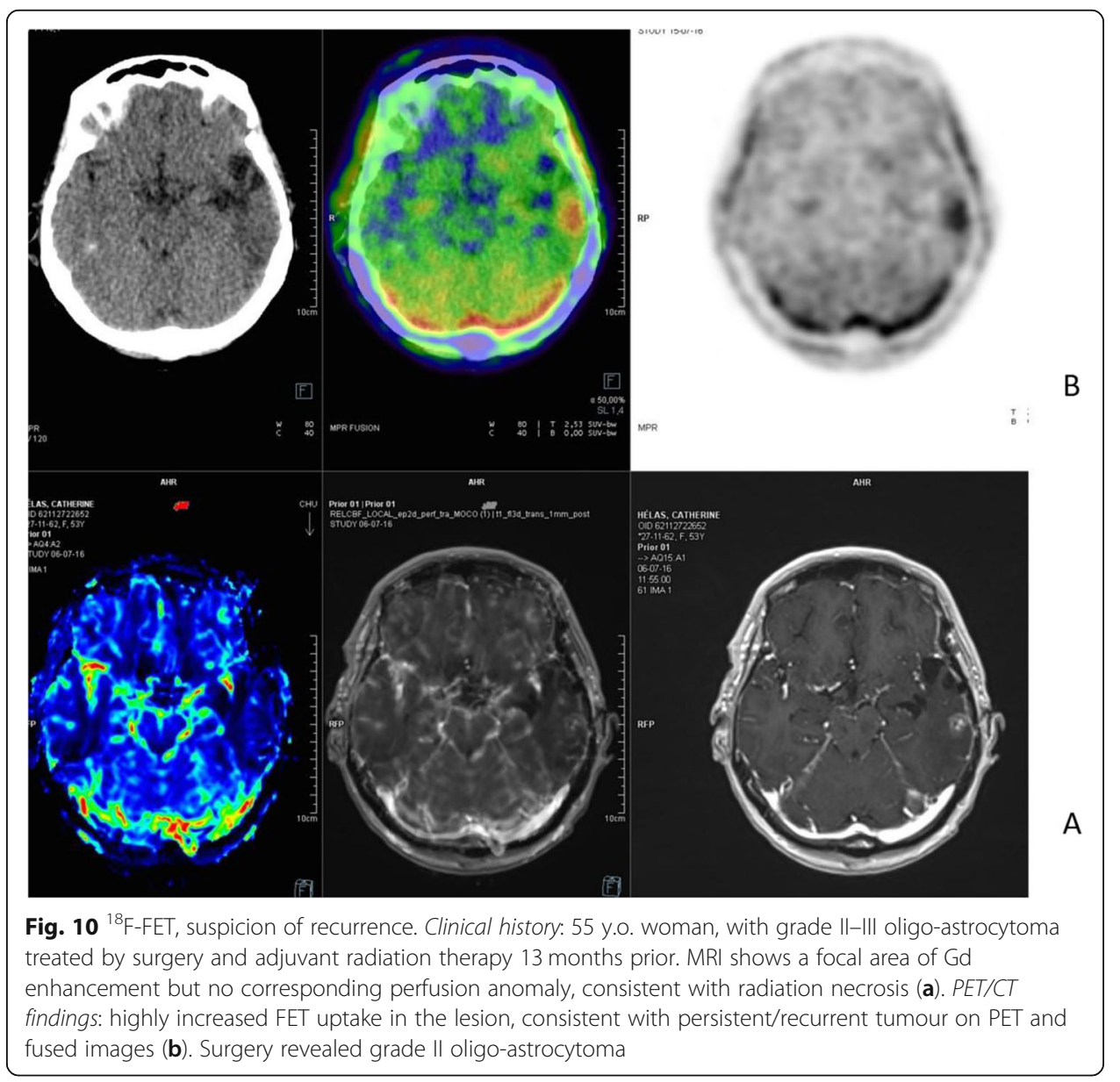




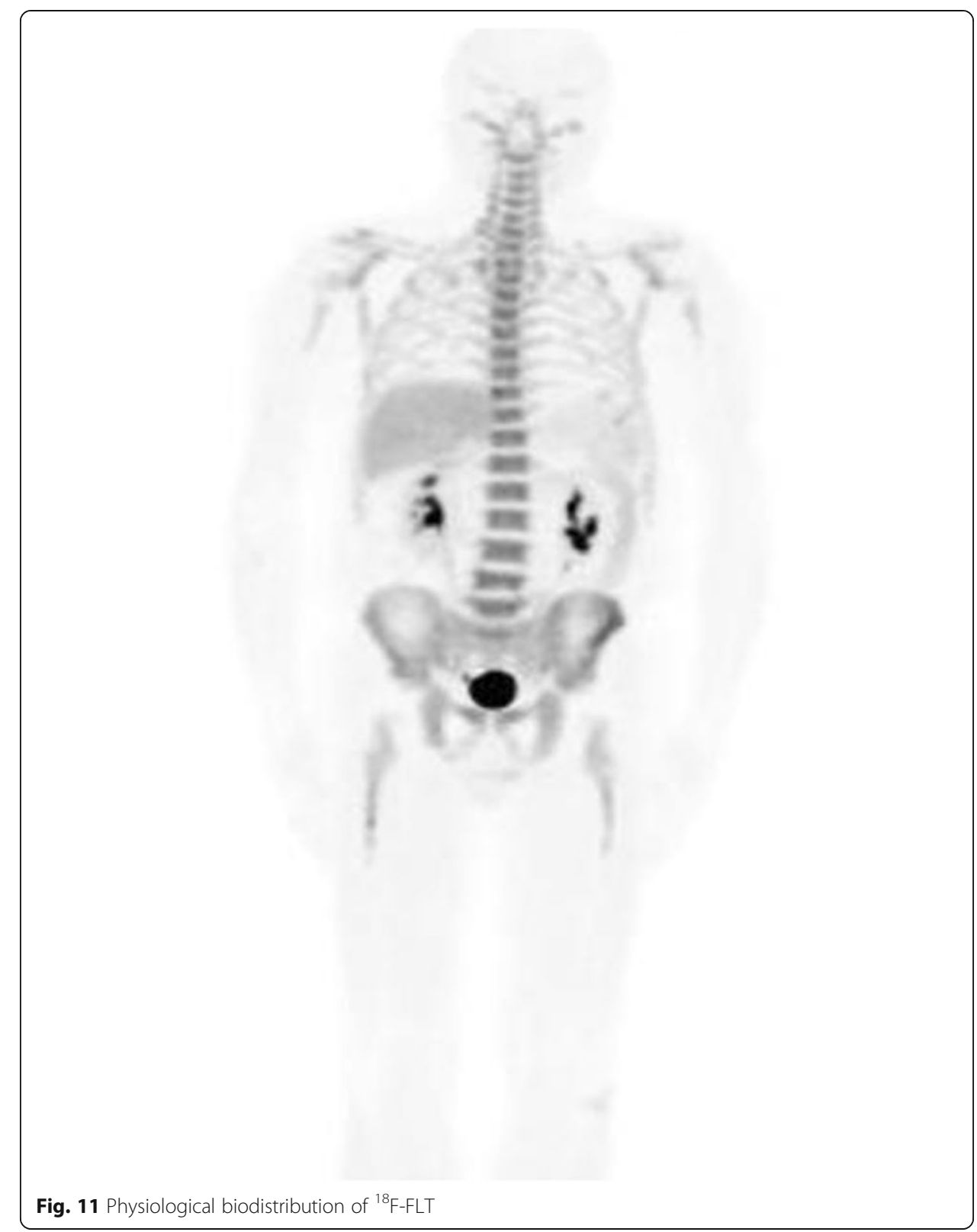

- $3 \mathrm{MBq} / \mathrm{kg}$ of ${ }^{11} \mathrm{C}$-Methionine iv

- Injection immediately before the start of the emission

Clinical indications in oncology (Figs. 16, 17, and 18)

${ }^{11} \mathrm{C}$-Methionine is used in the detection of brain tumours, primarily gliomas. The gliomas present an increased protein metabolism and capture ${ }^{11} \mathrm{C}$-Methionine through specific carriers, in contrast to normal tissues that show low uptake.

\section{Choline}

Names:

1. $[11 \mathrm{C}] \mathrm{CH},{ }^{11} \mathrm{C}$-choline

2. $\left[{ }^{18} \mathrm{~F}\right] \mathrm{CH},{ }^{18} \mathrm{~F}$-fluorocholine 

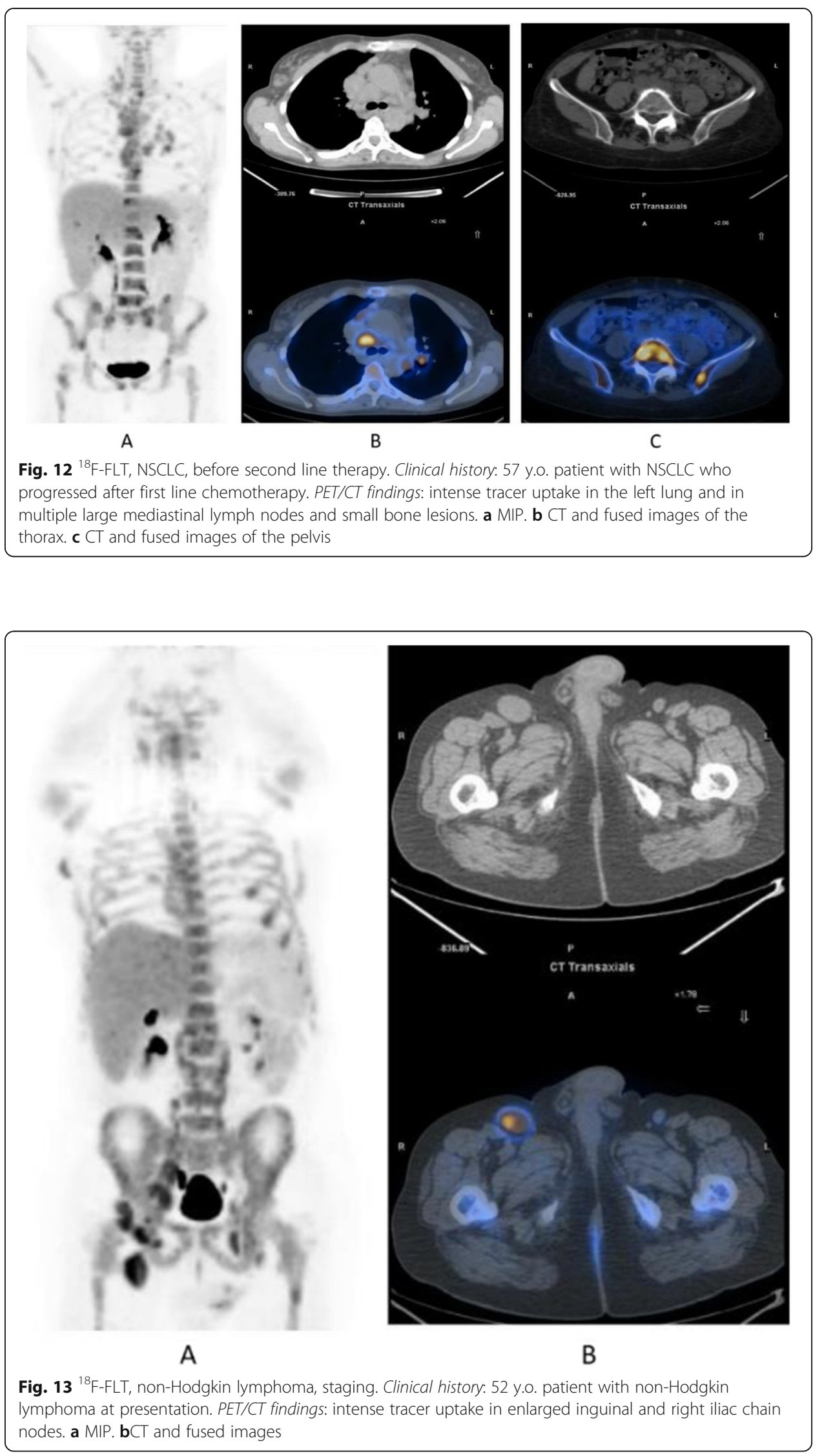


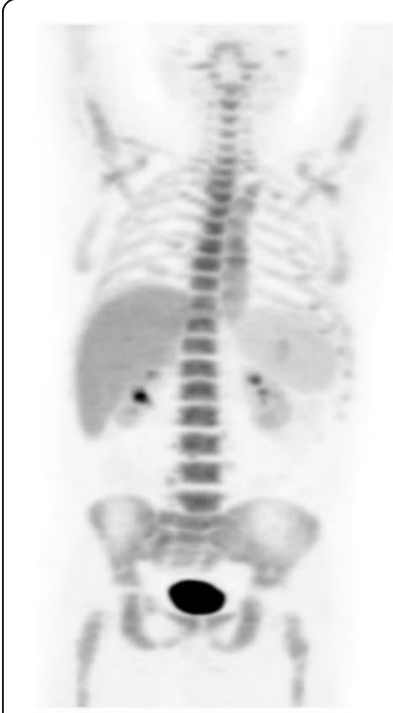

A

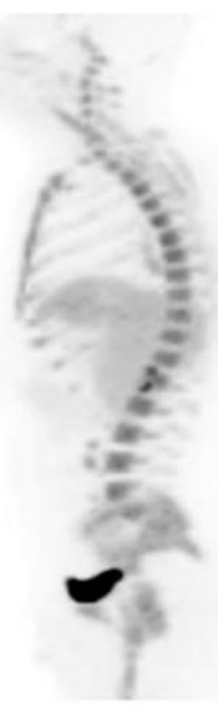

B

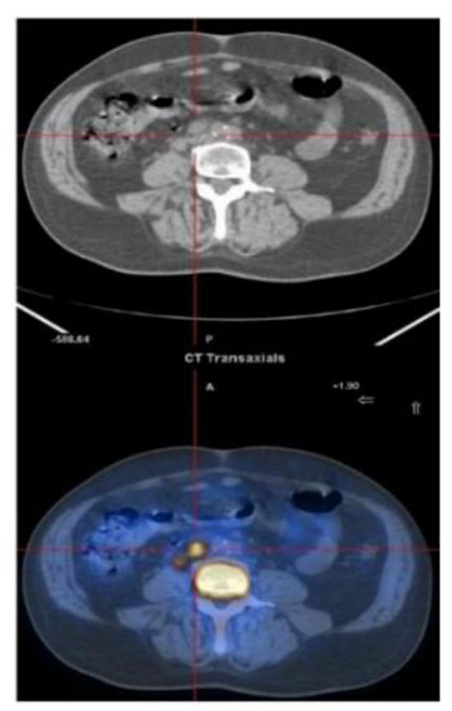

C

Fig. $14{ }^{18} \mathrm{~F}-\mathrm{FLT}$, Hodgkin lymphoma, response evaluation. Clinical history: 32 y.o. patient with Hodgkin lymphoma after second-line therapy. PET/CT findings: moderate uptake of the tracer in two retroperitoneal lymph nodes. a MIP. b MIP in a sagittal view. c CT and fused images

Biodistribution and metabolism (Fig. 19)

After injection, the tracer rapidly clears from the circulation $(<3 \mathrm{~min})$, with high clearance by liver and kidneys. Increased metabolism will lead to an increased uptake of choline in the cell membranes and tissues.

${ }^{11} \mathrm{C}$-choline distributes mainly to the pancreas, kidneys, liver, spleen, and colon. Based upon the relatively low urinary excretion of radioactivity, renal distribution is predominantly to the organ itself, rather than via formation of urine.

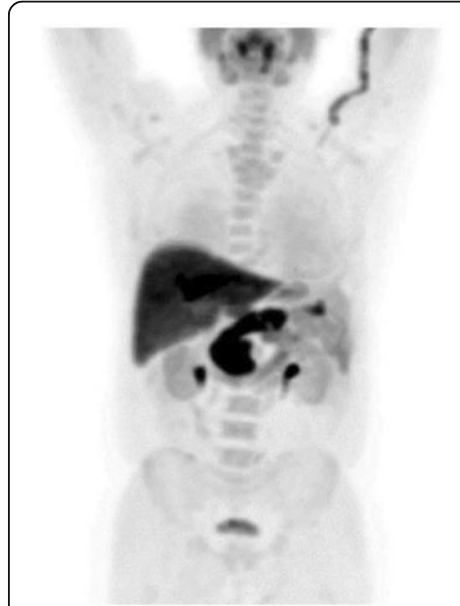

A

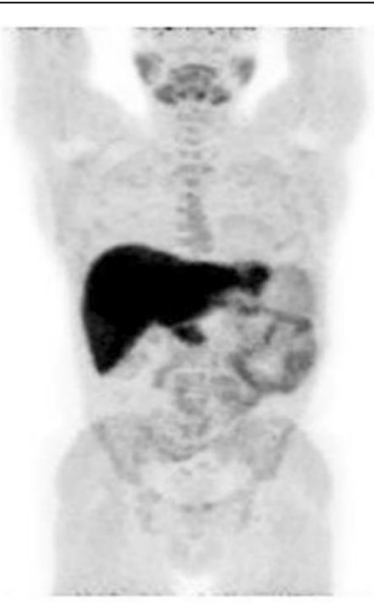

B

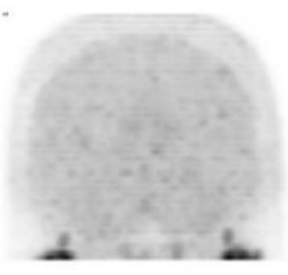

C

Fig. 15 Physiological biodistribution of 11C-Methionine. MIP at $10 \mathrm{~min}$ (a) and $20 \mathrm{~min}$ (b) after administration; brain (c): there is only faint tracer uptake in the brain. There is low, variable uptake in the bowel. In most cases, no radioactive urine is detected in the ureters or bladder at 20 mins after injection 


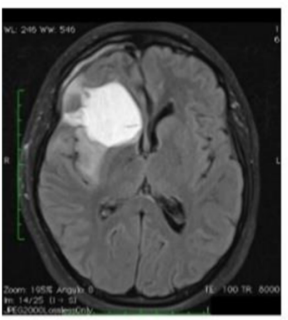

A

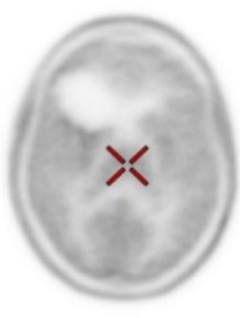

Fig. $16{ }^{11} \mathrm{C}$-Methionine, Glioblastoma grade 2, surgical changes. Clinical history: 25 y.o. female. Glioblastoma grade 2. Surgical treatment with macroscopically complete resection of right frontal glioblastoma. MRI: T2FLAIR image shows heterogeneous hyperintensity (a) and T1 using Gd shows peripheral contrast enhancement. PET/CT findings: slight tracer uptake in margins of surgical field, compatible with inflammatory activity in PET/CT images (b)

B
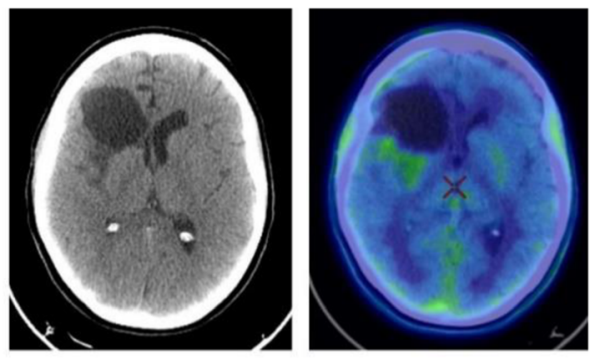

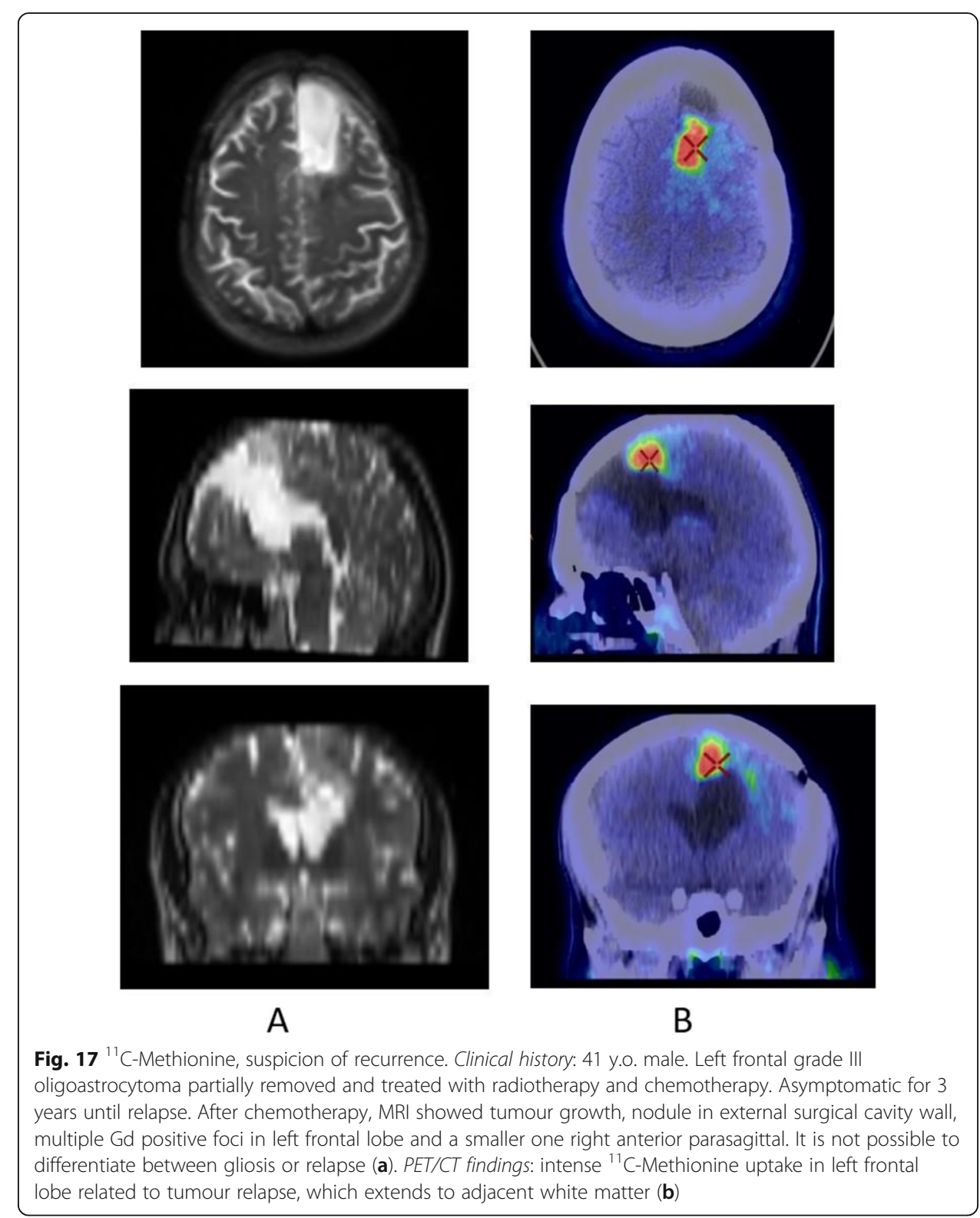




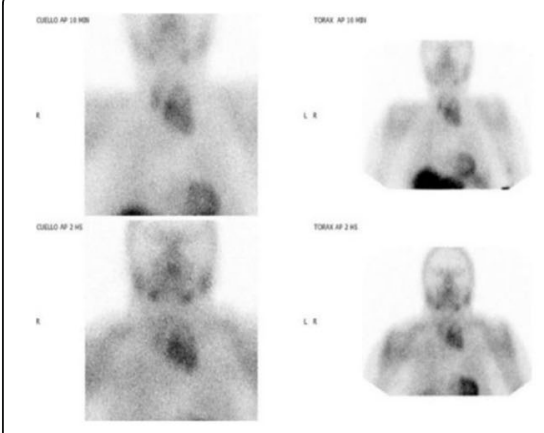

A

Fig. $18{ }^{11} \mathrm{C}$-Methionine, Primary hyperparathyroidism. Clinical history: 74 y.o. female patient with chronic renal failure and goitre. Parathyroid hormone $68 \mathrm{pg} / \mathrm{mL}$. 99mTc-MIBI SPECT: multinodular goitre that extends to the thorax with a left moderate uptake nodule. There is no evidence of hyperfunctioning parathyroid tissue (a). PET/CT findings: multinodular goitre with a large mass in the left lobe that displaces the trachea to the right on $\mathrm{CT}(\mathbf{b})$. In the anterolateral and lower left section of this mass there is a nodule with focal tracer uptake without a clear plane of cleavage with the gland on fused images (c). These findings suggest a parathyroid adenoma

The urinary excretion of ${ }^{18} \mathrm{~F}$-fluorocholine has been reported to be about $5 \%$ of the administered activity in female patients and $2 \%$ in male patients within $60 \mathrm{~min}$ after injection (Mitterhauser et al. 2005; DeGrado et al. 2001; DeGrado et al. 2002).

Scan acquisition

- Fasting of $4 \mathrm{~h}$ is suggested

- 4 or $5 \mathrm{MBq} \backslash \mathrm{Kg}$ of ${ }^{11} \mathrm{C}$-choline iv/300 MBq ${ }^{18} \mathrm{~F}$-fluorocholine iv

- Uptake time $2-5$ min for ${ }^{11} \mathrm{C}$-choline/30 $\min$ for ${ }^{18} \mathrm{~F}$-fluorocholine

- Acquisition starts from the pelvis for ${ }^{11} \mathrm{C}$-choline/head-thorax for ${ }^{18} \mathrm{~F}$-fluorocholine

Clinical indications in oncology (Figs. 20, 21, 22, 23, and 24)

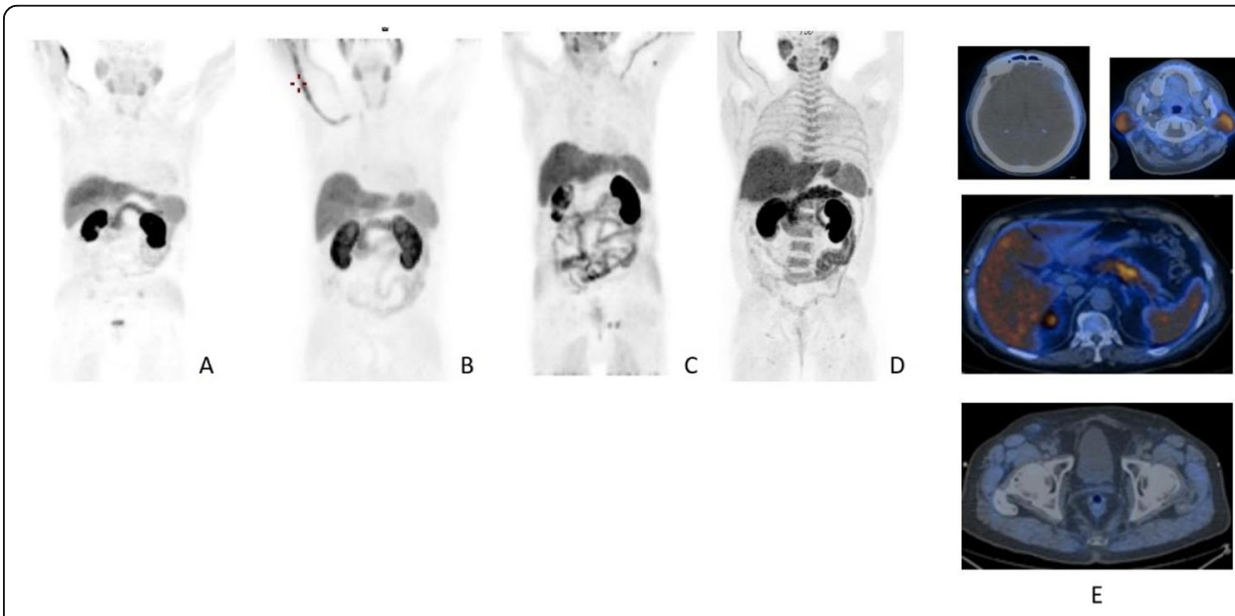

Fig. 19 Physiological bio-distribution and normal variants of ${ }^{11} \mathrm{C}$-choline $2-5 \mathrm{~min}$ after administration: main findings. a Normal biodistribution but a small amount of radioactive urine is present in the bladder; mild uptake in the thyroid. $\mathbf{b}$ The presence of intense uptake in the vessels in which the tracers has been injected is a relatively common finding; some mild thyroid uptake is present. c Moderate uptake in the bowel may be present. $\mathbf{d}$ Some diffuse faint uptake in the bone marrow may be present especially after treatments as a bone marrow rebound 


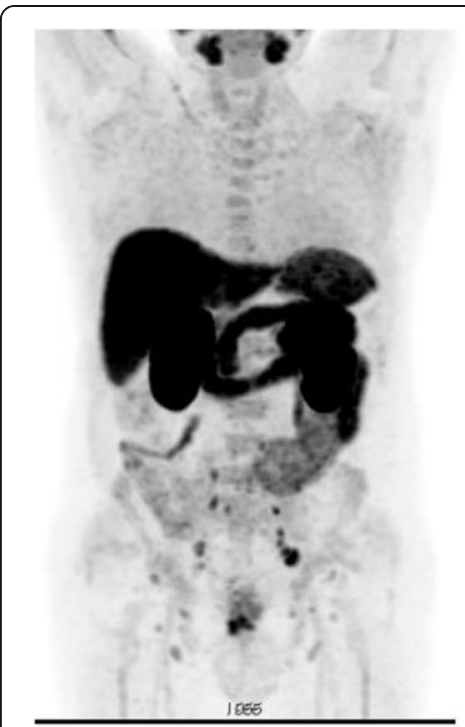

A
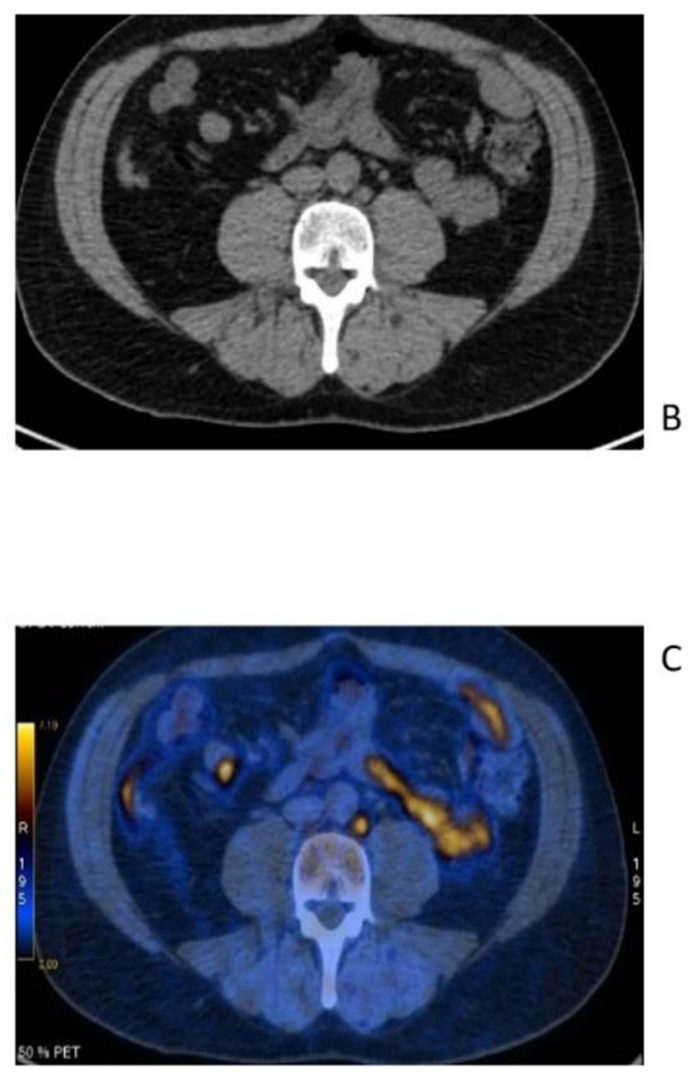

C

Fig. $20{ }^{11} \mathrm{C}$-choline, Initial staging: in very high-risk prostate cancer. Clinical history: 74 y.o. man with prostate cancer, Gleason score $4+5$ according to biopsy. PSA $=126 \mathrm{ng} / \mathrm{ml}$, T3a according to TRUS, candidate for radical prostatectomy. PET/CT findings: multiple foci of increased uptake seen through the pelvis and retroperitoneum, representing pathological uptake in the prostate and lymph node metastases. However, there is no evidence of osseous or visceral involvement. MIP (a), CT (b), and fused images (c)

The main clinical application of choline is in prostate cancer patients for staging and restaging the disease in case of biochemical recurrence after primary treatment (Kryza et al. 2008; Evangelista et al. 2013).

PSMA

Names: $\left[{ }^{68} \mathrm{Ga}\right]$ prostate-specific membrane antigen ligand; ${ }^{68} \mathrm{Ga}$-PSMA

Biodistribution and metabolism (Fig. 25)

Prostate specific membrane antigen (PSMA), a tumour-associated antigen and type II transmembrane protein, is expressed on the membrane of prostatic epithelial cells and overexpressed on prostate tumour cells. Upon internalisation of the radiotracer, PSMA-expressing tumour cells can be detected during PET imaging (Heidenreich et al. 2014; Afshar-Oromieh et al. 2016; Demirci et al. 2016).

Scan acquisition

- Fasting of $4 \mathrm{~h}$ is suggested

- 2 or $3 \mathrm{MBq} \backslash \mathrm{Kg}$ of ${ }^{68} \mathrm{Ga}$-PSMA iv

- Uptake time 60-100 min

- Acquisition starts from the pelvis 


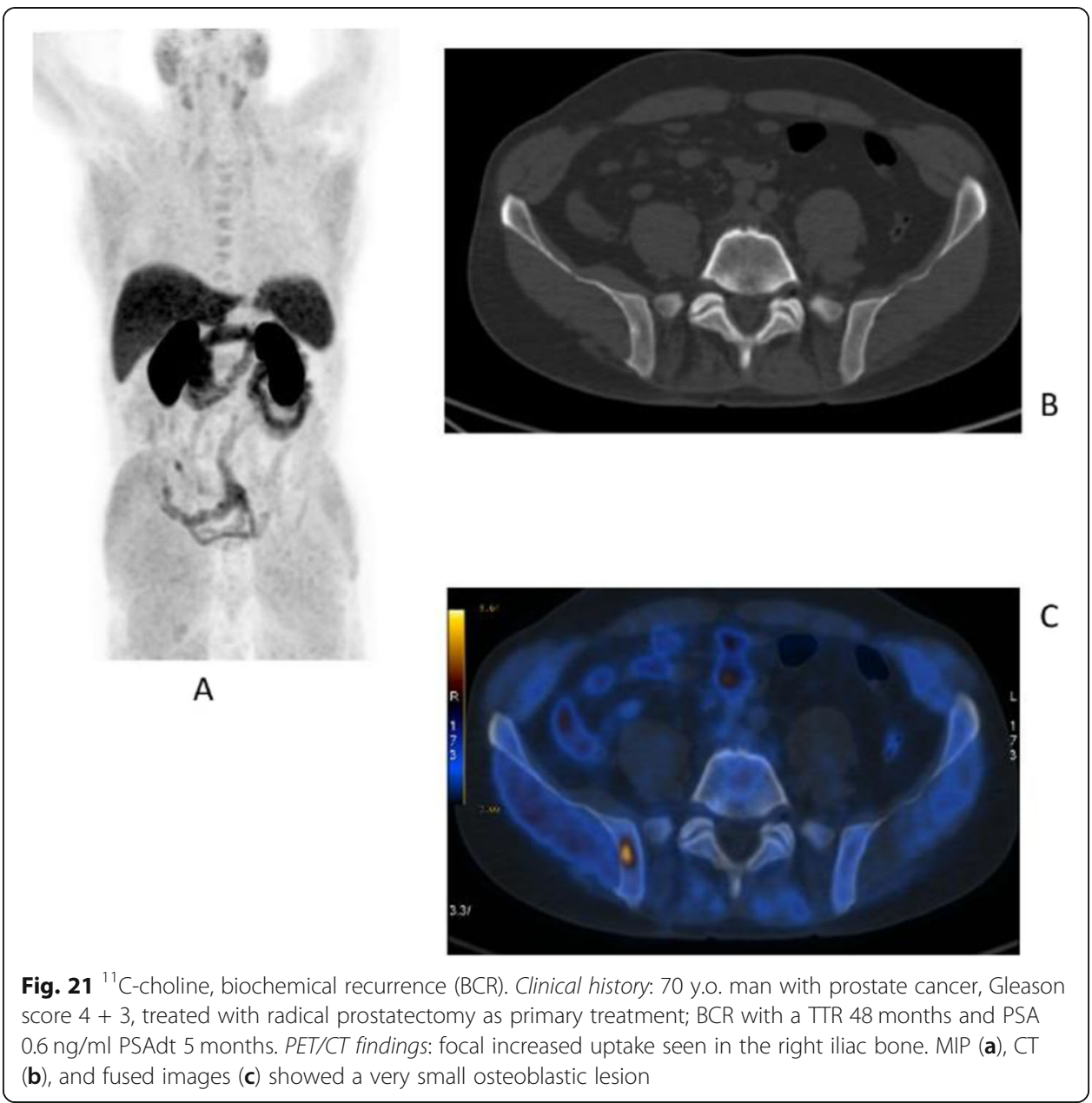

Clinical indications in oncology (Figs. 26, 27, 28, 29, 30, 31, 32, 33, 34, 35, 36, and 37) The main clinical application of ${ }^{68} \mathrm{Ga}$-PSMA is in prostate cancer patients, namely initial diagnosis (Fendler et al. 2017), nodal staging (Schneider et al. 2016), restaging in case of biochemical recurrence (Calais et al. 2018; Maurer et al. 2016), and theranostic in case of ${ }^{177}$ Lu-PSMA treatment (Mottet et al. 2011; Zamboglou et al. 2016), or alfa emitters such as ${ }^{225}$ AcPSMA (Maurer et al. 2016).

\section{DOPA}

Names: L-3,4-Dihydroxy-6- $\left[{ }^{18} \mathrm{~F}\right]$ fluorophenylalanine, ${ }^{18} \mathrm{~F}$-DOPA, ${ }^{18} \mathrm{~F}$-Fluoro-L-DOPA

Biodistribution and metabolism (Fig. 38)

${ }^{18} \mathrm{~F}$-DOPA reflects all stages of DOPA transport, storage, and metabolism. The tracer is metabolised in the striatum, but also in peripheral tissues such as liver, kidneys, and lung (Rahbar et al. 2017).

Scan acquisition

- Fasting for more than $4 \mathrm{~h}$

- $2-3 \mathrm{MBq} / \mathrm{Kg}$ of ${ }^{18} \mathrm{~F}-\mathrm{DOPA}$ iv

- Uptake time $60 \mathrm{~min}$ for extra-cranial tumours. An additional acquisition of $10 \mathrm{~min}$ after injection is suggested in medullary thyroid cancer. 

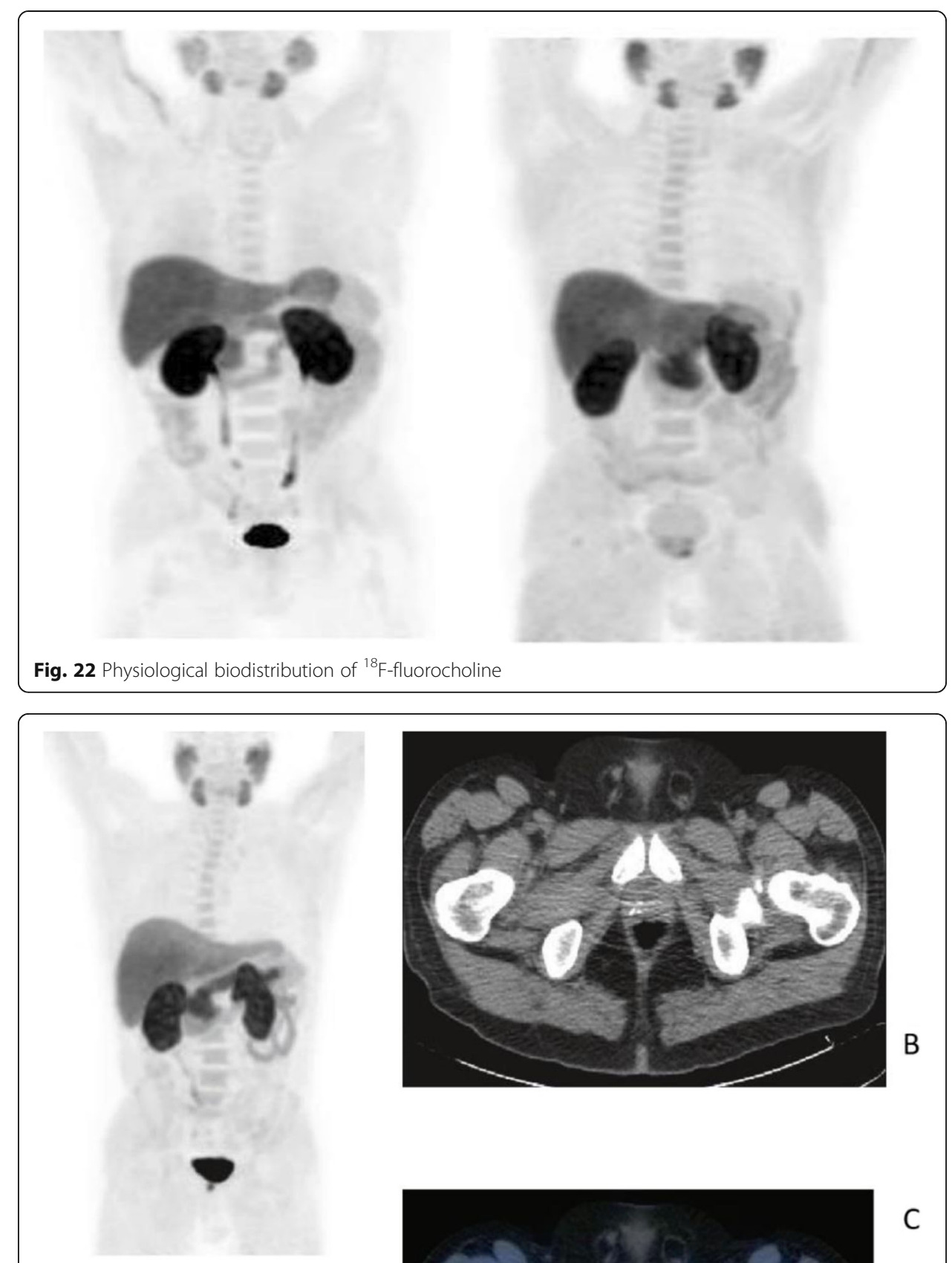

A

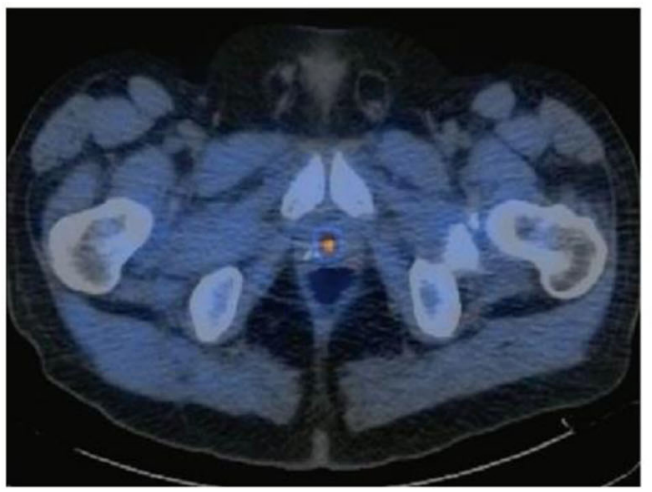

C

Fig. $23{ }^{18} \mathrm{~F}$-fluorocholine, prostate cancer, biochemical recurrence (BCR). Clinical history: 72 y.o. man with prostate cancer, Gleason score $3+3$, treated with radiation therapy. Patient underwent transuretral prostate resection prior to radiotherapy. BCR with a TTR 14 months and PSA $0.8 \mathrm{ng} / \mathrm{ml}$ PSAdt 13 months. PET/CT findings: focal increased uptake below the bladder seen on MIP (a), CT (b), and fused images (c) 


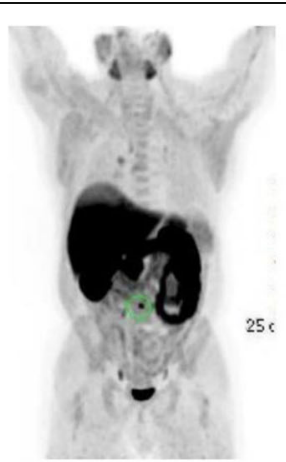

A

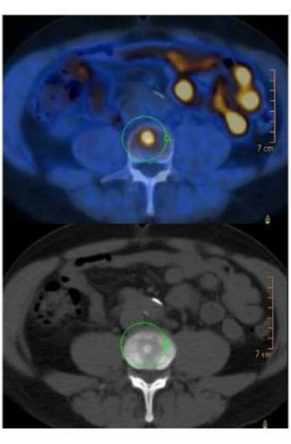

B

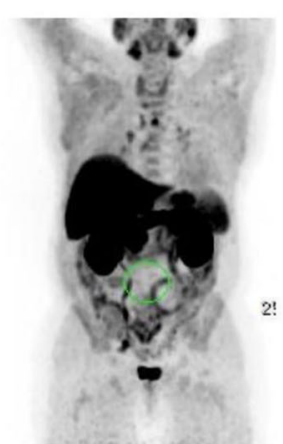

C

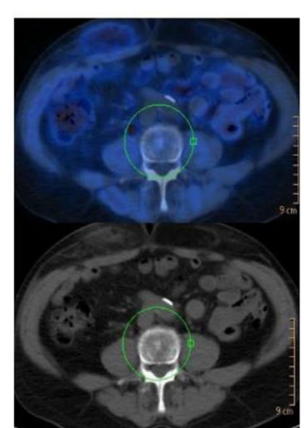

D

Fig. $24{ }^{18} \mathrm{~F}$-fluorocholine, prostate cancer, response evaluation. Clinical history: 73 y.o. man with prostate cancer, Gleason score $4+3$, treated with radical prostatectomy. BCR with PSA $2.3 \mathrm{ng} / \mathrm{ml}$ PSAdt 6 months; evaluation after 2 months of hormonal treatment (PSA $0.5 \mathrm{ng} / \mathrm{ml}$ ). PET/CT findings: intense ${ }^{18} \mathrm{~F}$-Choline uptake in the vertebra before therapy (a MIP; $\mathbf{b}$ fused and CT) not visible after 2 months of hormonal treatment (c MIP; $\mathbf{d}$ fused and CT)

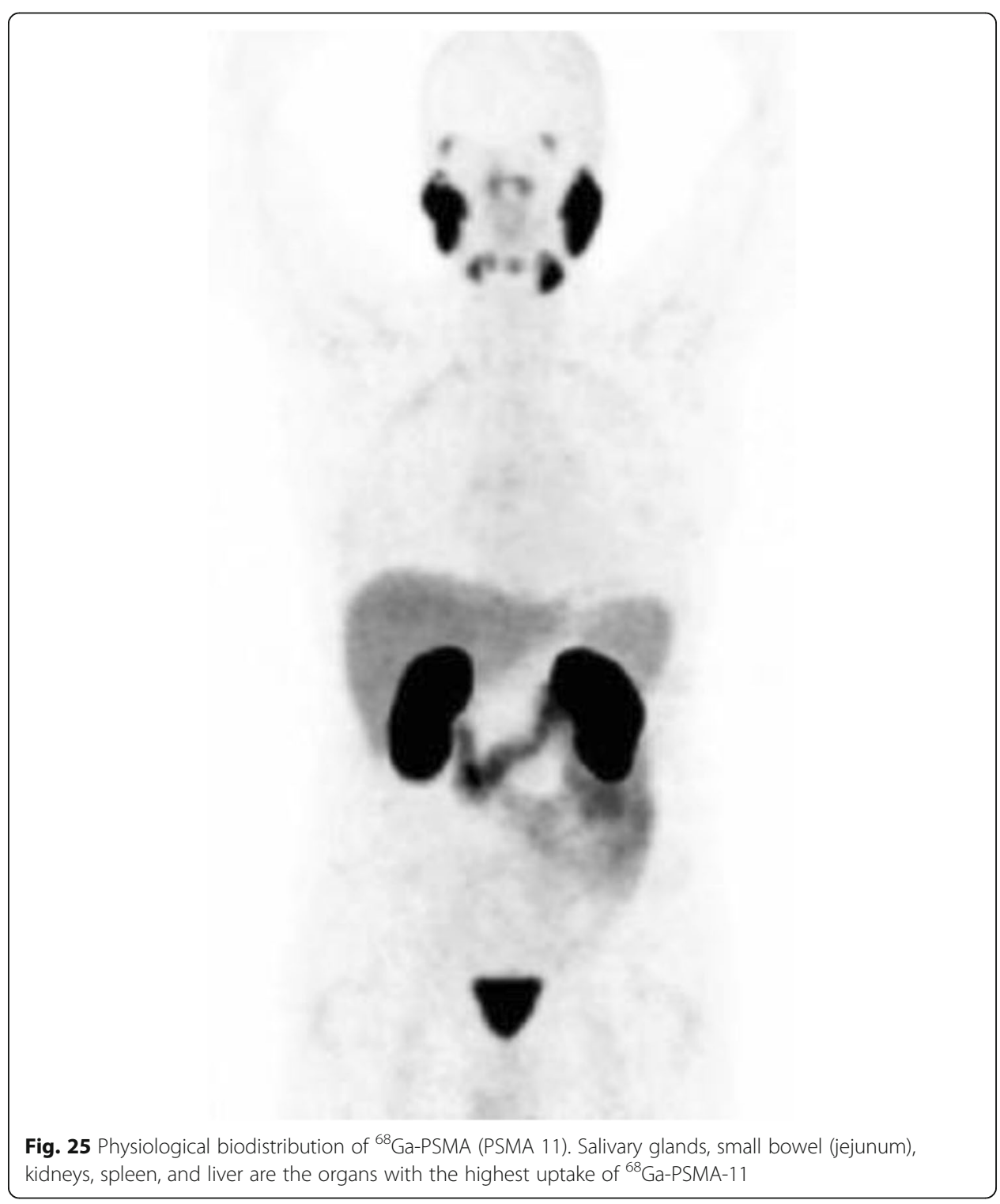



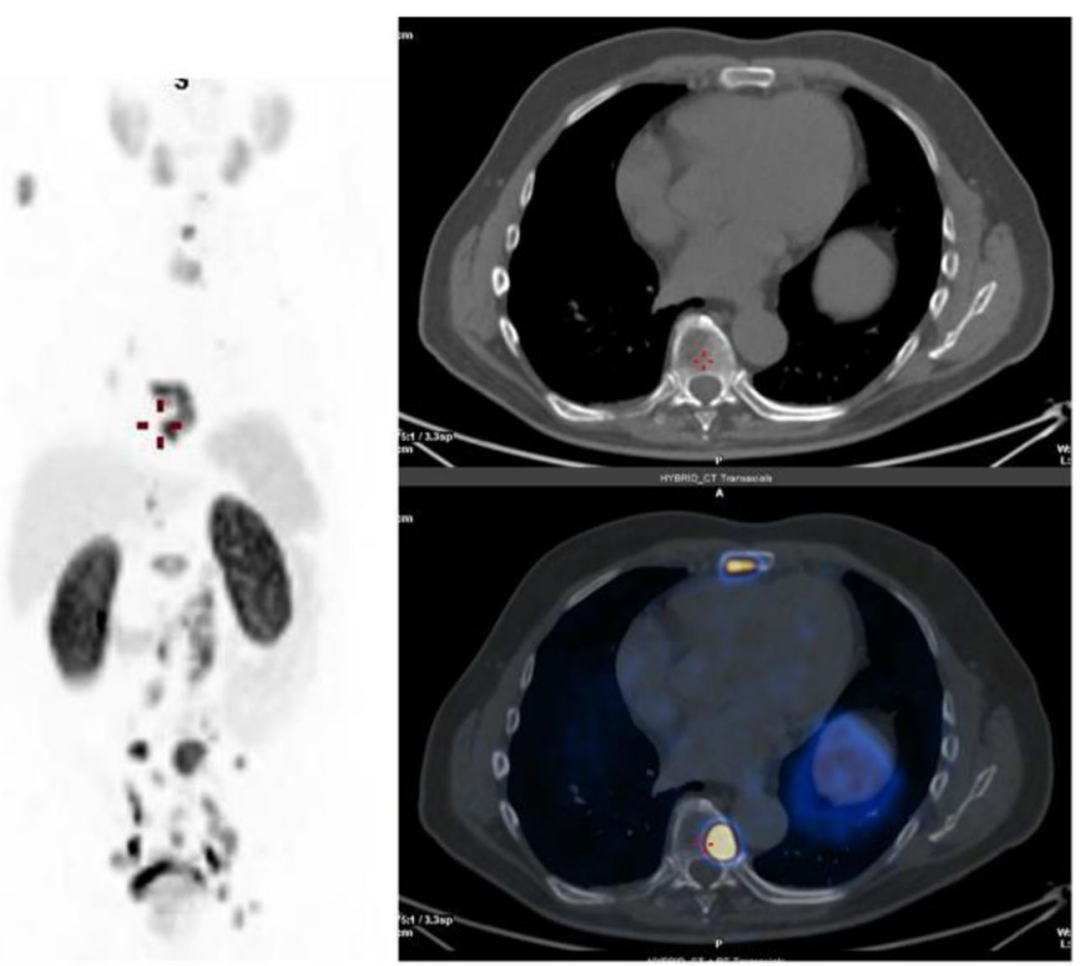

B

\section{A}

Fig. $26{ }^{68} \mathrm{Ga}$-PSMA, prostate cancer, staging. Clinical history: 56 y.o. man with prostate cancer. At presentation, Gleason score $4+5 ;$ PSA $=14 \mathrm{ng} / \mathrm{ml}$, candidate to radical prostatectomy. PET/CT findings: multiple foci of increased uptake involving prostate, lymph nodes, and bones (a MIP). Vertebral lesion seen on fused images (c) is not evident on $C T(\mathbf{b})$

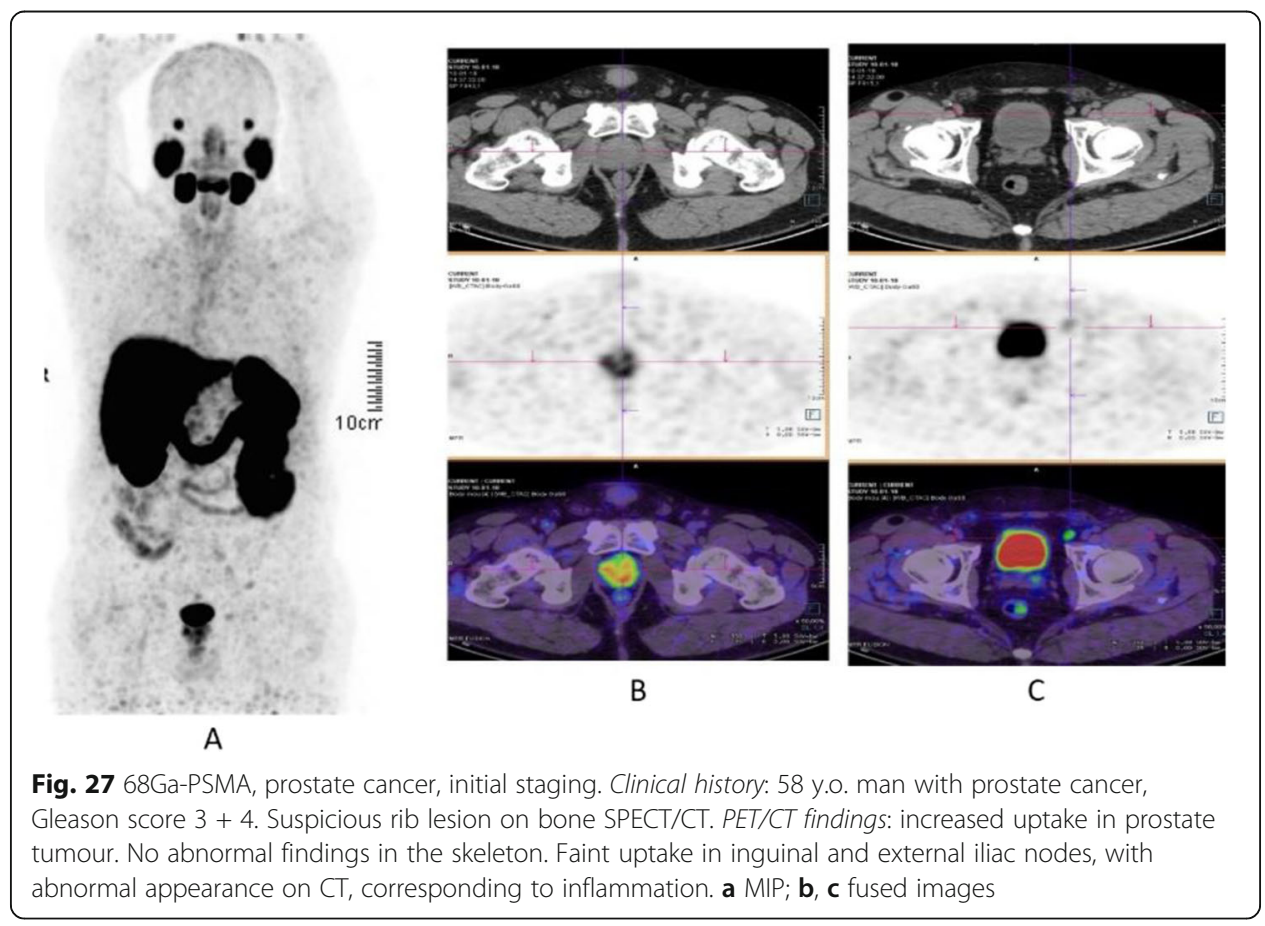




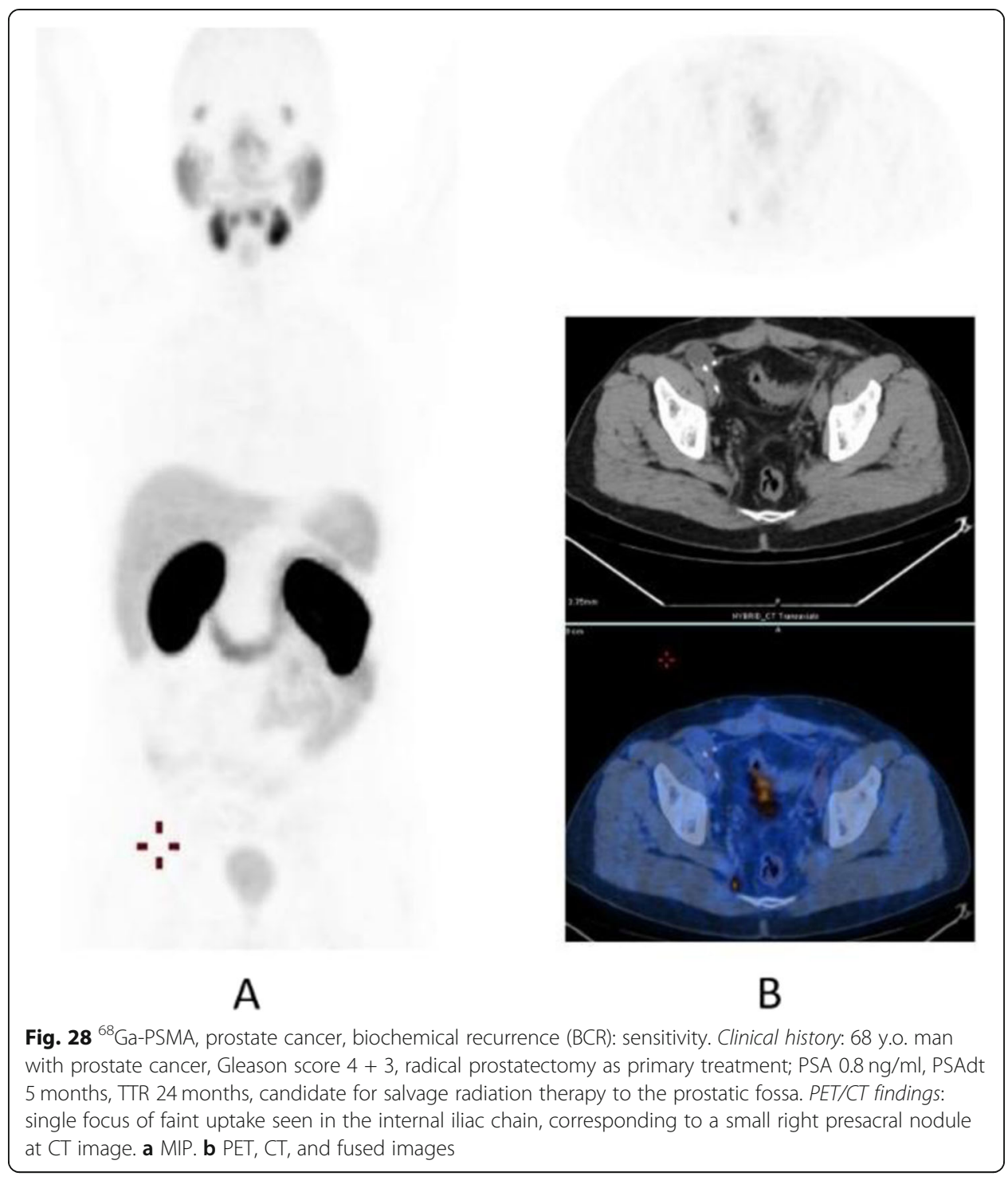

- Uptake time 10 min for primary brain tumours.

Clinical indications in oncology (Fig. 39, 40, 41, 42, and 43)

${ }^{18} \mathrm{~F}$-DOPA is used in the detection of neuroendocrine tumours. It is the PET tracer of choice for recurrence detection in patients with medullary thyroid cancer and may play a role in the management of patients with pheochromocytoma and neuroblastoma. ${ }^{18} \mathrm{~F}$-DOPA PET/CT is also used in recurrent glioma (Kratochwil et al. 2017; Chondrogiannis et al. 2013; Soussan et al. 2012; Amodru et al. 2018).

\section{5-HTP}

Names: $\left[{ }^{11} \mathrm{C}\right]$ 5-hydroxytryptophan; ${ }^{11} \mathrm{C}$-HTP

Biodistribution and metabolism (Fig. 44)

${ }^{11} \mathrm{C}$-HTP is taken up into neuroendocrine tumours cells by L-large amino acid transporter followed by decarboxylation to serotonin. The resulting end-product is then transported into storage vesicles through the vesicular monoamine transporter 


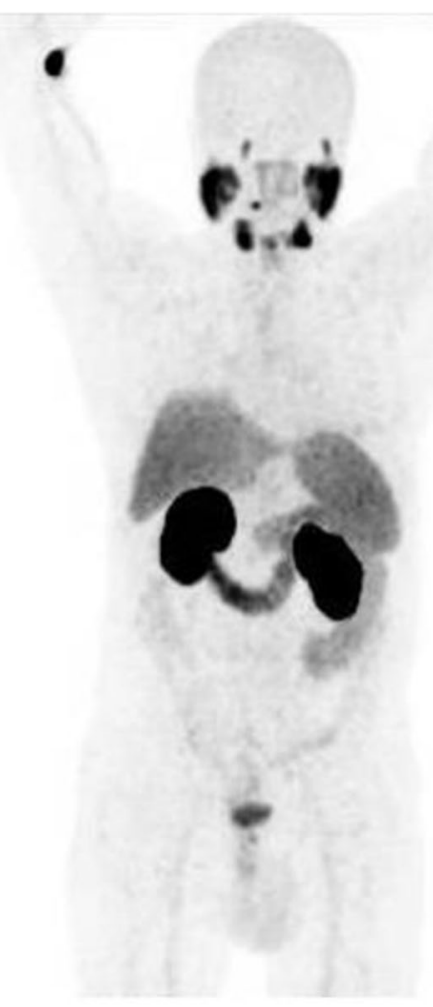

A

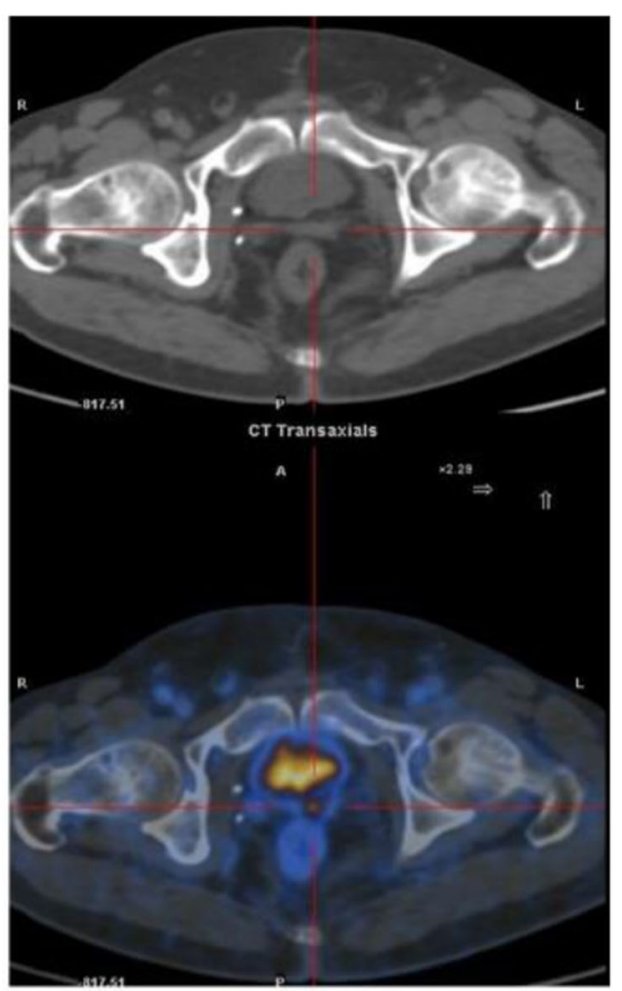

B

Fig. $29{ }^{68} \mathrm{Ga}-\mathrm{PSMA}$, prostate cancer, biochemical recurrence (BCR). Clinical history: 62 y.o. man with prostate cancer, radical prostatectomy as primary treatment Gleason score $4+4$; PSA $=0.7 \mathrm{ng} / \mathrm{ml}$, PSAdt 5 months, TTR 24 months, candidate to salvage radiation therapy to the prostatic fossa. PET/CT findings: single focus of increased uptake seen in the prostatic fossa consistent with local relapse after biopsy. $\mathbf{a} \mathrm{MIP} ; \mathbf{b} \subset T$ and fused images

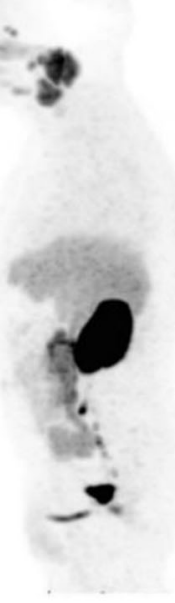

A

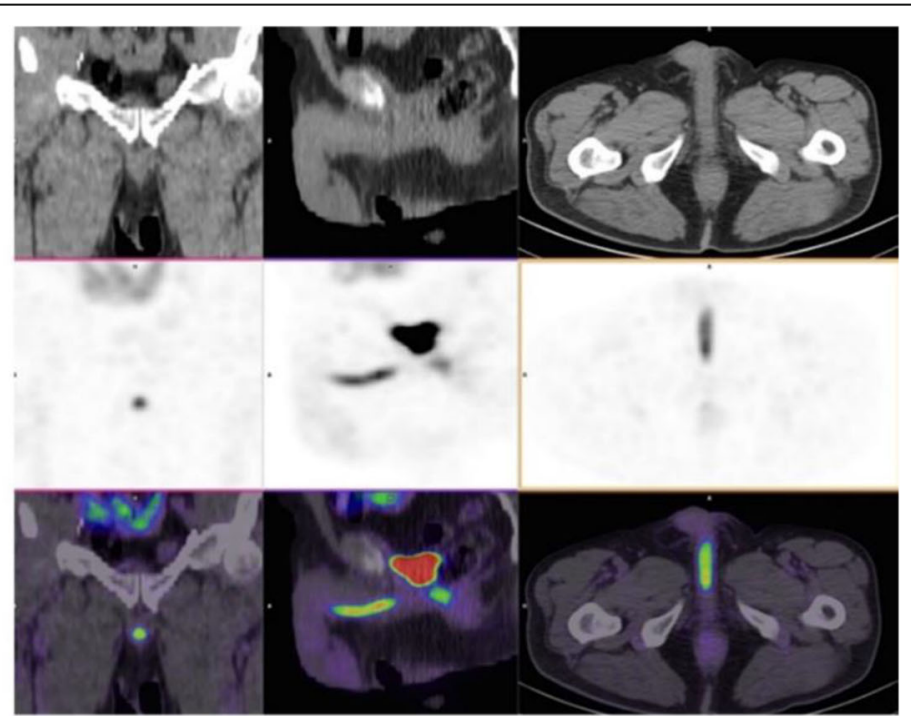

B

Fig. $30{ }^{68} \mathrm{Ga}-\mathrm{PSMA}$, prostate cancer, biochemical recurrence (BCR): specificity. Clinical history: 68 y.o. man with prostate cancer, prostatectomy as primary treatment, Gleason score $4+5$; pT3NOMx + adjuvant radiotherapy. Three years later: PSA $=2.49 \mathrm{ng} / \mathrm{ml}$, PSAdt 8 months. PET/CT findings: no evidence of recurrent disease, but urinary activity is evident in the prostatic fossa and the urethra. a MIP in a lateral view; $\mathbf{b} C T$, PET, and fused images 


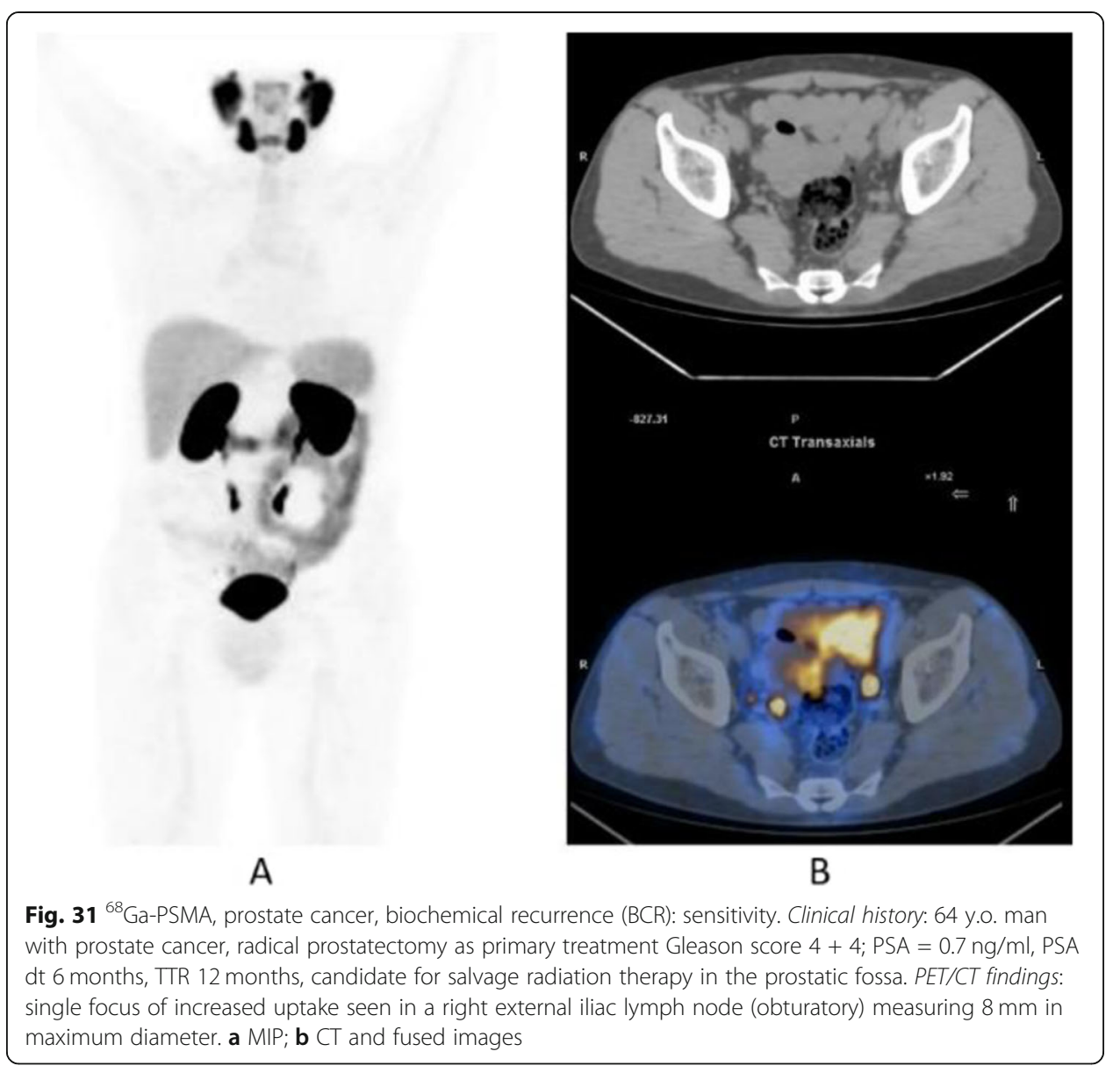

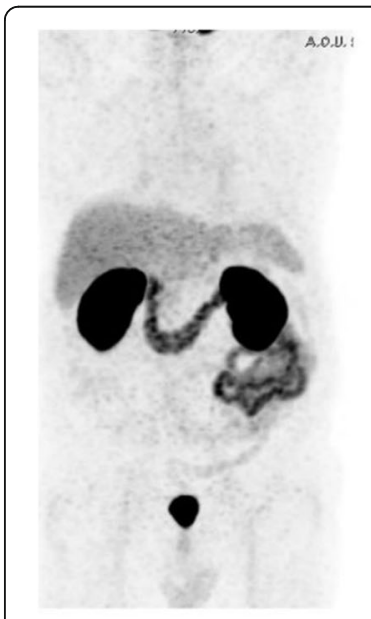

A

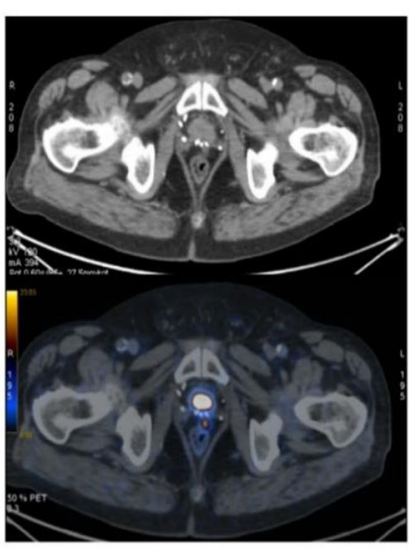

B

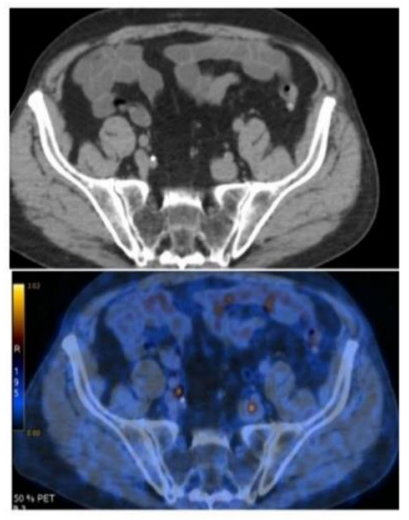

C

Fig. $32{ }^{68} \mathrm{Ga}$-PSMA, prostate cancer, biochemical recurrence (BCR): sensitivity. Clinical history: 72 y.o. man with prostate cancer, radical prostatectomy as primary treatment Gleason score $4+5$; PSA $=0.4 \mathrm{ng} / \mathrm{ml}$, PSA dt 6 months, TTR 10 months, candidate for salvage radiation therapy in the prostatic fossa. PET/CT findings: a focus of increased uptake is seen in the prostatic fossa and a right common iliac lymph node measuring 7 $\mathrm{mm}$ in maximum diameter. a MIP; b CT and fused images, local relapse; c CT and fused images, iliac lymph node 


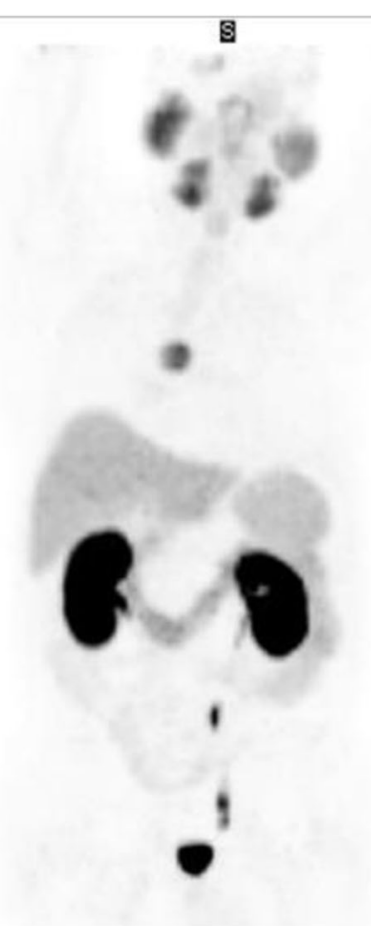

A

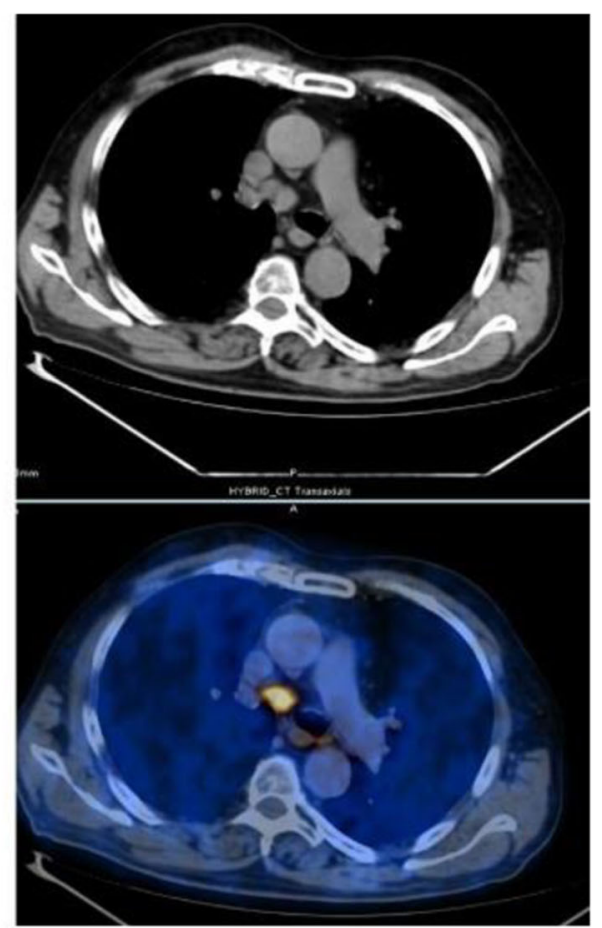

B

Fig. $33{ }^{68} \mathrm{Ga}-\mathrm{PSMA}$, prostate cancer, biochemical recurrence (BCR): uncommon precarinal solitary metastasis Clinical history: 64 y.o. man with prostate cancer, radical prostatectomy as primary treatment Gleason score $4+5 ;$ PSA $=1.9 \mathrm{ng} / \mathrm{ml}$, PSA dt 6 months, TTR 28 months. PET/CT findings: focus of increased uptake seen in an enlarged precarinal lymph node $(24 \mathrm{~mm})$. Transbronchial biopsy diagnosed prostate cancer relapse. a MIP images; $\mathbf{b} C T$ and fused images

as well as went through the metabolic pathway of serotonin (Addeo et al. 2018; Piccardo et al. 2012).

Scan acquisition

- No special diet is required

- $370 \mathrm{MBq}$ of ${ }^{11} \mathrm{C}-\mathrm{HTP}$ iv

- Uptake time $1 \mathrm{~h}$

Clinical indications in oncology (Fig. 45)

${ }^{11} \mathrm{C}$-HTP is used in the detection of neuroendocrine tumours. Since the uptake is related to the serotonergic pathway, ${ }^{11} \mathrm{C}$-HTP is a possible alternative to ${ }^{68} \mathrm{Ga}$-DOTApeptide or ${ }^{18} \mathrm{~F}$-DOPA (Neels et al. 2006).

\section{Somatostatin analogues}

Names: $\left[{ }^{68} \mathrm{Ga}\right](1,4,7,10$-tetraazacyclododecane-N, N', N", N"'-tetraacetic acid)-1- (d)Phe1-Thy3-octreotate (DOTATATE)- (d)-Phe1-Thy3-octreotide (DOTATOC)- NaI3octreotide (DOTANOC)

Biodistribution and metabolism (Fig. 46)

Synthetic somatostatin peptides show long biological half-life and stronger and more specific affinity for somatostatin receptors available on the cellular surface of 


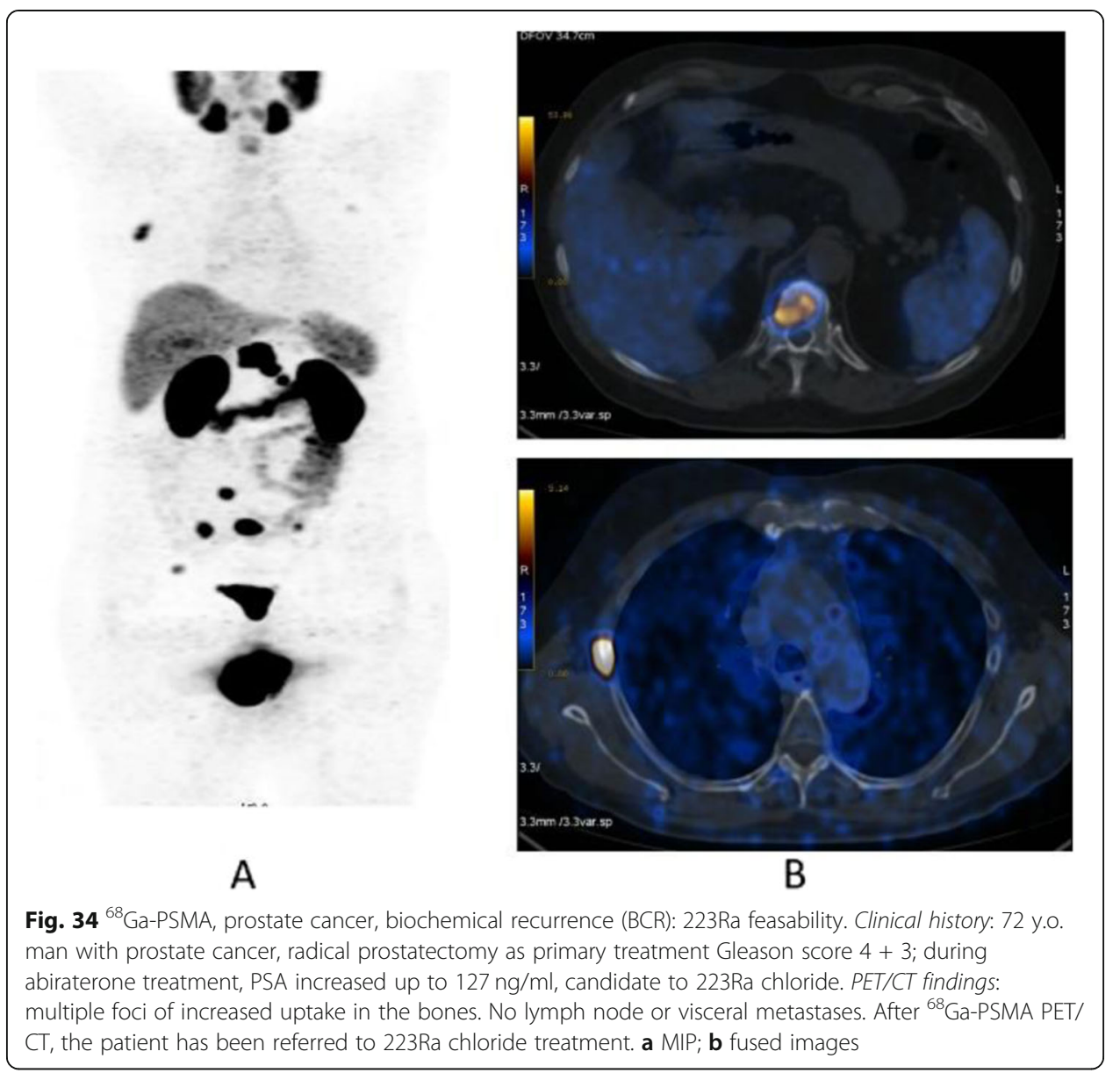

neuroendocrine tumours. DOTATATE, DOTATOC, and DOTANOC have different affinities for receptor subtypes (Kroiss et al. 2013; Bergeret et al. 2019).

Scan acquisition

- No special diet is required

- 2-3 MBq $\backslash \mathrm{Kg}$ of ${ }^{68} \mathrm{Ga}$-DOTA-Peptide iv

- Uptake time $1 \mathrm{~h}$

Clinical indications in oncology (Figs. 47, 48, 49, 50, 51, 52, 53, 54, 55, 56, 57, 58, 59, $60,61,62,63,64$, and 65 )

In the management of NETs ${ }^{68} \mathrm{Ga}$-DOTA-conjugated peptide, PET/CT is used to localise primary tumours and detect sites of metastatic disease (staging); follow-up patients with known disease to detect residual, recurrent or progressive disease (restaging); determine somatostatin status; monitor response to therapy; and select patients with metastatic disease for peptide receptor radionuclide therapy (Skoura et al. 2016; Sundin 2018; Singh et al. 2018; Waseem et al. 2019).

FMISO

Names: 1-(2-Nitro-imidazolyl)-3- $\left[{ }^{18} \mathrm{~F}\right]$ fluoro-2-propanol; ${ }^{18}$ F-FMISO

Biodistribution and metabolism (Fig. 66) 


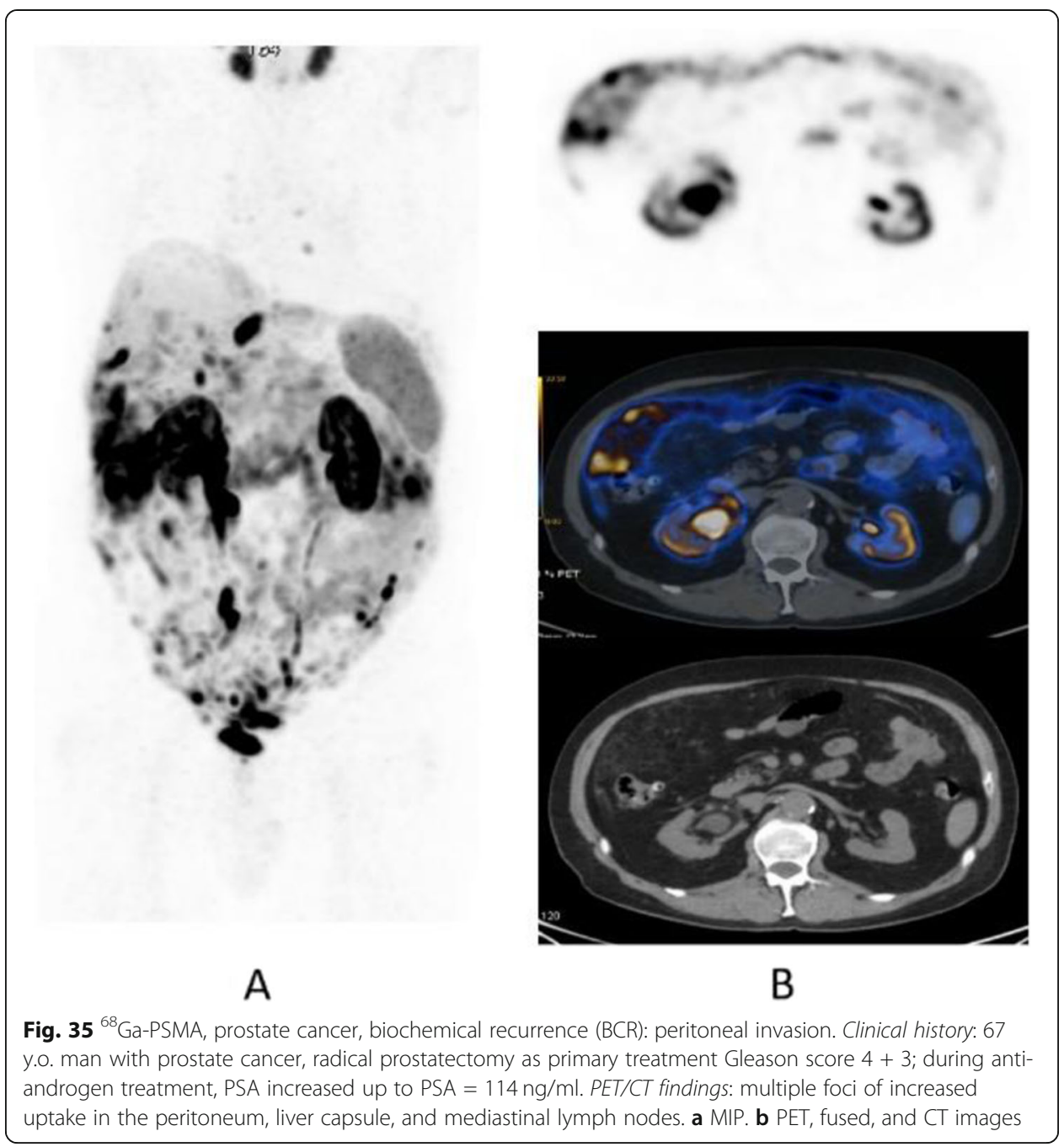

Nitro-group are postulated to undergo reduction in hypoxic condition (pO2 $\leq 2-3$ $\mathrm{mmHg}$ ), forming highly reactive oxygen radicals that subsequently bind covalently to macromolecules inside the cells (Visser et al. 2014; Orlefors et al. 2005).

${ }^{18}$ F-FMISO is relatively hydrophilic and diffuses across cell membranes, showing a passive distribution in normal tissues, resulting in slow clearance kinetics and a high lipophilicity, resulting in substantially high background.

Scan acquisition

- Fasting for at least $2 \mathrm{~h}$

- $6 \mathrm{MBq} \backslash \mathrm{Kg}$ of ${ }^{18} \mathrm{~F}$-FMISO iv

- Uptake time 3-4h

Clinical indications in oncology (Fig. 67)

PET-CT with ${ }^{18} \mathrm{~F}$-FMISO is a non-invasive method for detecting and characterising hypoxia in several tumours. Ischemia in tumours is associated with a poor prognosis, increased invasion rate, metastasis, and resistance to chemo- and radiation therapy (Institute NC 2013; Nehmeh et al. 2008; Gagel et al. 2006; Hirata et al. 2012; Lin et al. 2008; Lopci et al. 2014; Reischl et al. 2007; Wack et al. 2015). 


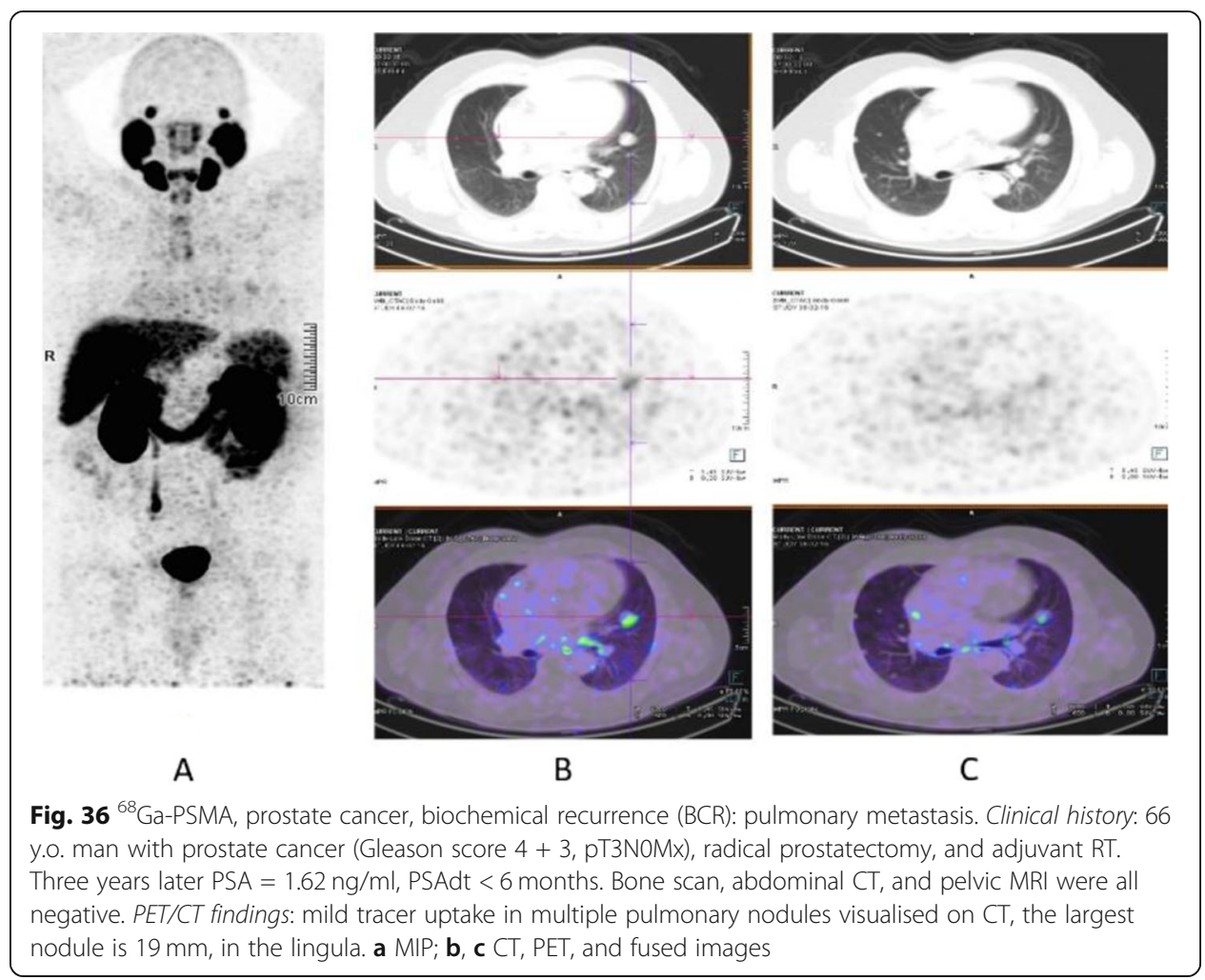

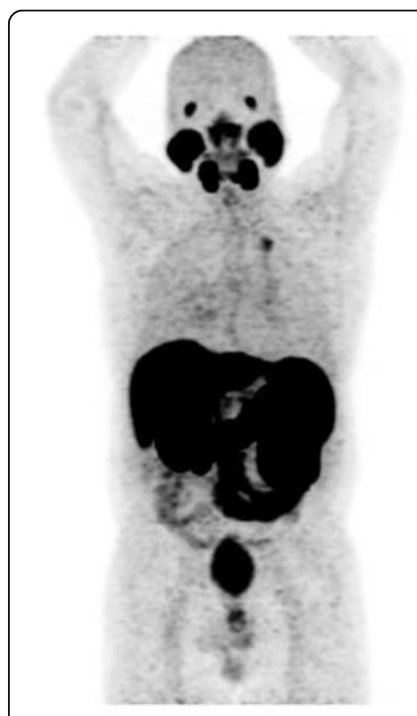

A
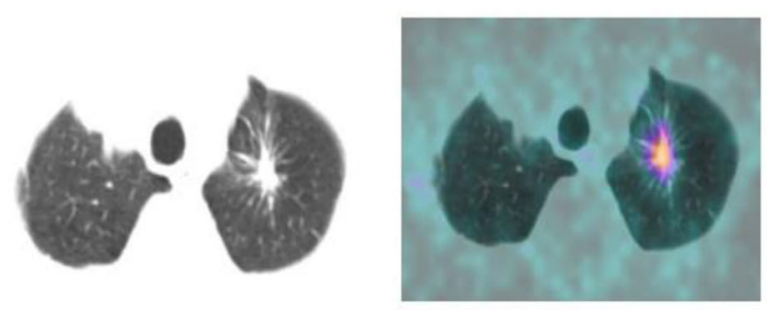

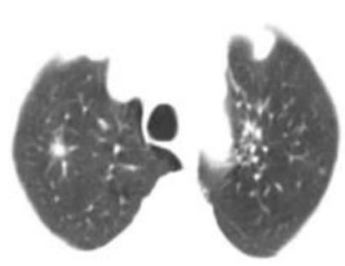

B

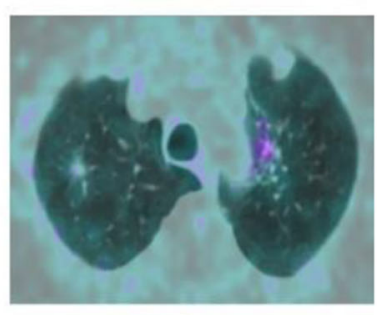

C

Fig. $37{ }^{68} \mathrm{Ga}-\mathrm{PSMA}$, prostate cancer, initial staging: lung lesion. Clinical history: 68 y.o. patient diagnosed with prostate cancer, treated with radical prostatectomy. First biochemical recurrence: PSA $0.39 \mathrm{ng} / \mathrm{ml}$. PET/ CT findings: increased uptake in a pulmonary nodule with irregular margins and spiculated edges in the left upper lobe. Biopsy diagnosed a primary lung adenocarcinoma. a MIP, b CT images, c fused images 


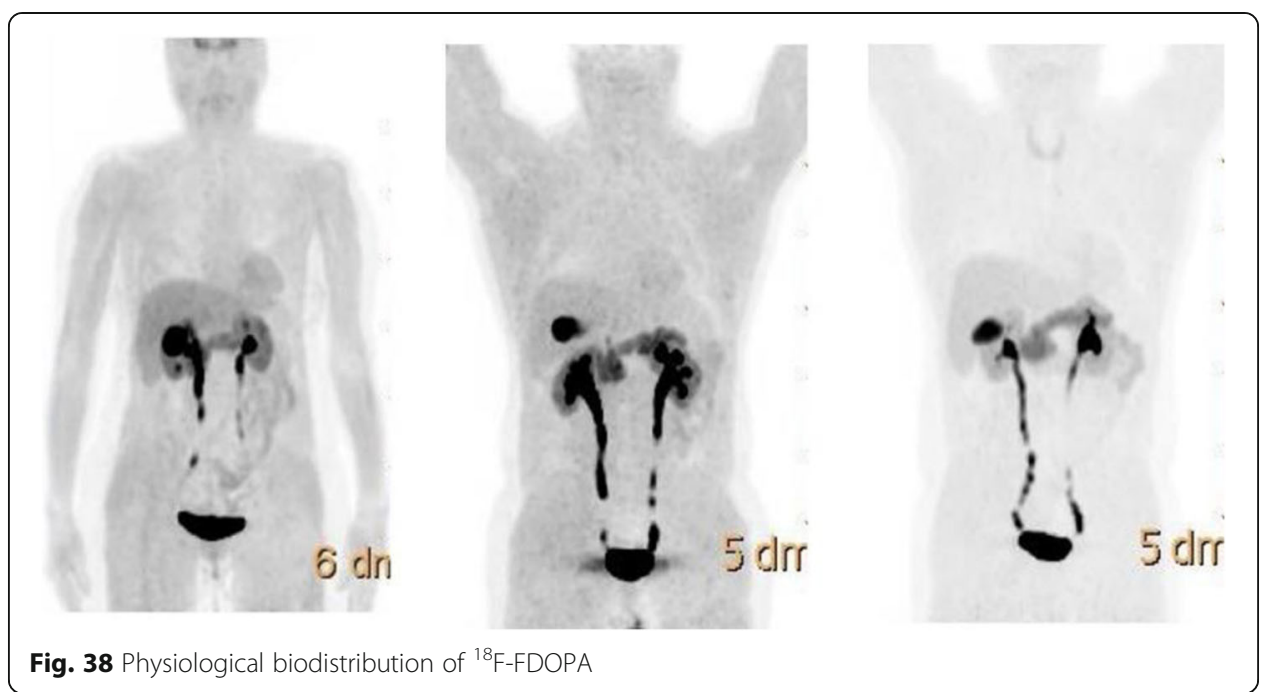

Fig. 38 Physiological biodistribution of ${ }^{18} \mathrm{~F}-\mathrm{FDOPA}$
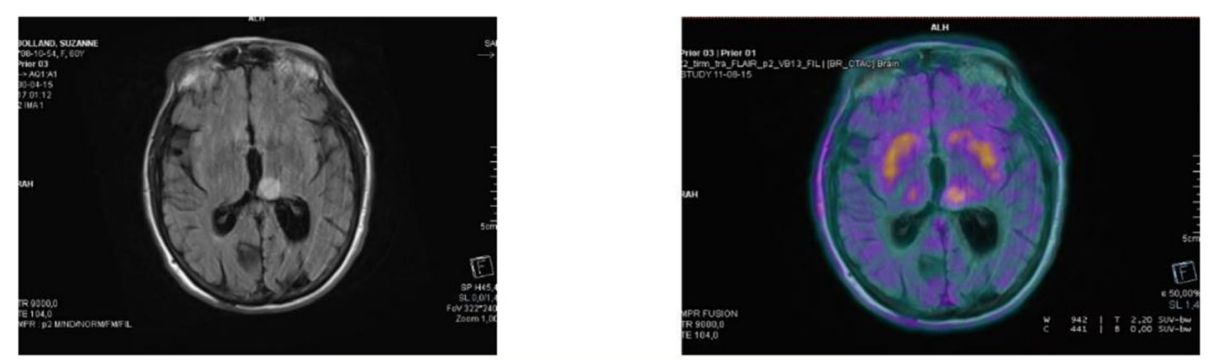

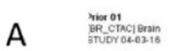

C

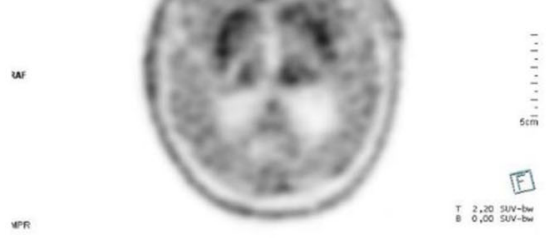

B

Fig. $39{ }^{18}$ F-FDOPA, glioma. Clinical history: 61 y.o. woman with indeterminate left thalamic lesion. MRI consistent with low grade glioma (a). PET/CT findings: mild ${ }^{18} \mathrm{~F}$-FDOPA uptake in the lesion, also consistent with low grade glioma (b PET, $\mathbf{c}$ fused PET and MR). Follow-up (2 years): no evolution 

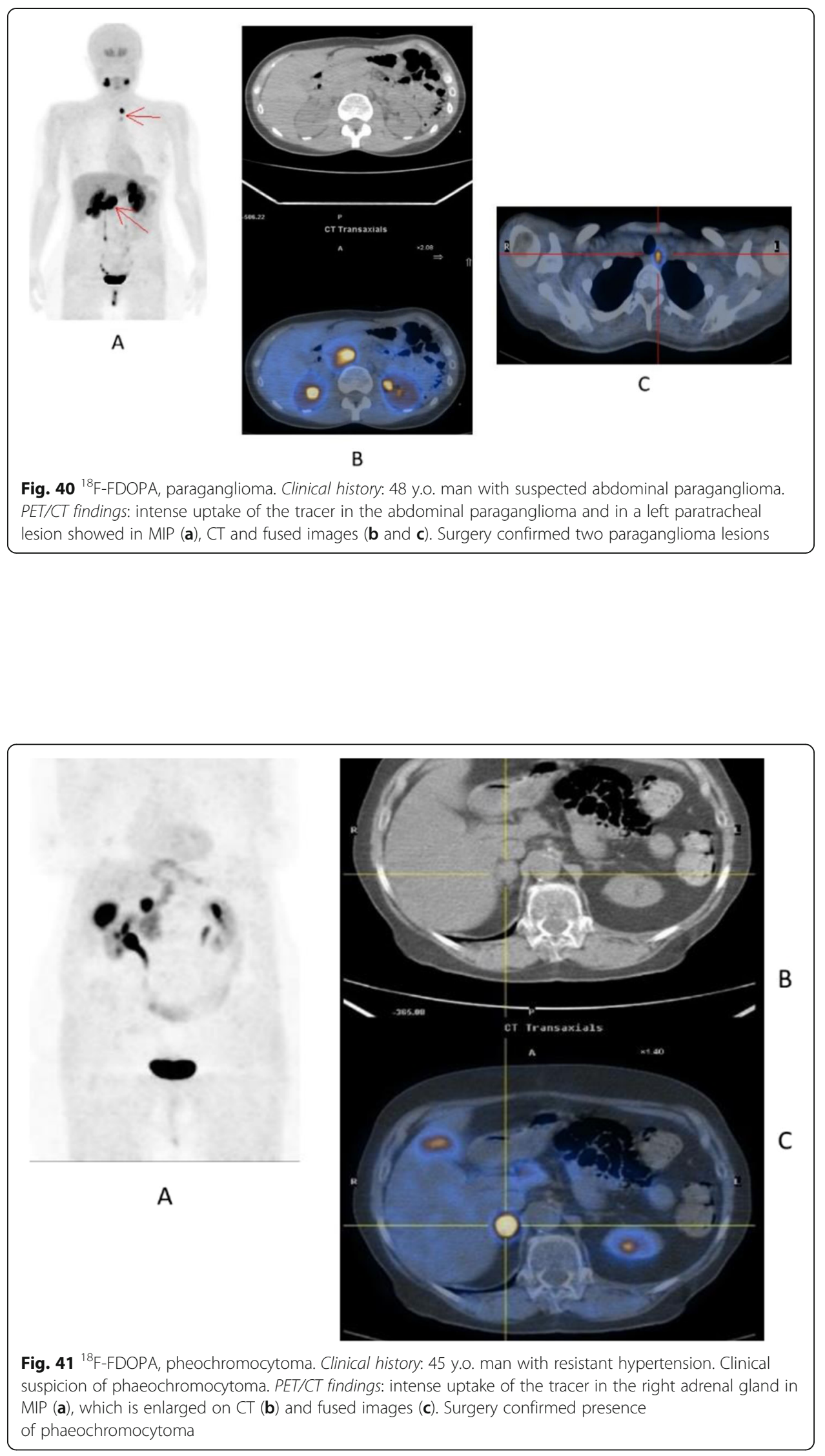

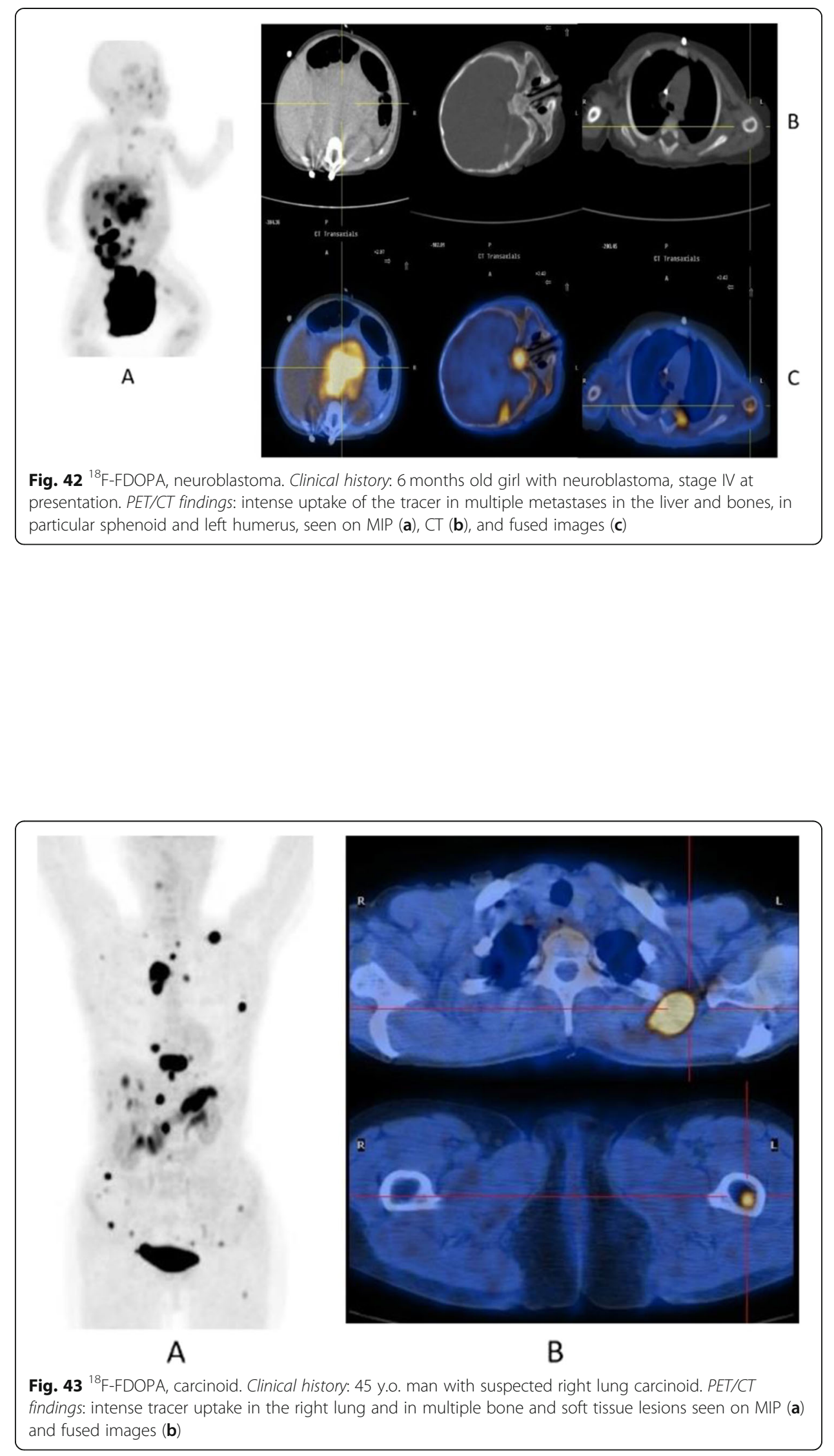

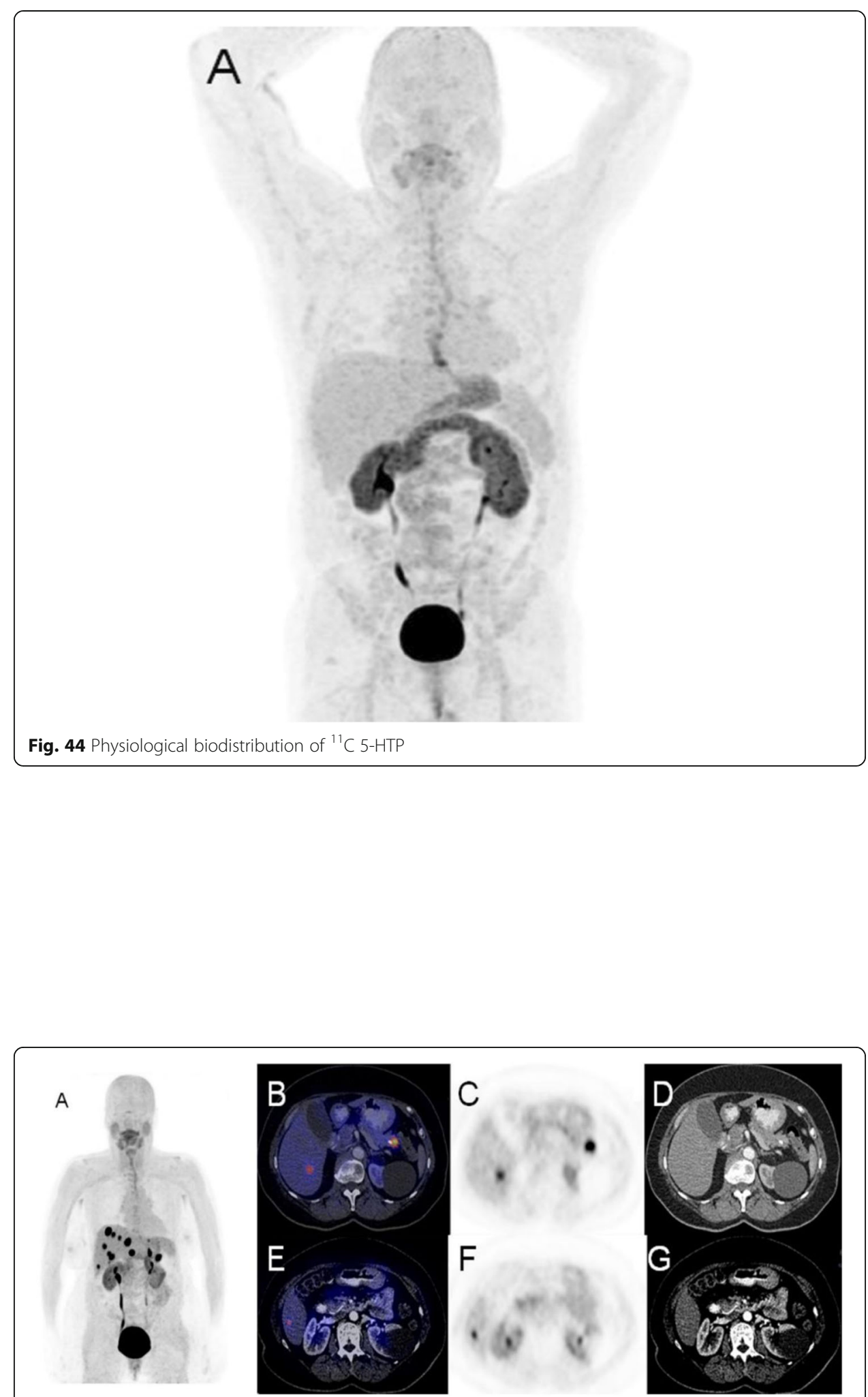

Fig. $45{ }^{11} \mathrm{C}$ 5-HTP NET of the pancreas, staging. Clinical history: 65 y.o. woman with pancreatic NET, metastatic to liver. PET/CT findings: MIP (a) showing multiple sites of intense tracer accumulation in the upper abdomen. Fused images of PET with diagnostic CT (b, e), PET only (c, f), and CT only $(\mathbf{d}, \mathbf{g})$ showing intense tracer accumulation in a lesion in the cauda of the pancreas, with vague contrast enhancement and a calcification on the CT as well as in liver metastases (b-d) 

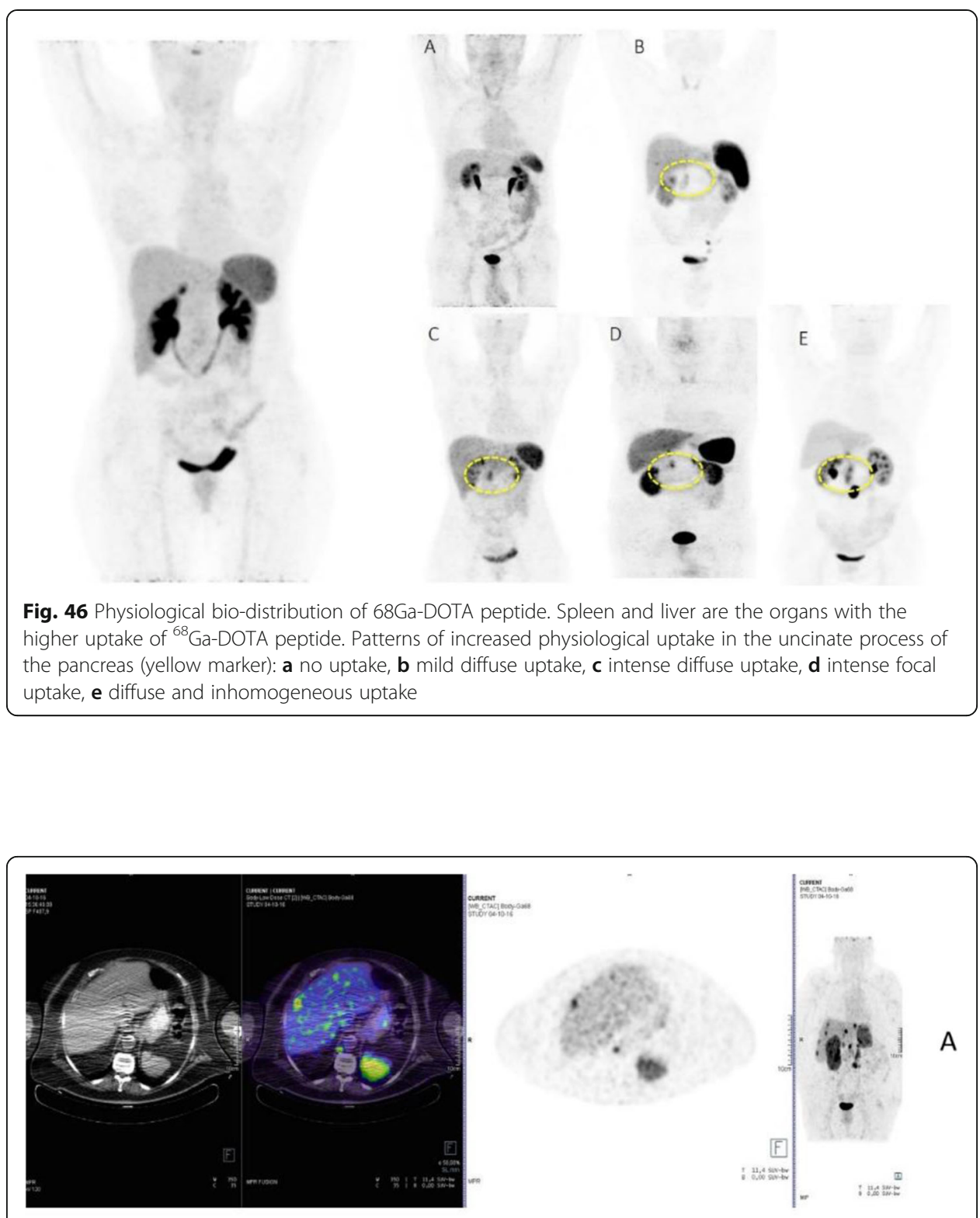

A
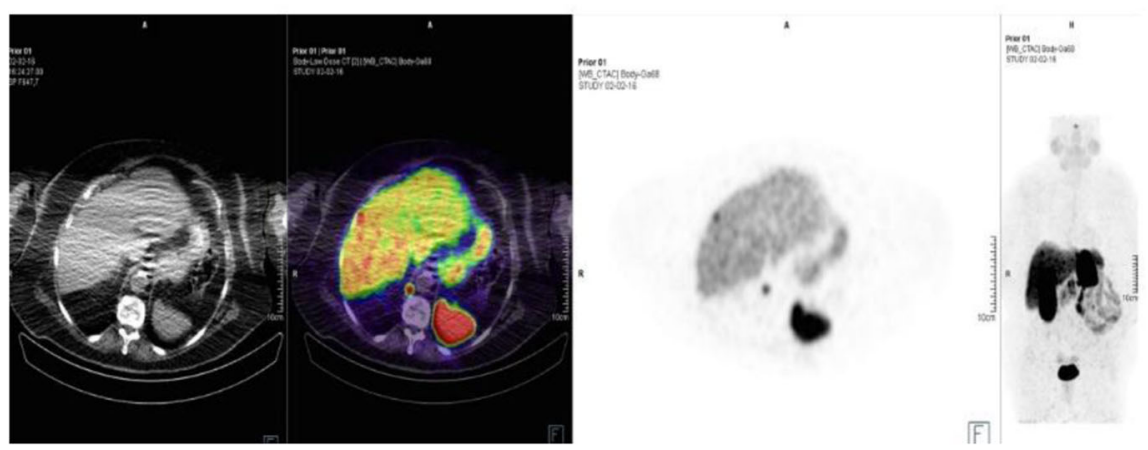

Fig. $\mathbf{4 7}{ }^{68} \mathrm{Ga}$-DOTA peptide, follow-up of NET, comparison ${ }^{68} \mathrm{Ga-DOTANOC},{ }^{68} \mathrm{Ga}$-DOTATATE. Clinical history: 68 y.o. woman with midgut NET and liver metastases treated with octreotide. PET/CT findings: ${ }^{68} \mathrm{Ga}-$ DOTANOC (a) and ${ }^{68} \mathrm{Ga}$-DOTATATE (b) performed 8 months apart show similar uptake in the metastatic lesions, but due to the higher liver ${ }^{68} \mathrm{Ga}$-DOTATATE uptake, more metastases are identified in the ${ }^{68}$ Ga-DOTANOC study 


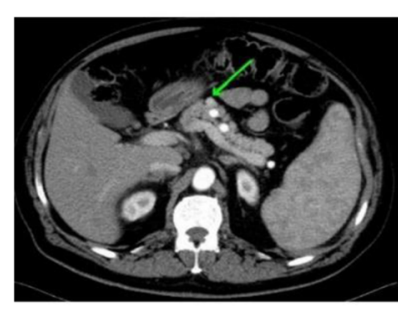

A

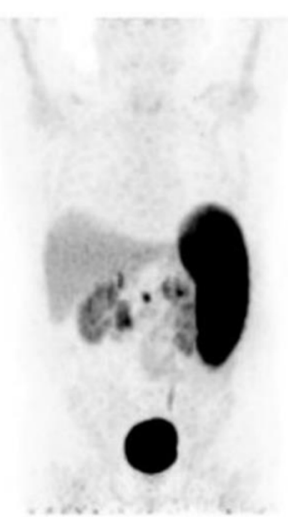

B

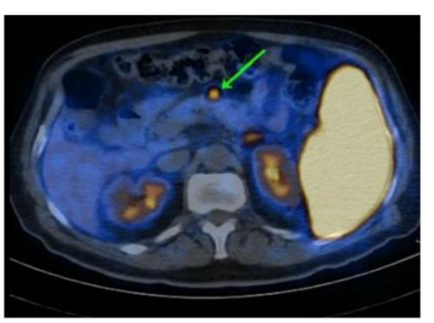

C

Fig. $48{ }^{68} \mathrm{Ga}$-DOTA peptide, suspected lesion of the pancreas, specificity. Clinical history: 50 y.o. woman; a hypervascular lesion in the pancreas was incidentally found on CT (a). PET/CT findings: focal area of high expression of somatostatin receptor analogues in the pancreas corresponding to the $\mathrm{CT}$ finding (b MIP, $\mathbf{c}$ fused). Surgery confirmed the presence of a well differentiated neuroendocrine tumour (Ki67 2\%)

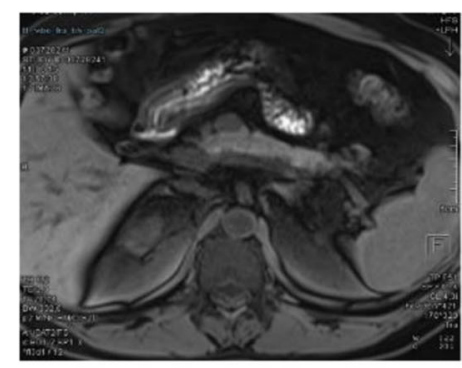

A

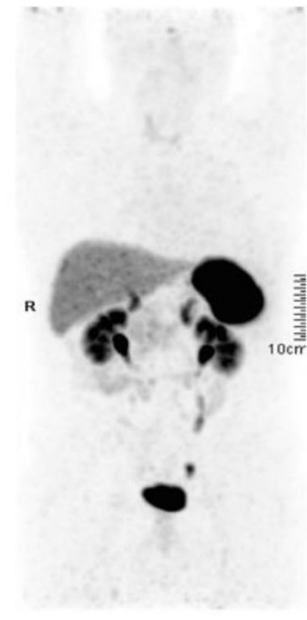

B
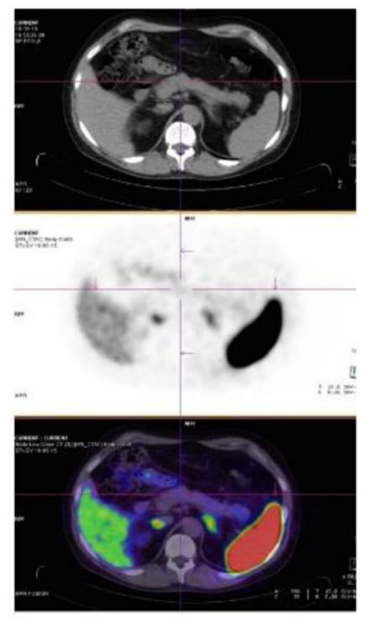

C

Fig. $49{ }^{68} \mathrm{Ga}$-DOTA peptide, suspected lesion of the pancreas, false negative. Clinical history: 48 y.o. man with lesion in the pancreatic body (a MRI). Clinical suspicion of insulinoma (hypoglycaemias). PET/CT findings: no uptake in the lesion (b MIP, c CT, PET, and fused images). The patient underwent surgery, which confirmed the presence of an insulinoma (frequently false negative with ${ }^{68} \mathrm{Ga}$-DOTA peptide) 

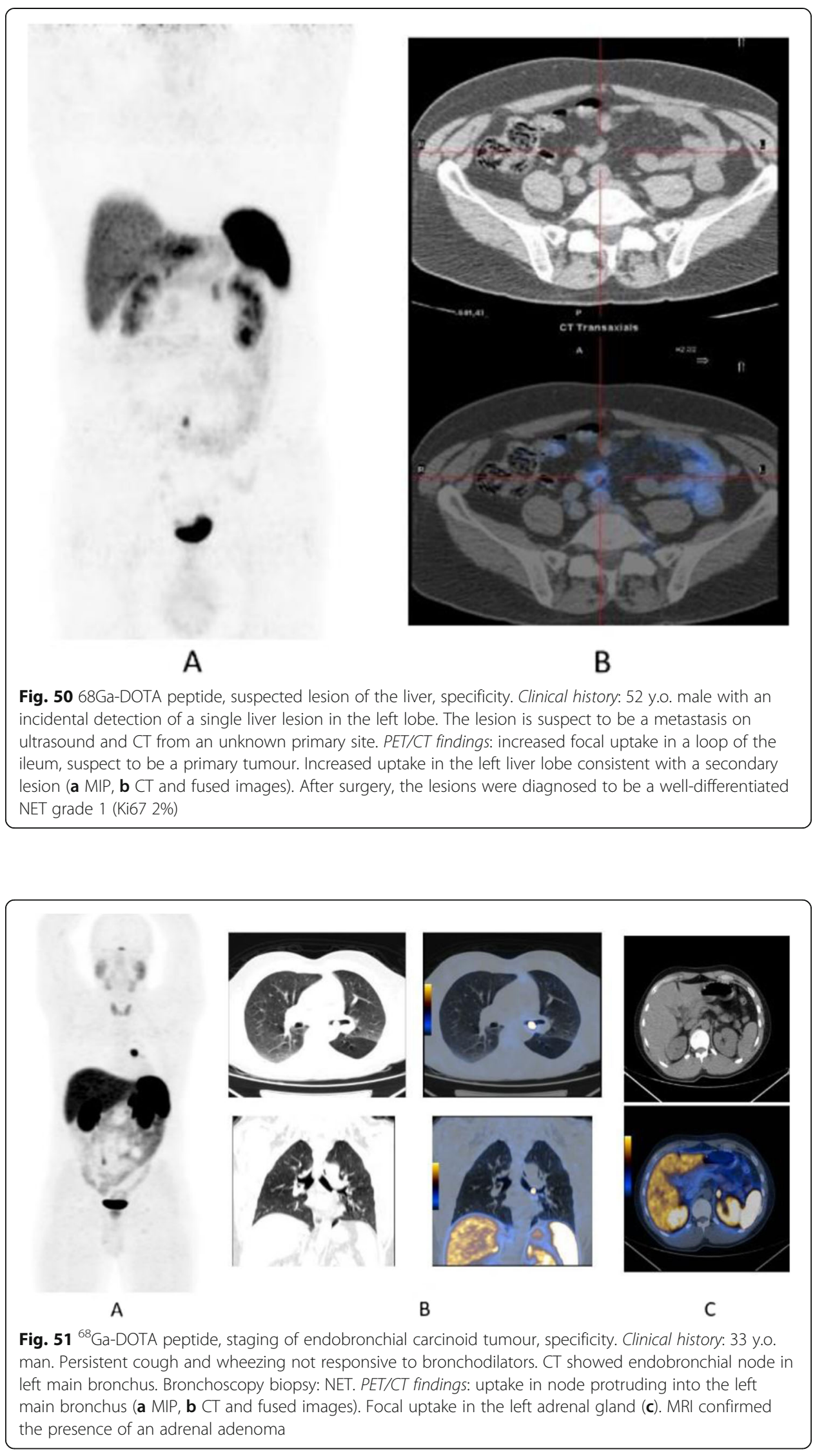


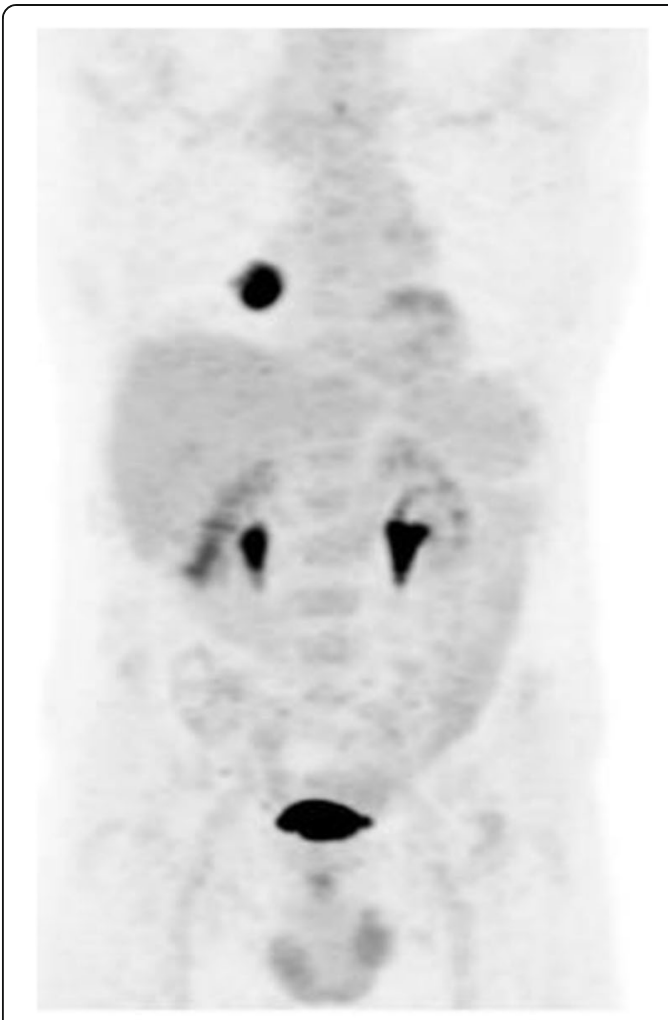

A

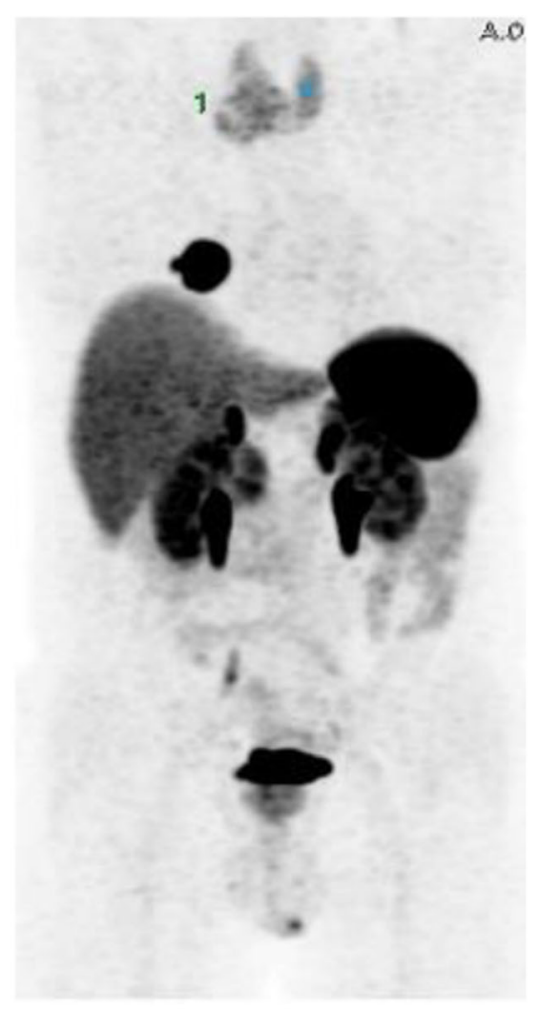

B

Fig. $52{ }^{68} \mathrm{Ga}$-DOTA peptide, staging of NET lung primary, comparison with FDG. Clinical history: 65 y.o. man. Staging of a lung mass with FDG PET and biopsy indicated a moderately differentiated NET (grade 2, Ki67 $8 \%$ ). Consequently, the patient underwent a second PET using ${ }^{68} \mathrm{Ga}$-DOTANOC to stage the disease more accurately. PET/CT findings: increased focal uptake in FDG PET in the right lung, without any other findings (a MIP). ${ }^{68} \mathrm{Ga}$-DOTANOC showed intense uptake in the lung and in the thyroid due to a known De Quervain thyroiditis (b MIP)

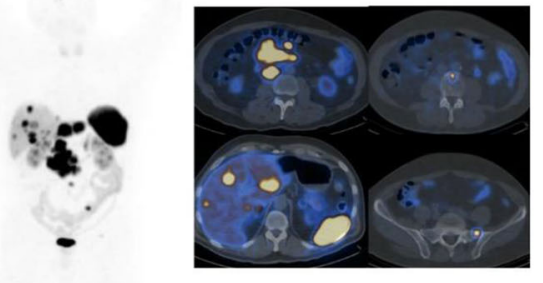

A
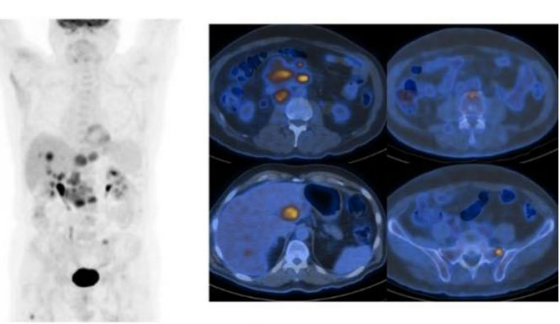

B

Fig. $\mathbf{5 3}{ }^{68} \mathrm{Ga}$-DOTA peptide, staging NET of the pancreas, comparison with FDG. Clinical history: 68 y.o. man with moderately differentiated multi-metastatic NET of pancreas (Ki67 8\%). PET/CT findings: ${ }^{68} \mathrm{Ga}$-DOTANOC PET/CT shows intense pathologic uptake of somatostatin receptor analogue by the known pancreatic tumour, as well as in lymph nodes, multiple liver lesions, and previously unknown bone lesions (a). FDGPET/CT confirms pathologic uptake of the tracer in pancreas and lymph nodes and in some of the known liver and bone lesions (b) 


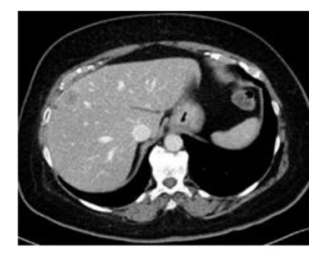

A

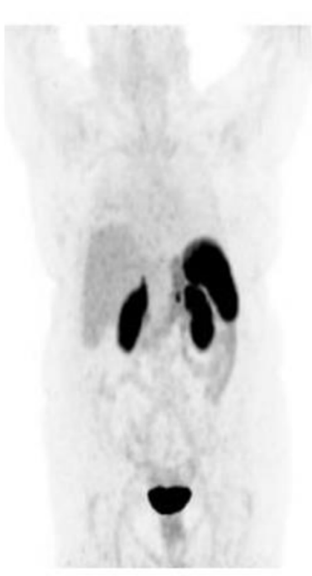

B

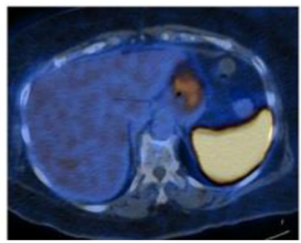

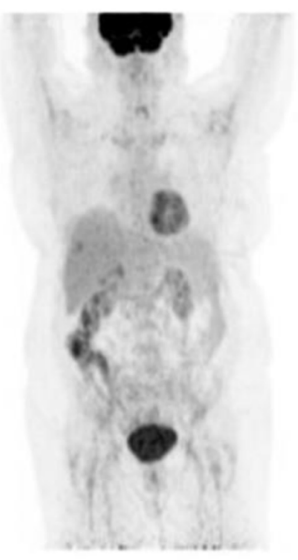

C

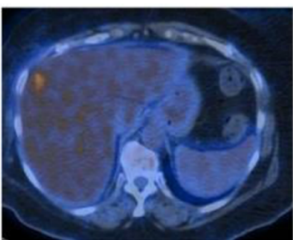

Fig. 54 68Ga-DOTA peptide, NET of the pancreas, suspicion of relapse, comparison with FDG. Clinical history: 63 y.o. man with known well differentiated pancreatic NET (Ki67:2\%); routine follow-up CT detected a suspicious lesion in the liver (a); PET/CT was requested to restage the patient. PET/CT findings: ${ }^{68} \mathrm{Ga}-$ DOTANOC PET/CT shows only physiological uptake of somatostatin receptor analogue (b MIP and fused PET/CT). FDG-PET/CT shows a mild pathologic uptake of the tracer in the liver and confirms liver involvement (c MIP and fused PET/CT)

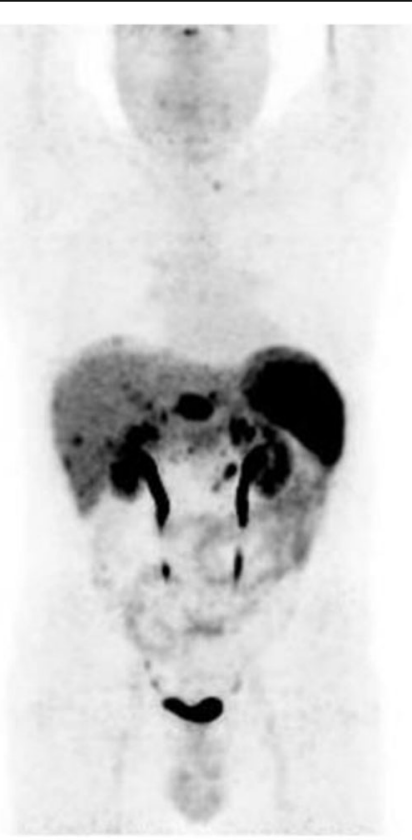

A

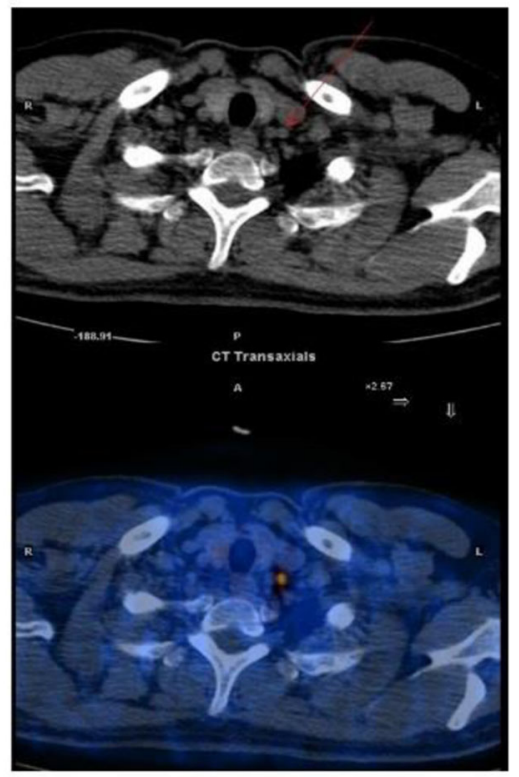

B

Fig. $55{ }^{68} \mathrm{Ga}$-DOTA peptide, staging NET of the pancreas, sensitivity. Clinical history: 60 y.o. man. Incidental finding of a NET of the pancreas grade 2 (Ki67 5\%). PET/CT findings: multiple areas of increased tracer uptake in the pancreas, liver, and abdominal lymph nodes (a MIP). Note the uptake in a left supraclavicular lymph node $5 \mathrm{~mm}$ in size (b CT and fused images) 

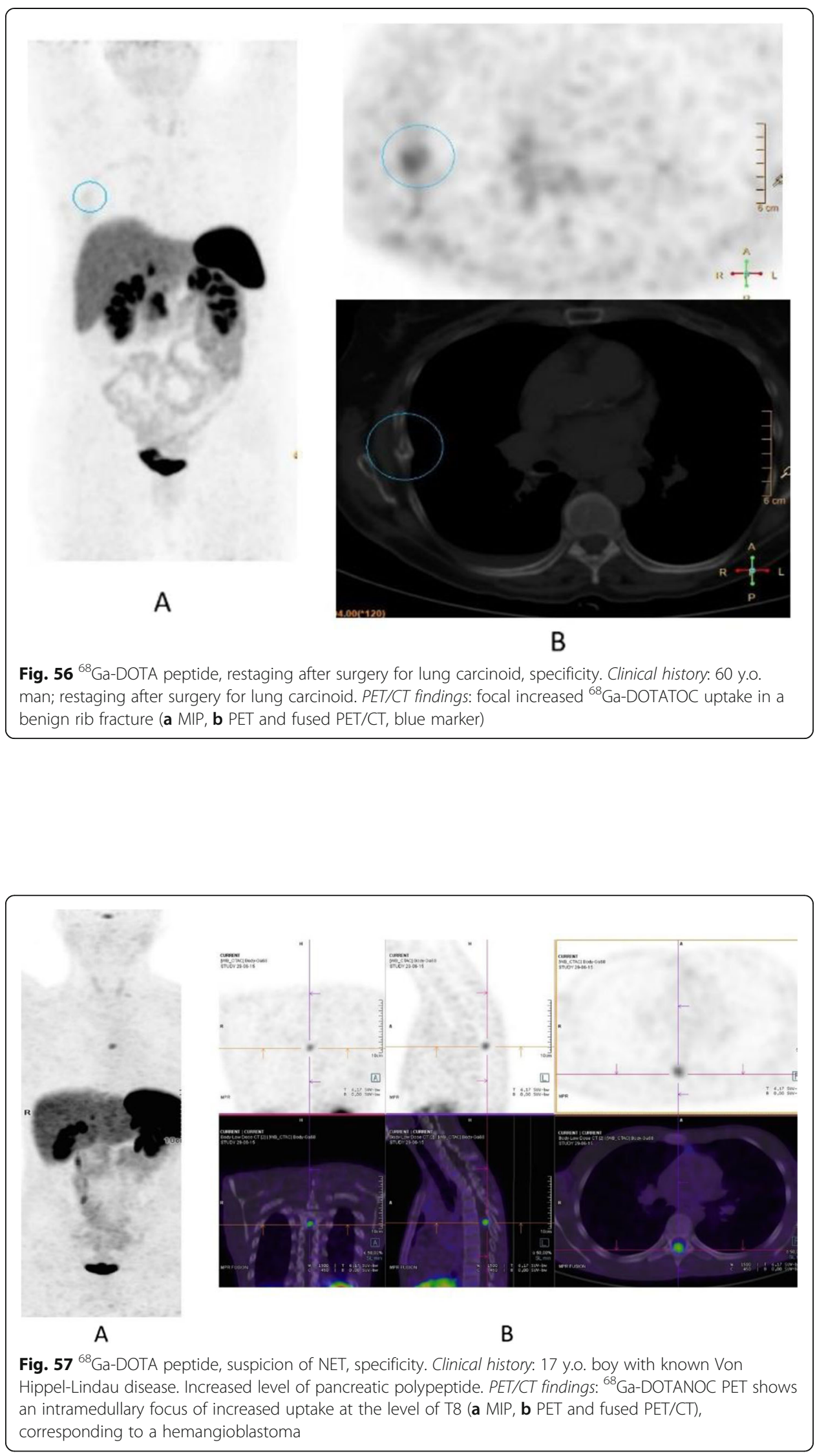


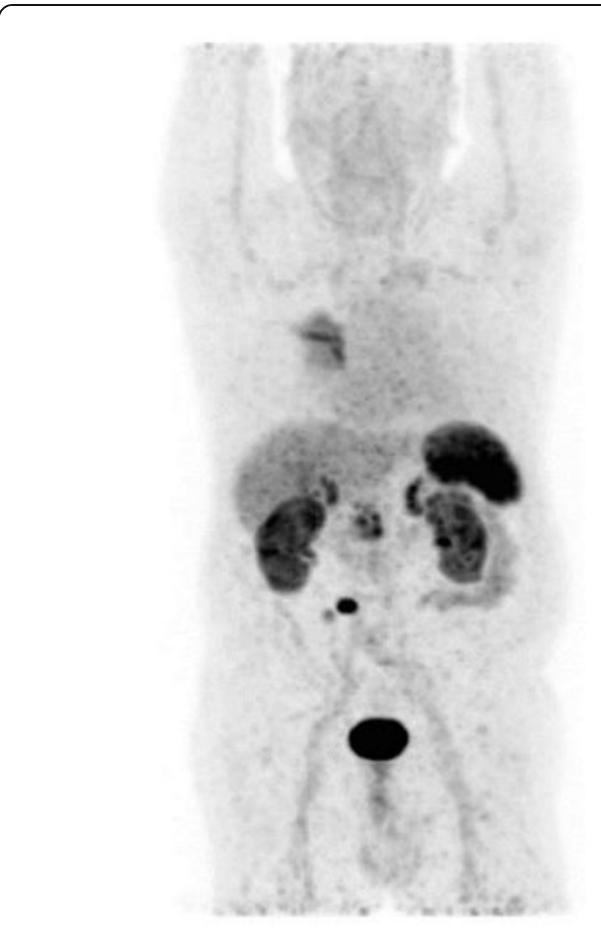

A
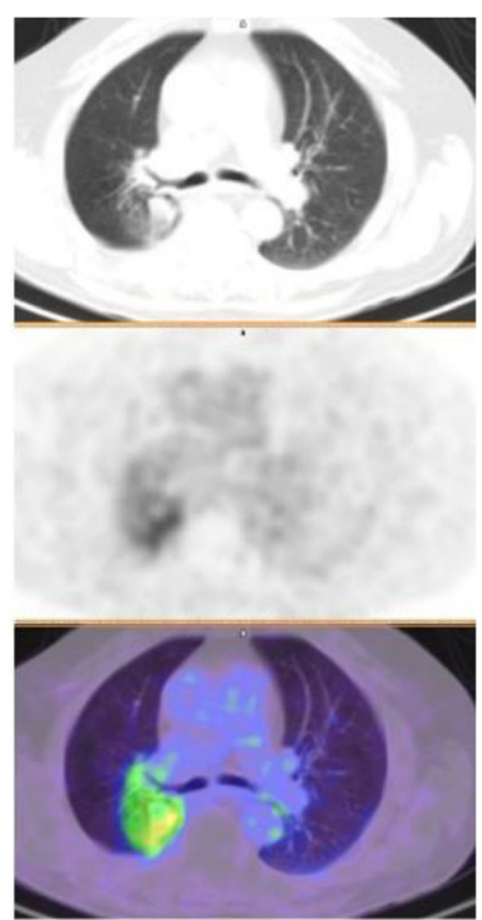

B

Fig. $58{ }^{68} \mathrm{Ga}$-DOTA peptide, follow-up of midgut NET, specificity. Clinical history: 69 y.o. woman with NET treated by surgery the year before. Right upper lobe lung adenocarcinoma treated by chemo- and radiation therapy 4 years prior. PET/CT findings: in addition to multifocal recurrent disease (a MIP), ${ }^{68} \mathrm{Ga}$-DOTANOC PET shows moderately increased uptake in the previously irradiated lung parenchyma (b)
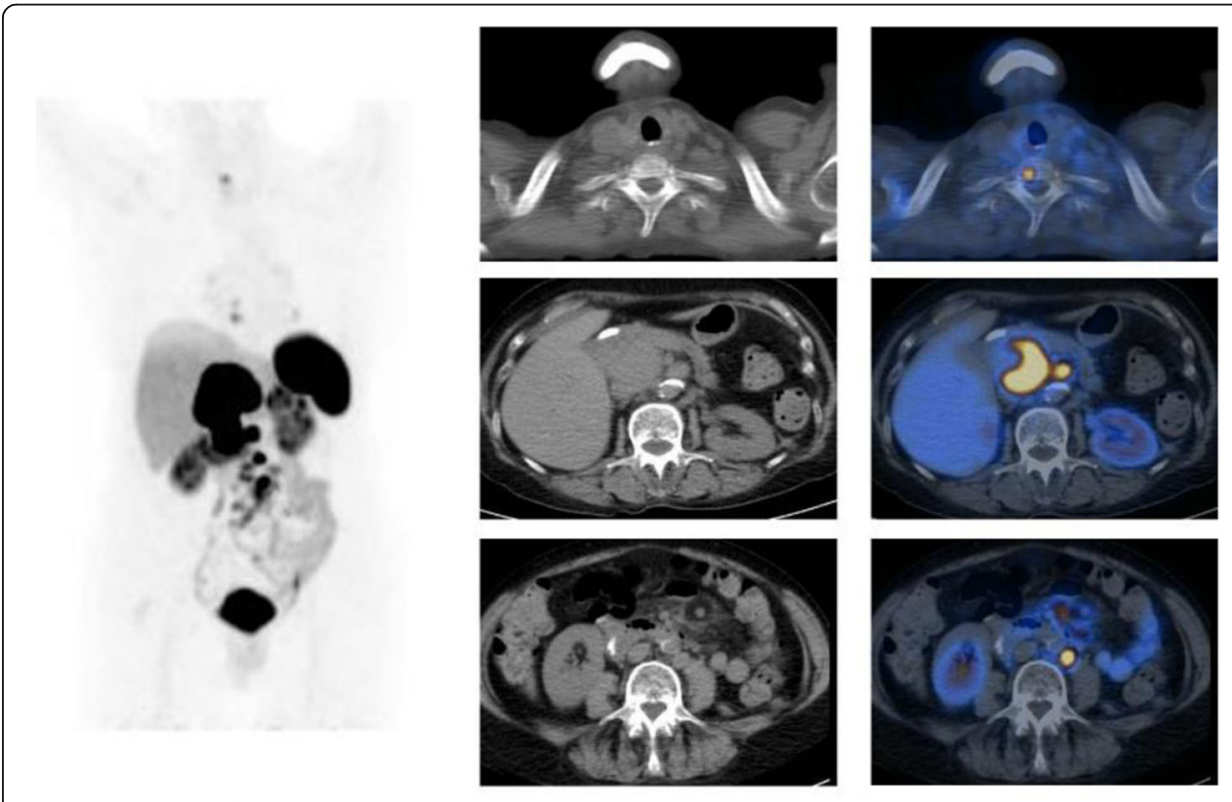

A

B
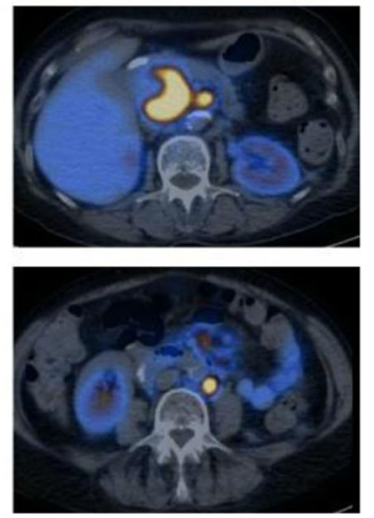

Fig. $59{ }^{68} \mathrm{Ga}$-DOTA peptide, staging NET of the pancreas, sensitivity. Clinical history: 54 y.o. man with known pancreatic NET, candidate for surgery. PET/CT findings: very high uptake in the known pancreatic lesion and as well as in previously unknown lymph nodes and bone lesions (a MIP, b CT and fused imaging) 

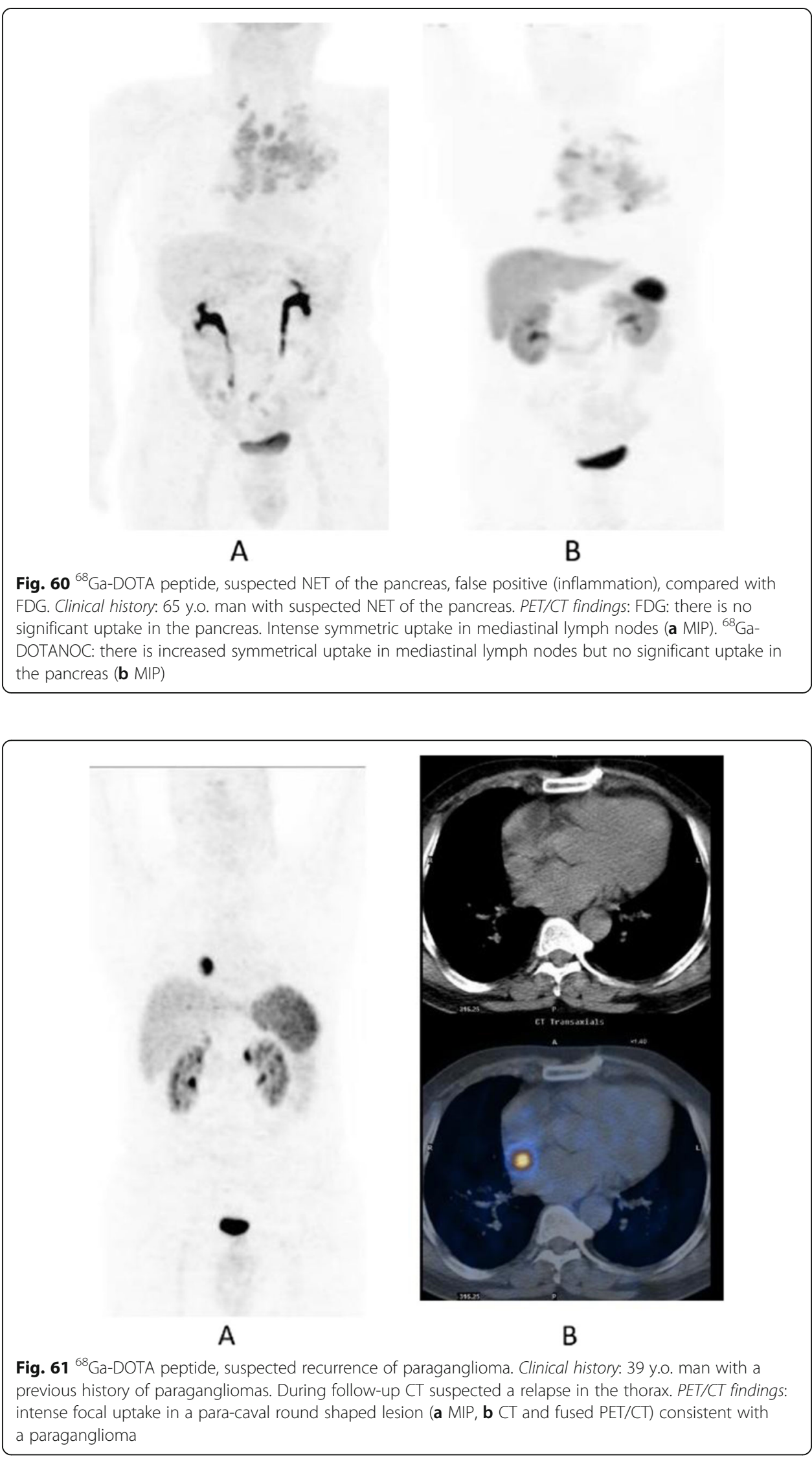

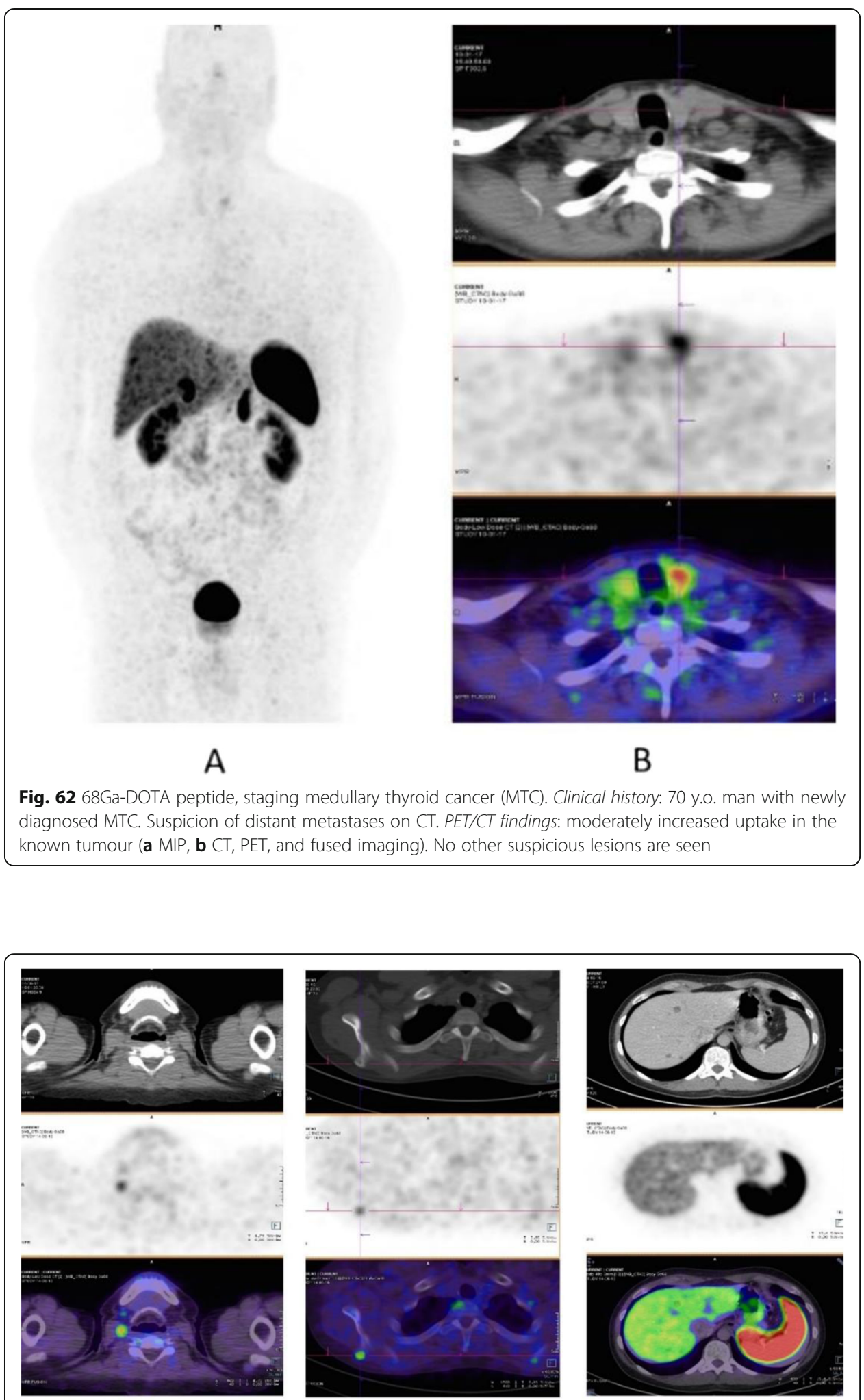

A

B

C

Fig. $63{ }^{68} \mathrm{Ga}$-DOTA peptide, recurrent medullary thyroid cancer (MTC). Clinical history: 56 y.o. man with previous history of MTC, treated by surgery. Progressive increase in calcitonin (TCT $=19200)$. PET/CT findings: increased uptake in cervical LN (a) and bone lesion (b right scapula). Additional hepatic metastases are seen on the diagnostic $C T$, but due to the high background they are not evident on PET images (c) 
A

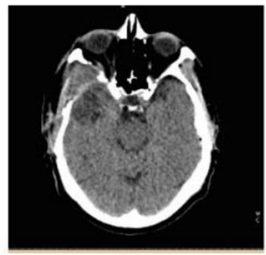

B

mace
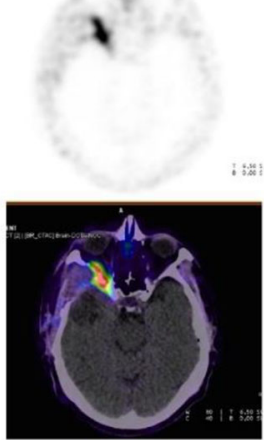

D

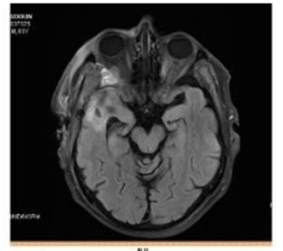

$\sin$
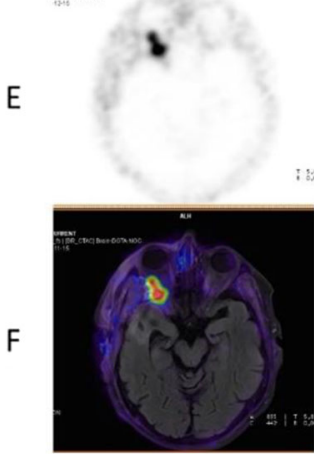

$\mathrm{H}$

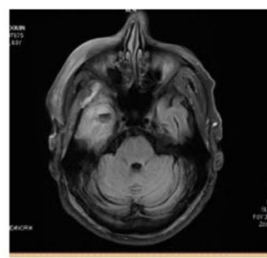

I
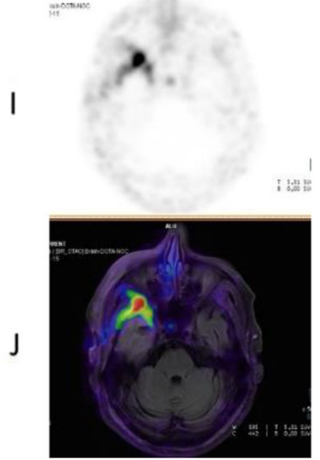

Fig. $64{ }^{68} \mathrm{Ga}$-DOTA peptide, meningioma. Clinical history: 70 y.o. man with meningioma of the skull basis. PET/CT findings: ${ }^{68} \mathrm{Ga}$-DOTATATE shows highly increased uptake in the right sphenoidal bone area with an extension to the orbital cavity, corresponding to the meningioma ( $\mathbf{a} C T ; \mathbf{d}, \mathbf{h} \mathrm{MRI} ; \mathbf{d}, \mathbf{e}, \mathbf{i} \mathrm{PET} ; \mathbf{c}$ fused PET/ $C T ; \mathbf{f}, \mathbf{j}$ fused PET and MRI)

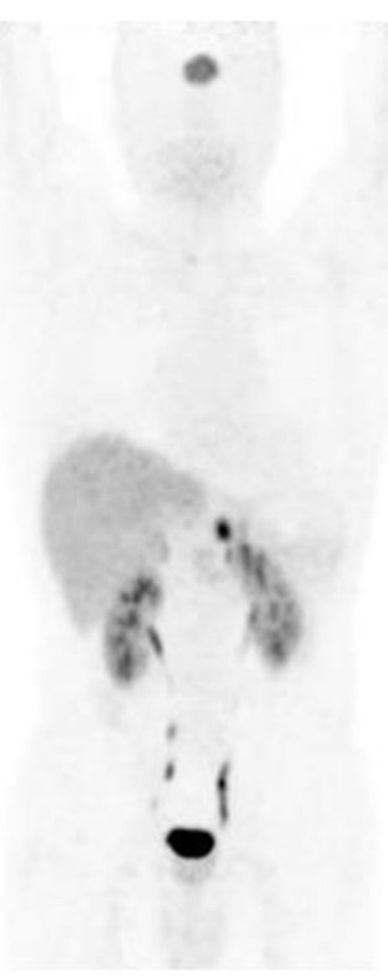

A

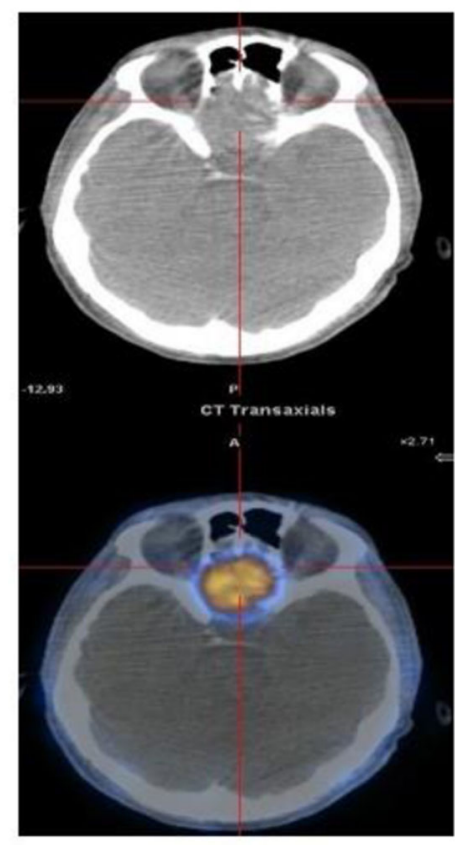

B

Fig. $65{ }^{68} \mathrm{Ga}$-DOTA peptide, meningioma. Clinical history: 57 y.o. woman with history of a NET of the tail of the pancreas (grade 1) treated with surgery. Suspect relapse in a peripancreatic lymph node. PET/CT findings: increased uptake in a peripancreatic lymph node consistent with relapse (a MIP). Intense uptake in a large lesion in the base of the cranium consistent with a meningioma (b CT and fused imaging) 


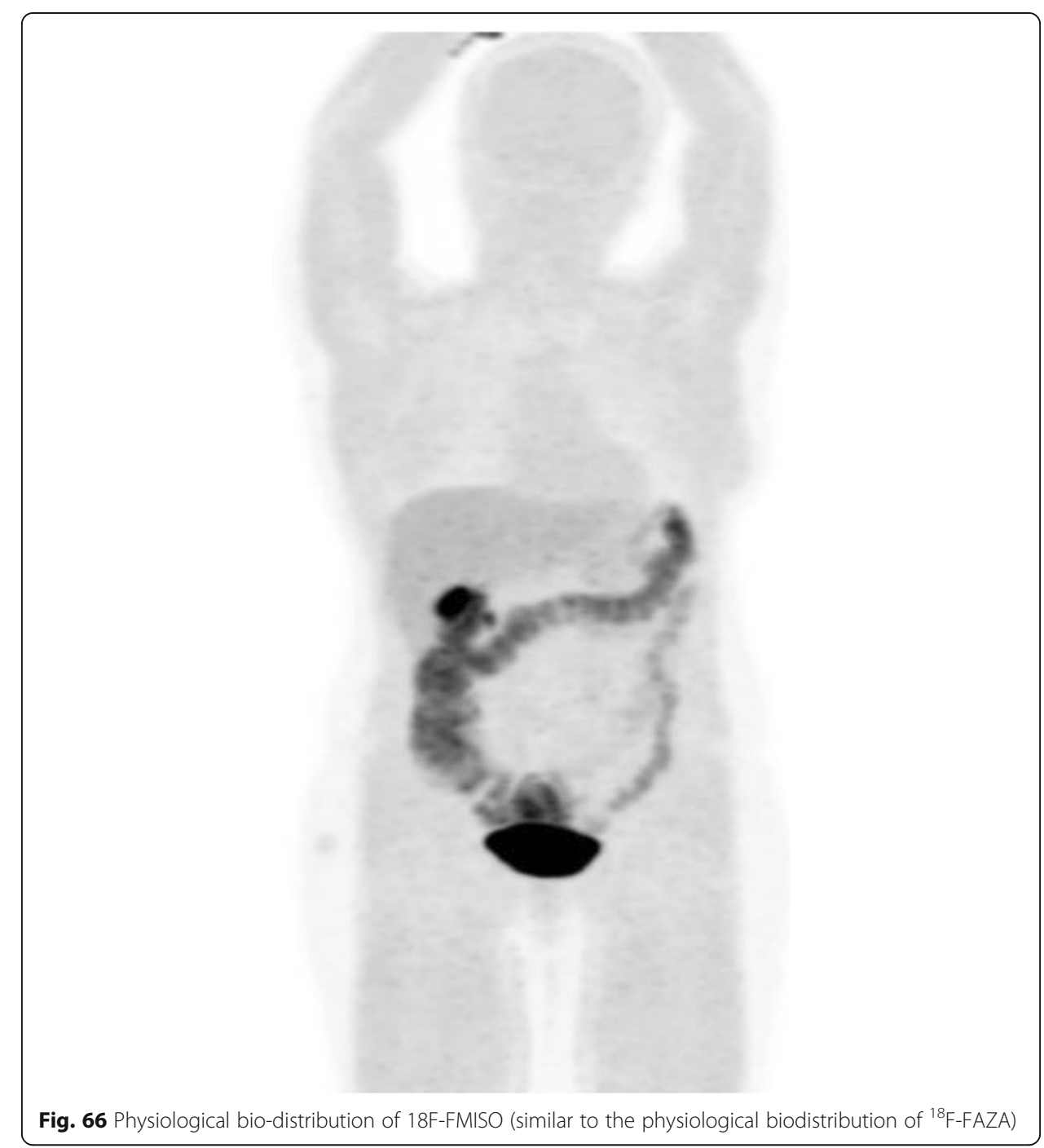

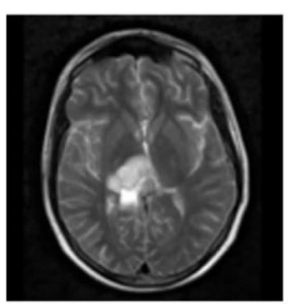

A

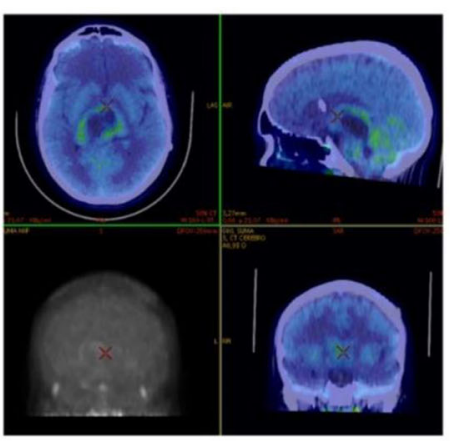

B

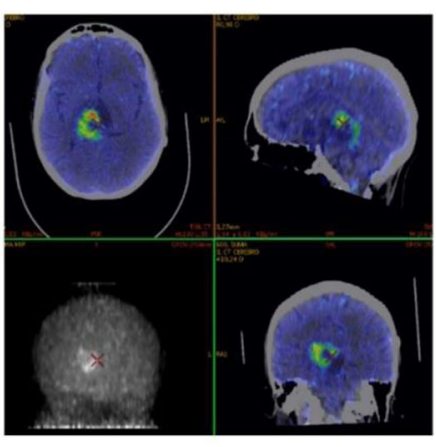

C

Fig. $67{ }^{18} \mathrm{~F}$-FMISO, characterisation of a brain lesion and comparison to ${ }^{11} \mathrm{C}$-methionine. Clinical history: 15 y.o. boy. High-grade glioblastoma, sub-totally removed and treated with radiotherapy. MRl: persistence of expansive lesion in thalamic area (a). PET/CT findings: ${ }^{11} \mathrm{C}$-methionine shows peripheral uptake in the right thalamus tumour, probably related to residual viable tumour or relapse despite its low intensity (b). ${ }^{18} \mathrm{~F}$ FMISO PET/CT showed hypoxic area in previously methionine uptake described lesion (c), suggesting a relapse 

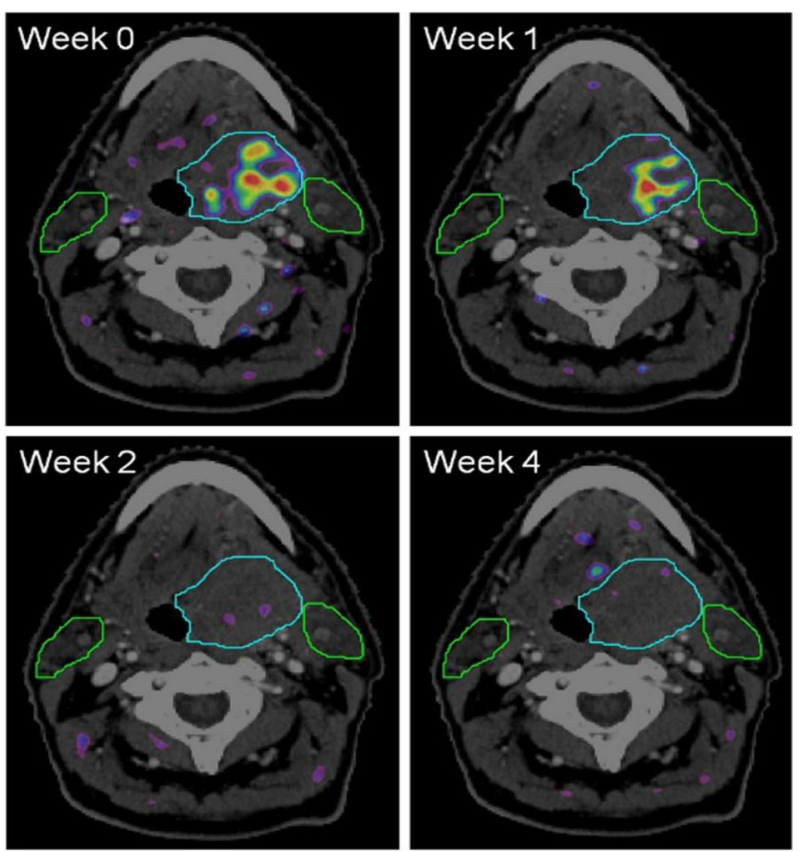

Fig. $68{ }^{18} \mathrm{~F}-\mathrm{FAZA}$, therapy evaluation of a brain lesion. PET/CT findings: four FAZA-PET-CT scans made at different weeks prior (week 0) and during (week 1, 2, and 4) the course of chemoradiation. The rainbow colours depict the amount of FAZA uptake. The light blue line depicts the extent of the primary tumour situated in the base of tongue. The green lines depict the extent of the parotid glands (left and right). Note that in week 2 and 4 no increased FAZA uptake is visible any more, demonstrating that the hypoxic area in week 0 and 1 disappeared

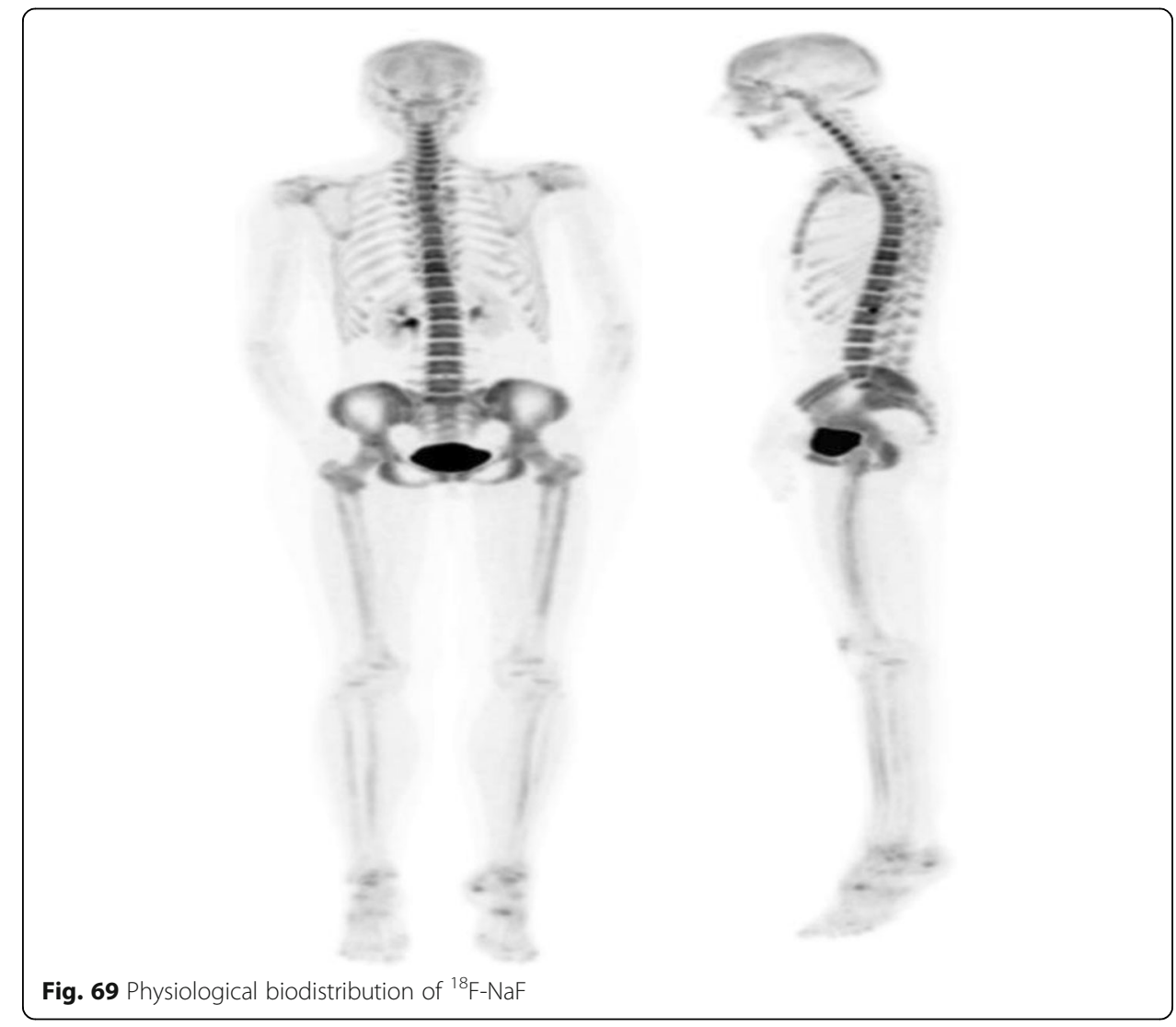




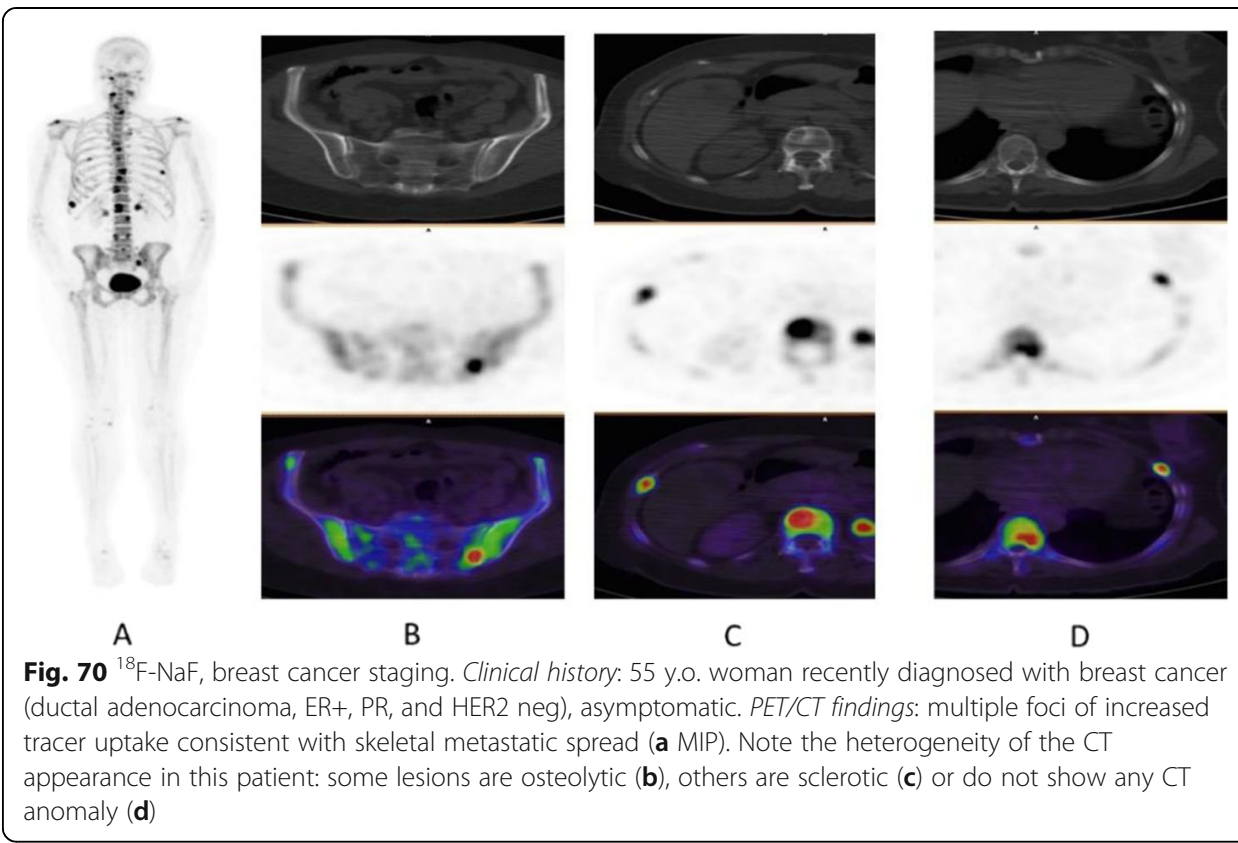

\section{FAZA}

Names: 1-(5- $\left[{ }^{18} \mathrm{~F}\right]$ Fluoro-5-deoxy- $\alpha$-D-arabinofuranosyl)-2-Nitroimidazole; ${ }^{18} \mathrm{~F}$-FAZA Biodistribution and metabolism (Fig. 66)

F-18 FAZA is a 2-nitroimidazole compound (reduced in hypoxic cellular media) with a sugar addition moiety showing more water solubility and better pharmacokinetics compared to ${ }^{18}$ F-FMISO (Zips et al. 2012; Bollineni et al. 2013; Bollineni et al. 2014).

\section{Scan acquisition}

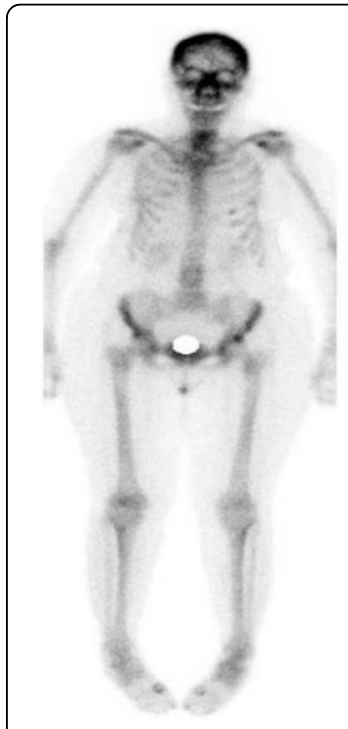

A

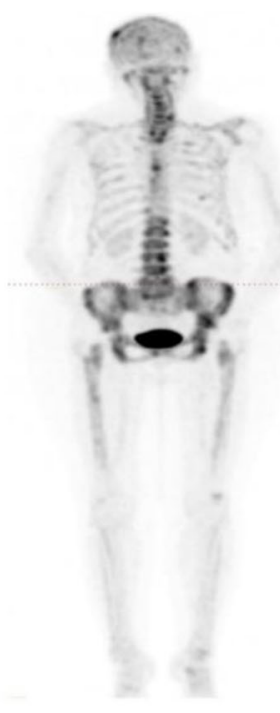

B

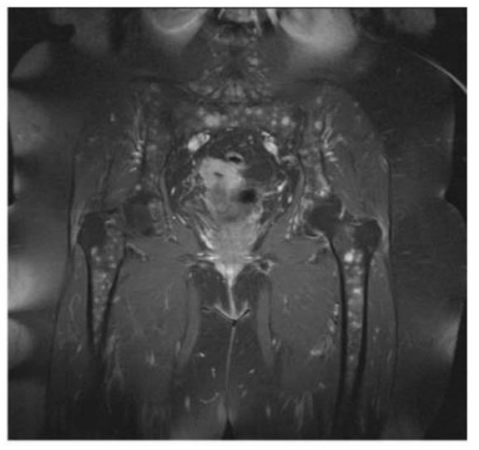

C

Fig. 71 18F-NaF, breast cancer restaging. Clinical history: 72 y.o. woman with history of breast cancer (infiltrating ductal carcinoma, ER+, PR, and HER2 neg). Diffuse bone pain, no evidence of bone metastases on bone scintigraphy (a anterior view). PET/CT findings: highly heterogeneous uptake in the cranium, spine, pelvic grid and femurs, consistent with bone marrow involvement (b MIP). MRI confirms multiple small sized lesions $(\mathbf{c})$ 
- No special diet is required

- $370 \mathrm{MBq}$ of ${ }^{18} \mathrm{~F}$-FAZA iv

- Uptake time $2 \mathrm{~h}$

Clinical indications in oncology (Fig. 68)

The indications are similar to ${ }^{18} \mathrm{~F}$-FMISO (Reischl et al. 2007; Wack et al. 2015; Zips et al. 2012).

NAF

Names: $\left[{ }^{18} \mathrm{~F}\right]$-Sodium fluoride; ${ }^{18} \mathrm{~F}-\mathrm{NaF}$

Biodistribution and metabolism (Fig. 69)

Fluoride ions are deposited in the bone matrix and reflect: bone remodelling and blood flow. The target organ is bone, but approximately $20 \%$ is excreted through the kidney in the urine in the first 1-2 h (Bruine de Bruin et al. 2015; Beheshti et al. 2015).

Scan acquisition

- No special diet is required but good hydration is important

- 50-200 MBq of ${ }^{18} \mathrm{~F}-\mathrm{NaF}$ iv

- Uptake time 20-60 min

Clinical indications in oncology (Figs. 70 and 71)

The indications are those of $99 \mathrm{mTc}$-labelled diphosphonate bone scintigraphy. ${ }^{18} \mathrm{~F}$ $\mathrm{NaF} \mathrm{PET} / \mathrm{CT}$ is more sensitive than bone scintigraphy, for most indications. The choice of PET or SPECT depends on the availability of the radiopharmaceuticals, PET/CT devices, and costs (Lofgren et al. n.d.).

\section{Conclusion}

The constant growth of PET/CT including the increasing use of novel non-FDG PET/ CT radiopharmaceuticals in cancer patients creates a need for training in the proper interpretation of complex imaging studies with compounds that have very different biodistribution, normal variants, and pitfalls. In addition, the use of several of these nonFDG PET radiopharmaceuticals, such as ${ }^{68} \mathrm{Ga}$-PSMA and ${ }^{68} \mathrm{Ga}$-DOTA peptides, constitutes an integral part of the evaluation of patients with cancer for theranostics. As this further increases the radiopharmaceuticals' clinical relevance, there is also the need for accurate interpretation of non-FDG PET/CT studies.

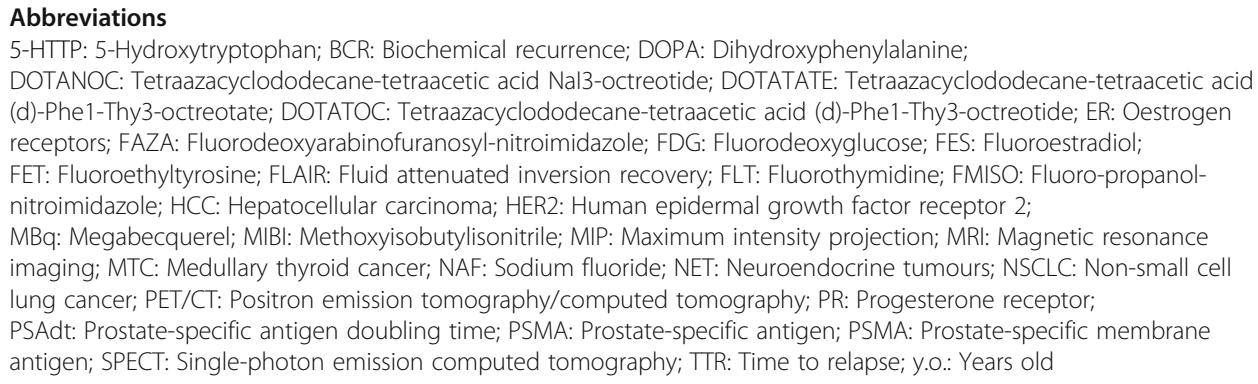


Authors' contributions

All authors contributed equally to the work. All authors read and approved the final manuscript.

Funding

No

Availability of data and materials

Yes (own data and materials)

Ethics approval and consent to participate

Yes

Consent for publication

Yes

Competing interests

The authors declare that they have no competing interests.

\section{Author details}

${ }^{1}$ Department of Nuclear Sciences and Applications, International Atomic Energy Agency, Vienna, Austria. ${ }^{2}$ Department of Nuclear Medicine, Sant'Orsola-Malpighi Hospital, 40138 Bologna, Italy. ${ }^{3}$ Medical Imaging Center, Department of Nuclear Medicine and Molecular Imaging, University Medical Center Groningen, Groningen, The Netherlands. ${ }^{4}$ Department of Nuclear Medicine, Bolzano Hospital, Bolzano, Italy. ${ }^{5}$ Department of Nuclear Medicine, CHU Liège, University of Liège, Liège, Belgium. ${ }^{6}$ Centro Uruguayo de Imagenología Molecular (CUDIM), Montevideo, Uruguay.

Received: 8 August 2019 Accepted: 22 October 2019

Published online: 29 November 2019

\section{References}

Abe K, Hayashi K, Sasaki M, Koga H, Kaneko K, Sawamoto H et al (2006) O-(2-[18F]fluoroethyl)-L-tyrosine (18F-FET) uptake in mouse thymoma cells, and its biodistribution in mice and human volunteers. Acta Radiol 47(10):1042-1048

Addeo P, Poncet G, Goichot B, Leclerc L, Brigand C, Mutter D et al (2018) The added diagnostic value of (18)FFluorodihydroxyphenylalanine PET/CT in the preoperative work-up of small bowel neuroendocrine tumors. J Gastrointest Surg 22(4):722-730

Afshar-Oromieh A, Hetzheim H, Kubler W, Kratochwil C, Giesel FL, Hope TA et al (2016) Radiation dosimetry of (68)Ga-PSMA11 (HBED-CC) and preliminary evaluation of optimal imaging timing. Eur J Nucl Med Mol Imaging 43(9):1611-1620

Albert NL, Weller M, Suchorska B, Galldiks N, Soffietti R, Kim MM et al (2016) Response assessment in neuro-oncology working group and European association for neuro-oncology recommendations for the clinical use of PET imaging in gliomas. Neuro-Oncology 18(9):1199-1208

Amodru V, Guerin C, Delcourt S, Romanet P, Loundou A, Viana B et al (2018) Quantitative (18)F-DOPA PET/CT in pheochromocytoma: the relationship between tumor secretion and its biochemical phenotype. Eur I Nucl Med Mol Imaging 45(2):278-282

Beheshti M, Mottaghy FM, Paycha F, Behrendt FFF, Van den Wyngaert T, Fogelman I et al (2015) (18)F-NaF PET/CT: EANM procedure guidelines for bone imaging. Eur J Nucl Med Mol Imaging 42(11):1767-1777

Bergeret S, Charbit J, Ansquer C, Bera G, Chanson P, Lussey-Lepoutre C (2019) Novel PET tracers: added value for endocrine disorders. Endocrine. 64(1):14-30

Bollineni VR, Kerner GS, Pruim J, Steenbakkers RJ, Wiegman EM, Koole MJ et al (2013) PET imaging of tumor hypoxia using 18F-fluoroazomycin arabinoside in stage III-IV non-small cell lung cancer patients. J Nucl Med 54(8):1175-1180

Bollineni VR, Koole MJ, Pruim J, Brouwer CL, Wiegman EM, Groen HJ et al (2014) Dynamics of tumor hypoxia assessed by 18F-FAZA PET/CT in head and neck and lung cancer patients during chemoradiation: possible implications for radiotherapy treatment planning strategies. Radiother Oncol 113(2):198-203

Bruine de Bruin L, Bollineni VR, Wachters JE, Schuuring E, van Hemel BM, van der Wal JE et al (2015) Assessment of hypoxic subvolumes in laryngeal cancer with (18)F-fluoroazomycinarabinoside ((18)F-FAZA)-PET/CT scanning and immunohistochemistry. Radiother Oncol 117(1):106-112

Calais J, Fendler WP, Eiber M, Gartmann J, Chu Fl, Nickols NG et al (2018) Impact of (68)Ga-PSMA-11 PET/CT on the management of prostate cancer patients with biochemical recurrence. J Nucl Med 59(3):434-441

Chondrogiannis S, Marzola MC, Al-Nahhas A, Venkatanarayana TD, Mazza A, Opocher G et al (2013) Normal biodistribution pattern and physiologic variants of 18F-DOPA PET imaging. Nucl Med Commun 34(12):1141-1149

Davis J, Yano Y, Cahoon J, Budinger TF (1982) Preparation of 11C-methyl iodide and L-[S-methyl-11C]methionine by an automated continuous flow process. Int J Appl Radiat Isot 33(5):363-369

DeGrado TR, Coleman RE, Wang S, Baldwin SW, Orr MD, Robertson CN et al (2001) Synthesis and evaluation of 18F-labeled choline as an oncologic tracer for positron emission tomography: initial findings in prostate cancer. Cancer Res 61(1): 110-117

DeGrado TR, Reiman RE, Price DT, Wang S, Coleman RE (2002) Pharmacokinetics and radiation dosimetry of 18Ffluorocholine. J Nucl Med 43(1):92-96

Deloar HM, Fujiwara T, Nakamura T, Itoh M, Imai D, Miyake M et al (1998) Estimation of internal absorbed dose of L-[methyl$11 \mathrm{Clm}$ methionine using whole-body positron emission tomography. Eur J Nucl Med 25(6):629-633

Demirci E, Sahin OE, Ocak M, Akovali B, Nematyazar J, Kabasakal L (2016) Normal distribution pattern and physiologica variants of 68Ga-PSMA-11 PET/CT imaging. Nucl Med Commun 37(11):1169-1179 
Evangelista L, Guttilla A, Zattoni F, Muzzio PC, Zattoni F (2013) Utility of choline positron emission tomography/computed tomography for lymph node involvement identification in intermediate- to high-risk prostate cancer: a systematic literature review and meta-analysis. Eur Urol 63(6):1040-1048

Fendler WP, Eiber M, Beheshti M, Bomanji J, Ceci F, Cho S et al (2017) (68)Ga-PSMA PET/CT: Joint EANM and SNMMI procedure guideline for prostate cancer imaging: version 1.0. Eur J Nucl Med Mol Imaging 44(6):1014-1024

Gagel B, Reinartz P, Demirel C, Kaiser HJ, Zimny M, Piroth M et al (2006) [18F] fluoromisonidazole and [18F] fluorodeoxyglucose positron emission tomography in response evaluation after chemo-/radiotherapy of non-small-cell lung cancer: a feasibility study. BMC Cancer 6:51

Galldiks N, Stoffels G, Filss C, Rapp M, Blau T, Tscherpel C et al (2015) The use of dynamic O-(2-18F-fluoroethyl)-I-tyrosine PET in the diagnosis of patients with progressive and recurrent glioma. Neuro-Oncology 17(9):1293-1300

Grierson JR, Shields AF (2000) Radiosynthesis of 3'-deoxy-3'-[(18)F]fluorothymidine: [(18)F]FLT for imaging of cellular proliferation in vivo. Nucl Med Biol 27(2):143-156

Hain SF, Maisey MN (2003) Positron emission tomography for urological tumours. BJU Int 92(2):159-164

Harris SM, Davis JC, Snyder SE, Butch ER, Vavere AL, Kocak M et al (2013) Evaluation of the biodistribution of 11C-methionine in children and young adults. J Nucl Med 54(11):1902-1908

Heidenreich A, Bastian PJ, Bellmunt J, Bolla M, Joniau S, van der Kwast T et al (2014) EAU guidelines on prostate cancer. Part II: Treatment of advanced, relapsing, and castration-resistant prostate cancer. Eur Urol 65(2):467-479

Hirata K, Terasaka S, Shiga T, Hattori N, Magota K, Kobayashi H et al (2012) (1)(8)F-Fluoromisonidazole positron emission tomography may differentiate glioblastoma multiforme from less malignant gliomas. Eur J Nucl Med Mol Imaging 39(5): 760-770

Ho CL, Yu SC, Yeung DW (2003) 11C-acetate PET imaging in hepatocellular carcinoma and other liver masses. J Nucl Med 44(2):213-221

Institute NC. Investigator's Brochure for [18F] fluoromisonidazole, 1H-1-(3-[18F]-fluoro-2-hydroxy-propyl)-2-nitro-imidazole, [18F]FMISO. An investigational positron emission tomography (PET) radiopharmaceutical for injection and intended for use as an in vivo diagnostic for imaging hypoxia in tumors. $\mathrm{NIH} ; 5^{\text {th }}$ ed, 2013.

Karanikas G, Beheshti M (2014) (1)(1)C-acetate PET/CT imaging: physiologic uptake, variants, and pitfalls. PET Clin 9(3):339-344

Kenny L, Coombes RC, Vigushin DM, Al-Nahhas A, Shousha S, Aboagye EO (2007) Imaging early changes in proliferation at 1 week post chemotherapy: a pilot study in breast cancer patients with 3'-deoxy-3'-[18F]fluorothymidine positron emission tomography. Eur J Nucl Med Mol Imaging 34(9):1339-1347

Kratochwil C, Bruchertseifer F, Rathke H, Bronzel M, Apostolidis C, Weichert W et al (2017) Targeted alpha-therapy of metastatic castration-resistant prostate cancer with (225)Ac-PSMA-617: dosimetry estimate and empiric dose finding. J Nucl Med 58(10):1624-1631

Kroiss A, Putzer D, Decristoforo C, Uprimny C, Warwitz B, Nilica B et al (2013) 68Ga-DOTA-TOC uptake in neuroendocrine tumour and healthy tissue: differentiation of physiological uptake and pathological processes in PET/CT. Eur J Nucl Med Mol Imaging 40(4):514-523

Kryza D, Tadino V, Filannino MA, Villeret G, Lemoucheux L (2008) Fully automated [18F]fluorocholine synthesis in the TracerLab MX FDG Coincidence synthesizer. Nucl Med Biol 35(2):255-260

Kunz M, Thon N, Eigenbrod S, Hartmann C, Egensperger R, Herms J et al (2011) Hot spots in dynamic (18)FET-PET delineate malignant tumor parts within suspected WHO grade II gliomas. Neuro-Oncology 13(3):307-316

Liao GJ, Clark AS, Schubert EK, Mankoff DA (2016) 18F-Fluoroestradiol PET: current status and potential future clinical applications. J Nucl Med 57(8):1269-1275

Lin Z, Mechalakos J, Nehmeh S, Schoder H, Lee N, Humm J et al (2008) The influence of changes in tumor hypoxia on dosepainting treatment plans based on 18F-FMISO positron emission tomography. Int J Radiat Oncol Biol Phys 70(4):1219-1228

Linden HM, Kurland BF, Peterson LM, Schubert EK, Gralow JR, Specht JM et al (2011) Fluoroestradiol positron emission tomography reveals differences in pharmacodynamics of aromatase inhibitors, tamoxifen, and fulvestrant in patients with metastatic breast cancer. Clin Cancer Res 17(14):4799-4805

Liu RS, Chang CP, Chu LS, Chu YK, Hsieh HJ, Chang CW et al (2006) PET imaging of brain astrocytoma with 1-11C-acetate. Eur J Nucl Med Mol Imaging 33(4):420-427

Löfgren J, Mortensen J, Rasmussen SH, Madsen C, Loft A, Hansen AE, Oturai P, Jensen KE, Mørk ML, Reichkendler M, Højgaard L, Fischer BM. A Prospective Study Comparing 99mTc-Hydroxyethylene-Diphosphonate Planar Bone Scintigraphy and Whole-Body SPECT/CT with 18F-Fluoride PET/CT and 18F-Fluoride PET/MRI for Diagnosing Bone Metastases. J Nucl Med. 2017:58(11):1778-85.

Lopci E, Grassi I, Chiti A, Nanni C, Cicoria G, Toschi L et al (2014) PET radiopharmaceuticals for imaging of tumor hypoxia: a review of the evidence. Am J Nucl Med Mol Imaging 4(4):365-384

Maurer T, Gschwend JE, Rauscher I, Souvatzoglou M, Haller B, Weirich G et al (2016) Diagnostic efficacy of (68)Gallium-PSMA positron emission tomography compared to conventional imaging for lymph node sStaging of 130 consecutive patients with intermediate to high risk prostate cancer. J Urol 195(5):1436-1443

Mitterhauser M, Wadsak W, Krcal A, Schmaljohann J, Eidherr H, Schmid A et al (2005) New aspects on the preparation of [11C]Methionine--a simple and fast online approach without preparative HPLC. Appl Radiat Isot 62(3):441-445

Mottet N, Bellmunt J, Bolla M, Joniau S, Mason M, Matveev V et al (2011) EAU guidelines on prostate cancer. Part II: Treatment of advanced, relapsing, and castration-resistant prostate cancer. Eur Urol 59(4):572-583

Neels OC, Jager PL, Koopmans KP, Eriks E, de Vries EG, Kema IP et al (2006) Development of a reliable remote-controlled synthesis of $\beta$-[1 1C]-5-hydroxy-L-tryptophan on a Zymark robotic system. J Lab Compounds Radiopharmaceuticals 49(10):889-895

Nehmeh SA, Lee NY, Schroder H, Squire O, Zanzonico PB, Erdi YE et al (2008) Reproducibility of intratumor distribution of (18)F-fluoromisonidazole in head and neck cancer. Int J Radiat Oncol Biol Phys 70(1):235-242

Oh SJ, Mosdzianowski C, Chi DY, Kim JY, Kang SH, Ryu JS et al (2004) Fully automated synthesis system of 3'-deoxy-3'[18F]fluorothymidine. Nucl Med Biol 31(6):803-809

Orlefors H, Sundin A, Garske U, Juhlin C, Oberg K, Skogseid B et al (2005) Whole-body 11C-5-hydroxytryptophan positron emission tomography as a universal imaging technique for neuroendocrine tumors: comparison with somatostatin receptor scintigraphy and computed tomography. J Clin Endocrinol Metab 90(6):3392-3400 
Park JW, Kim JH, Kim SK, Kang KW, Park KW, Choi Jl et al (2008) A prospective evaluation of 18F-FDG and 11C-acetate PET/CT for detection of primary and metastatic hepatocellular carcinoma. J Nucl Med 49(12):1912-1921

Peterson LM, Kurland BF, Link JM, Schubert EK, Stekhova S, Linden HM et al (2011) Factors influencing the uptake of 18Ffluoroestradiol in patients with estrogen receptor positive breast cancer. Nucl Med Biol 38(7):969-978

Piccardo A, Lopci E, Conte M, Garaventa A, Foppiani L, Altrinetti V et al (2012) Comparison of 18F-dopa PET/CT and 1231MIBG scintigraphy in stage 3 and 4 neuroblastoma: a pilot study. Eur J Nucl Med Mol Imaging 39(1):57-71

Poulsen SH, Urup T, Grunnet K, Christensen IJ, Larsen VA, Jensen ML et al (2017) The prognostic value of FET PET at radiotherapy planning in newly diagnosed glioblastoma. Eur J Nucl Med Mol Imaging 44(3):373-381

Rahbar K, Ahmadzadehfar H, Kratochwil C, Haberkorn U, Schafers M, Essler M et al (2017) German multicenter study investigating 177Lu-PSMA-617 radioligand therapy in advanced prostate cancer patients. J Nucl Med 58(1):85-90

Reischl G, Dorow DS, Cullinane C, Katsifis A, Roselt P, Binns D et al (2007) Imaging of tumor hypoxia with [1241]IAZA in comparison with [18F]FMISO and [18F]FAZA--first small animal PET results. J Pharm Pharm Sci 10(2):203-211

Sandblom G, Sorensen J, Lundin N, Haggman M, Malmstrom PU (2006) Positron emission tomography with C11-acetate for tumor detection and localization in patients with prostate-specific antigen relapse after radical prostatectomy. Urology. 67(5):996-1000

Schneider B, Zhu H, Ma X, Cheng Z, lagaru A, Kopka K et al (2016) Preparation and chemical analysis of clinical-grade 68GaPSMA-HBED-CC, an emerging tracer for imaging of prostate cancers. J Nucl Med 57(supplement 2):1117

Seltzer MA, Jahan SA, Sparks R, Stout DB, Satyamurthy N, Dahlbom M et al (2004) Radiation dose estimates in humans for (11)C-acetate whole-body PET. J Nucl Med 45(7):1233-1236

Shankar LK (2012) The clinical evaluation of novel imaging methods for cancer management. Nat Rev Clin Oncol 9(12):738-744

Singh S, Poon R, Wong R, Metser U (2018) 68Ga PET imaging in patients with neuroendocrine tumors: a systematic review and meta-analysis. Clin Nucl Med 43(11):802-810

Skoura E, Michopoulou S, Mohmaduvesh M, Panagiotidis E, Al Harbi M, Toumpanakis C et al (2016) The impact of 68GaDOTATATE PET/CT imaging on management of patients with neuroendocrine tumors: experience from a national referral center in the United Kingdom. J Nucl Med 57(1):34-40

Soussan M, Nataf V, Kerrou K, Grahek D, Pascal O, Talbot JN et al (2012) Added value of early 18F-FDOPA PET/CT acquisition time in medullary thyroid cancer. Nucl Med Commun 33(7):775-779

Sundin A (2018) Novel functional imaging of neuroendocrine tumors. Endocrinol Metab Clin N Am 47(3):505-523

Turcotte E, Wiens LW, Grierson JR, Peterson LM, Wener MH, Vesselle H (2007) Toxicology evaluation of radiotracer doses of 3'deoxy-3'-[18F]fluorothymidine (18F-FLT) for human PET imaging: laboratory analysis of serial blood samples and comparison to previously investigated therapeutic FLT doses. BMC Nucl Med 7:3

Unterrainer M, Schweisthal F, Suchorska B, Wenter V, Schmid-Tannwald C, Fendler WP et al (2016) Serial 18F-FET PET imaging of primarily 18F-FET-negative glioma: does it make sense? J Nucl Med 57(8):1177-1182

van Kruchten M, de Vries EGE, Brown M, de Vries EFJ, Glaudemans A, Dierckx R et al (2013a) PET imaging of oestrogen receptors in patients with breast cancer. Lancet Oncol 14(11):e465-ee75

van Kruchten M, Glaudemans AW, de Vries EF, Beets-Tan RG, Schroder CP, Dierckx RA et al (2012) PET imaging of estrogen receptors as a diagnostic tool for breast cancer patients presenting with a clinical dilemma. J Nucl Med 53(2):182-190

van Kruchten M, Hospers GA, Glaudemans AW, Hollema H, Arts HJ, Reyners AK (2013b) Positron emission tomography imaging of oestrogen receptor-expression in endometrial stromal sarcoma supports oestrogen receptor-targeted therapy: case report and review of the literature. Eur J Cancer 49(18):3850-3855

Venema CM, Apollonio G, Hospers GA, Schroder CP, Dierckx RA, de Vries EF et al (2016) Recommendations and technical aspects of 16alpha-[18F]Fluoro-17beta-estradiol PET to image the estrogen receptor in vivo: the Groningen experience. Clin Nucl Med 41(11):844-851

Vesselle H, Grierson J, Peterson LM, Muzi M, Mankoff DA, Krohn KA (2003) 18F-Fluorothymidine radiation dosimetry in human PET imaging studies. J Nucl Med 44(9):1482-1488

Visser AK, Ramakrishnan NK, Willemsen AT, Di Gialleonardo V, de Vries EF, Kema IP et al (2014) [(11)C]5-HTP and microPET are not suitable for pharmacodynamic studies in the rodent brain. J Cereb Blood Flow Metab 34(1):118-125

Wack L, Monnich D, van Elmpt W, Zegers CM, Troost EG, Zips D et al (2015) Comparison of [18F]-FMISO, [18F]-FAZA and [18F]-HX4 for PET imaging of hypoxia--a simulation study. Acta Oncol 54(9):1370-1377

Waseem N, Aparici CM, Kunz PL (2019) Evaluating the role of theranostics in grade 3 neuroendocrine neoplasms. J Nucl Med 60(7):882-891

Zamboglou C, Wieser G, Hennies S, Rempel I, Kirste S, Soschynski M et al (2016) MRI versus (6)(8)Ga-PSMA PET/CT for gross tumour volume delineation in radiation treatment planning of primary prostate cancer. Eur I Nucl Med Mol Imaging 43(5):889-897

Zips D, Zophel K, Abolmaali N, Perrin R, Abramyuk A, Haase R et al (2012) Exploratory prospective trial of hypoxia-specific PET imaging during radiochemotherapy in patients with locally advanced head-and-neck cancer. Radiother Oncol 105(1):21-28

\section{Publisher's Note}

Springer Nature remains neutral with regard to jurisdictional claims in published maps and institutional affiliations. 